\title{
Angiogenesis and leukocyte infiltration in malignant tumors
}

Citation for published version (APA):

Baeten, C. G. M. I. (2005). Angiogenesis and leukocyte infiltration in malignant tumors. [Doctoral Thesis, Maastricht University]. Datawyse / Universitaire Pers Maastricht. https://doi.org/10.26481/dis.20051222cb

Document status and date:

Published: 01/01/2005

DOI:

10.26481/dis.20051222cb

Document Version:

Publisher's PDF, also known as Version of record

\section{Please check the document version of this publication:}

- A submitted manuscript is the version of the article upon submission and before peer-review. There can be important differences between the submitted version and the official published version of record.

People interested in the research are advised to contact the author for the final version of the publication, or visit the DOI to the publisher's website.

- The final author version and the galley proof are versions of the publication after peer review.

- The final published version features the final layout of the paper including the volume, issue and page numbers.

Link to publication

\footnotetext{
General rights rights.

- You may freely distribute the URL identifying the publication in the public portal. please follow below link for the End User Agreement:

www.umlib.nl/taverne-license

Take down policy

If you believe that this document breaches copyright please contact us at:

repository@maastrichtuniversity.nl

providing details and we will investigate your claim.
}

Copyright and moral rights for the publications made accessible in the public portal are retained by the authors and/or other copyright owners and it is a condition of accessing publications that users recognise and abide by the legal requirements associated with these

- Users may download and print one copy of any publication from the public portal for the purpose of private study or research.

- You may not further distribute the material or use it for any profit-making activity or commercial gain

If the publication is distributed under the terms of Article $25 \mathrm{fa}$ of the Dutch Copyright Act, indicated by the "Taverne" license above, 


\section{Angiogenesis and leukocyte infiltration in malignant tumors}

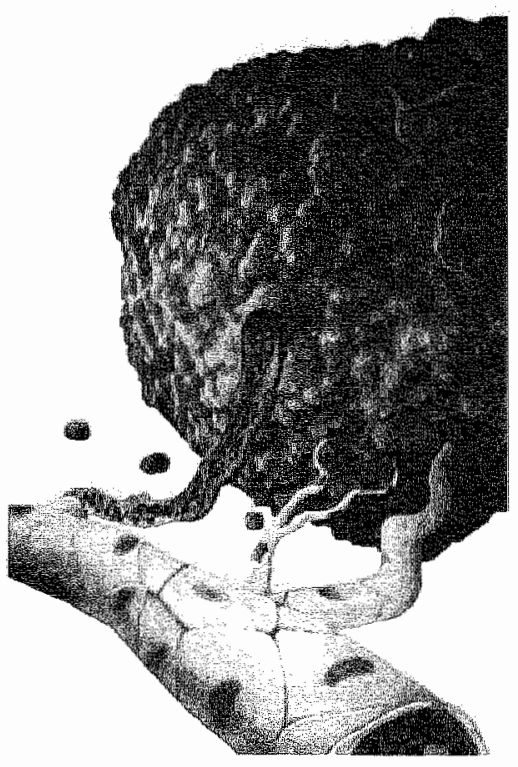


ISBN 9052785066

Datawyse / Universitaire Pers Maastricht

Copyright $\odot$ Coen I.M. Baeten 2005

The studies presented in this thesis were supported by grants of the Jules Coenegracht Sr. Stichting,

Maastricht University and University Hospital Maastricht 


\section{Angiogenesis and leukocyte infiltration in malignant tumors}

Proefschrift

ter verkrijging van de graad van doctor aan de Universiteit Maastricht, op gezag van de Rector Magnificus, Prof. Mr. G.P.M.F. Mols volgens het besluit van het College van Decanen, in het openbaar te verdedigen op donderdag 22 december 2005 om 16.00 uur

door

Coen Ignatius Maria Baeten Geboren te Maastricht
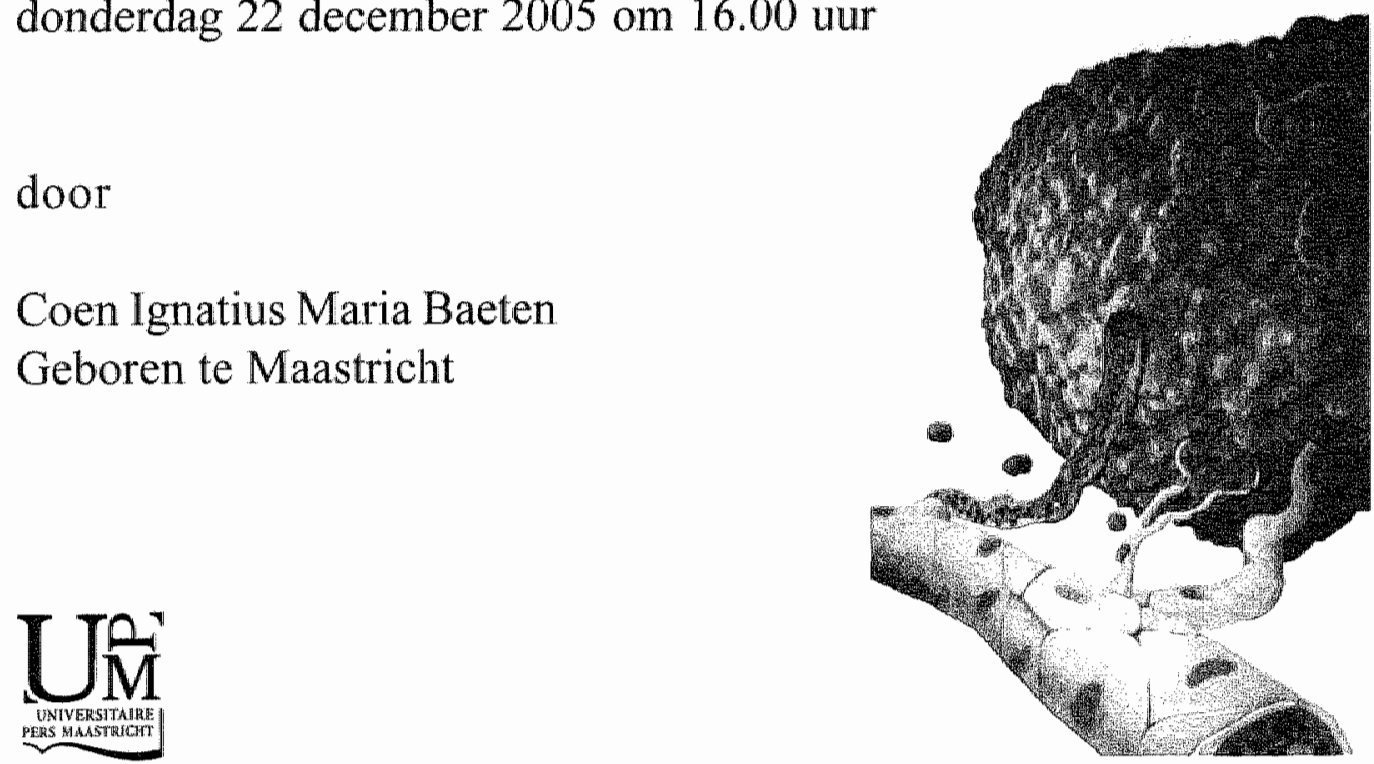


\section{Promotor}

Prof. dr. H.F.P. Hillen

Co-promotor

Dr. A.W. Griffioen

Beoordelings commissie

Prof. dr. M.F. von Meyenfeldt (voorzitter)

Prof. dr. J.W. Cohen Tervaert

Prof. dr. P. Lambin

Prof. dr. L. Påhlman (Uppsala, Sweden)

Prof. dr. F.C.S. Ramaekers 
To

my parents

Laurence 
Printing of this thesis was financially supported by Johnson\& Johnson and AC Design. 


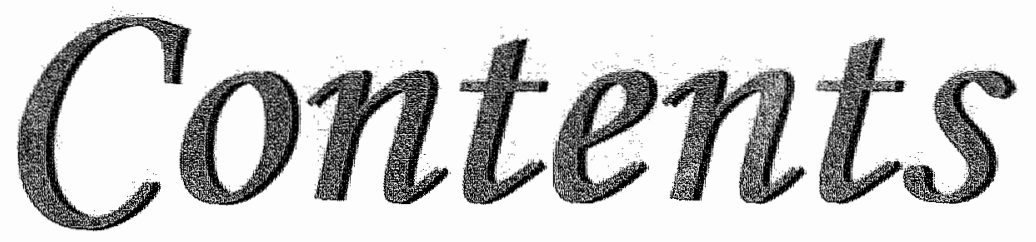

Chapter 1 General introduction

Chapter 2 Flow cytometric quantification of tumour endothelial cells; an objective alternative for microvessel density assessment Br J Cancer. 2002 Jul 29:87(3):344-7

Chapter 3 Angiogenic profile of breast carcinoma determines leukocyte infiltration Clin Cancer Res. 2004 Nov 1;10(21):7171-8 related prognostic markers in colorectal cancer Submitted

Chapter 5 Effects of radiotherapy and chemotherapy on angiogenesis and leukocyte infiltration in rectal cancer Submitted"

Chapter 6 Intratumoral extravascular erythrocytes as a new prognostic marker in colorectal cancer Submitted

Chapter 7 General Discussion

Chapter 8 Summary / Samenvatting / Dankwoord en Curriculum Vitae

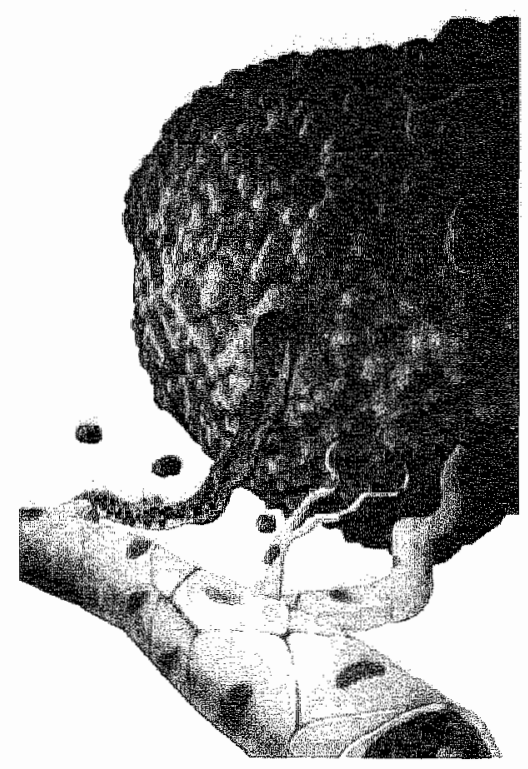




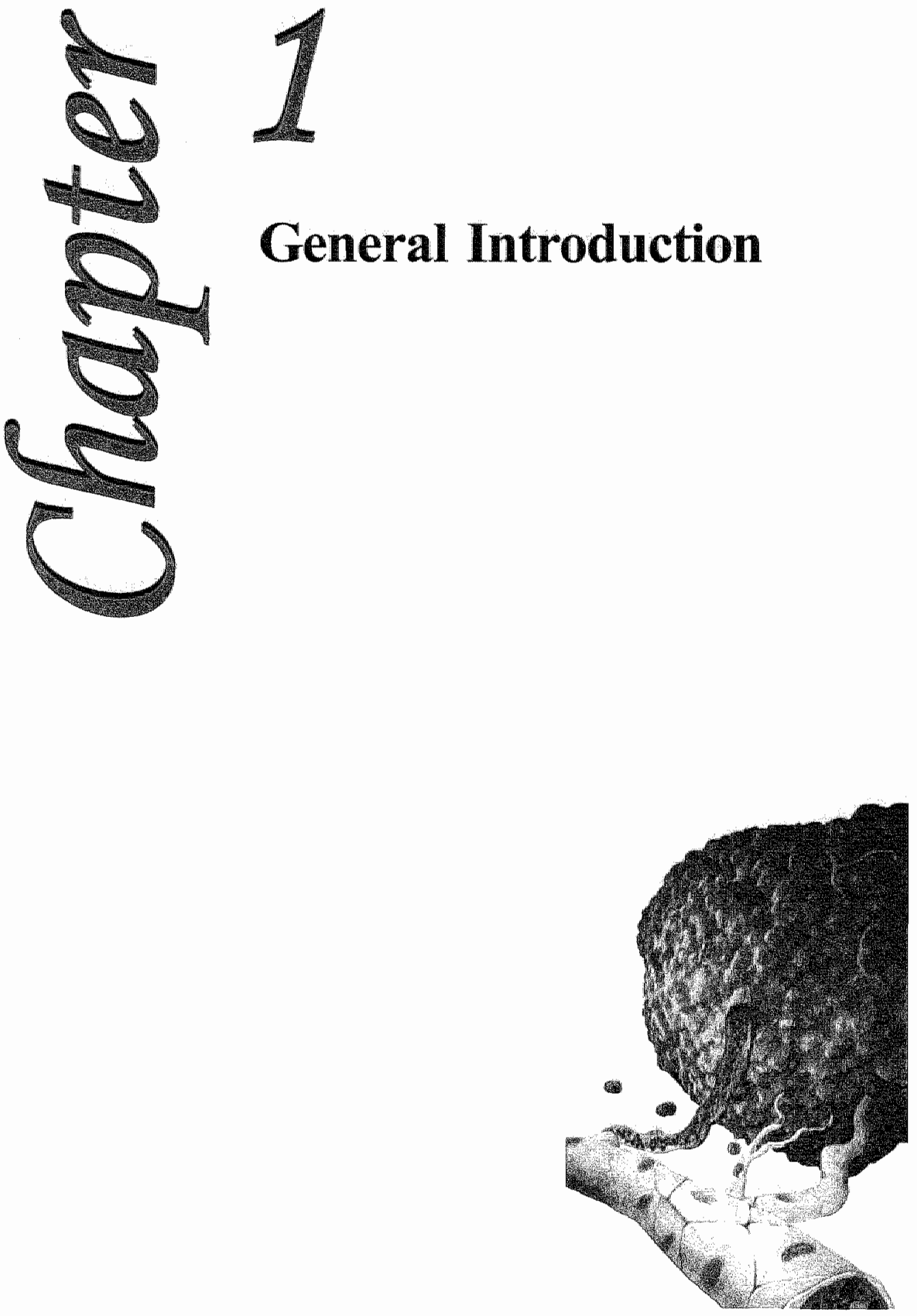


\section{Cancer}

Around $1600 \mathrm{BC}$ ancient Egyptians already described treatments for tumors '. Between 460 and $370 \mathrm{BC}$, Hippocrates was the first to describe the words "karkinos" (crab) and "karkinoma" to describe a range of lumbs".

The word "tumor" was described around $30 \mathrm{BC}$ by Celsus. He"s still known for his identifying signs for inflammation, rubor, calor, dolor and tumor ${ }^{3}$. After the invention of the microscope in the $17^{\text {th }}$ century studies of diseases, including cancer, became more important. In 1666 Marcello Malpighi confirmed William Harvey's blood circulation theories, by proving the existence of capillary blood vessels, which, until then, were unknown ${ }^{4}$. It was found that a capillary exists from the inside of an intima, a monolayer of endothelial cells, surrounded by a matrix. In 1665, Robert Hooke described the word 'cell' for the first time in his book Micrographia. He chose the word 'cell' because the 'empty small chambers' he discovered in cork reminded him of the cubicles of a monastery 5. Nowadays there is a better understanding of how cancer arises and develops.

Each cell has its own cell cycle, is uniquely organized in each organ and is mediated by stimulatory and inhibitory factors. A deficit in this highly balanced organization can lead to cancerous tissue. A cancerous tissue needs nutrients to grow, which are transported with bloodflow. Initially cancer cells co-opt with existing vasculature without new blood vessel formation and extend nutrient diffusion to a longer track ${ }^{6.7}$. Diffusion deficit leads to a non-vascular tumor, resulting in a hypoxic area which can lead to massive cell loss. In response to hypoxia angiogenic factor release (angiogenic factors like VEGF, II-8 and bFGF) is initiated, in order to attract new blood vessels ${ }^{8,4}$. This initiation has been described as the angiogenic switch, and induces angiogenesis (angio = "a vessel"; geno = "development") "10.

\section{Angiogenesis}

Angiogenesis, sprouting or growth of a blood vessel out of an existing blood vessel, was first described in $1935^{11}$. Angiogenesis is a physiological (for instance wound healing and menstruation) as well as a pathological (tumor growth, retinopathy) process. In this thesis the focus will be on pathological angiogenesis in cancer. In 1966 Folkman showed that tumors need formation of new blood vessels (angiogenesis) in order to supply nutrients, which are necessary for their growth ${ }^{12,13}$. This was proven in several studies showing tumors limit growth and inhibit their invasiveness after they reach a size of approximately $2 \mathrm{~mm}^{3}$, when angiogenesis is not permitted ${ }^{14-19}$. Normally there is a delicate balance between factors that induce and factors that inhibit angiogenesis ${ }^{20}$. Stimulating factors of angiogenesis (angiogenic factors) were first described before purification was technically possible ${ }^{21-24}$. In 1978 bFGF was the first angiogenic factor to be purified and many more followed ${ }^{8,25-27}$. So did inhibitors of angiogenesis ${ }^{28-30}$. Nowadays diagnostics develop rapidly as new proteins and receptors are found. 
The angiogenic process can be simplistically divided into (Figure 1):

Initiation; Resident cells lack nutrients and as a result release angiogenic factors

Activation; Endothelial cells are activated by angiogenic factors and as a result release matrix degrading cytokines

Migration; Endothelial cells abandon their nest and move towards the resident cells

Proliferation; Multiplying of endothelial cells in order to form a copulative smooth layer

Maturisation; Maturisation of endothelial cells and a restored matrix is created

Figure 1

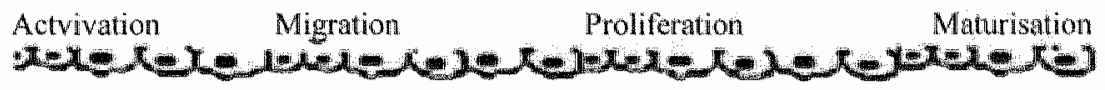

Luman

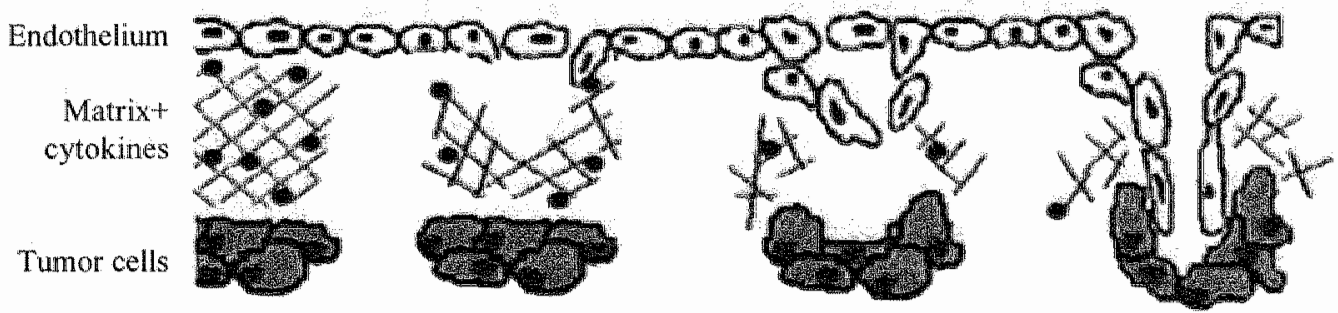

Angiogenesis is often determined by micro vessel density (MVD) ${ }^{31}$. The amount of (overall or hotspot count) bloodvessels in a tissue area was thought to represent the angiogenic activity. Striking results with respect to correlations between angiogenesis and clinicall outcome, directed research to develop new techniques ${ }^{32}$. Computer based MVD quantification, serum angiogenic cytokine determination and magnetic imaging were techniques to determine angiogenesis ${ }^{33-36}$. So far none of these methods has proven to be a better method. Only one method, measuring ongoing angiogenesis, might be a better measurement for angiogenesis determination. Vermeulen et al. developed this technique using a double staining, by which proliferating endothelial cells can be determined 37. 38. Nevertheless all staining techniques are laborious and often show a large intra- and inter-observer variety. Therefore we developed a new method to determine angiogenesis. In chapter 2 we show this technique, which is based on flowcytometry and quantifies the percentages of cells in a tissue. The technique not solely enables determination of endothelial cells but can also determine other cell subsets as leukocytes.

Unlike normal angiogenesis, as in wound repair, tumor angiogenesis is chaotic and irregular. Inhibition of intercellular adhesion molecules between endothelial cells (in order to grow) results in openings in the vascular wall (fenestrae and cellular holes). Not fully differentiated endothelial cells and incompletely developed or attached basal membranes (basal matrix) give tumor cells direct access to the circulation ${ }^{7.39-42}$. This direct access 
of tumor cells might also give tumor cells a possibility to line bloodflow. In 2000 Chang presented a study in which mosaic vessel formation was described. He found LS174T colon cell line cells and endothelial cells, together forming a blood vessel in vivo ${ }^{43}$. Not only mosaic vessel formation, but also full vessel formation by tumor cells allowing bloodflow are described ${ }^{44,45}$. This last phenomenon, named vasculogenic mimicry (VM), is described in several tumor types: melanoma, breast, ovarian, prostate; osteosarcoma and rhabdomyosarcoma ${ }^{46-54}$. Interestingly, cancers expressing VM show significant shorter survival and therefore the detection of VM needs implementation in clinical setting ${ }^{55.57}$. This phenomenon has so far not been described in colorectal cancers. In chapter 6 we show that a related phenomenon to vasculogenic mimicry exists in colorectal carcinomas and moreover that it shows a strong prognostic relation with survival.

\section{Tumor leukocyte infiltration}

White blood cells or leukocytes are the body defense system and are responsible for immune responses. Downregulation of immune responses is important in disease to viral, parasitic or bacterial infection. The pathogen uses several ways to escape recognition as adoption of intracellular lifestyle, antigenic variation of surface molecules and production of factors. The pathogens misguide responses or blanket responses completely through immunosuppression ${ }^{58}$.

There are different sorts of leukocytes: T-cells, B-cells, granulocytes and macrophages, which all use different target elimination techniques. There are two major classes in the immune system, a cellular and a humoral defense system. The cellular immune system mainly targets cells that misbehave or are infected with a virus. The humoral immune system mainly targets bacteria and toxins. Communication between resident tissue cells and circulating leukocytes is mediated by the endothelial cell layer. Resident antigen presenting cells release cytokines like TNF-a, IL-1, IFN-y and histamine in response to an inflammatory reaction ${ }^{59-61}$. Endothelial cells respond to the cytokine release by expressing adhesion molecules on their surface in order to enable leukocytes to adhere to their surface. There are two important adhesion molecule families for leukocyte endothelial adhesion; selectins and integrins. The extravasation of leukocytes can be simplified as a three step process (Figure 2).

- First step; Selectins have carbonhydrate ligands which interact with severall glycoproteins on leukocyte as well as endothelial membranes. Upregulation of selectins on endothelial cell membranes allows leukocytes to adhere reversibly and "roll" along the endothelial layer.

- Second step; Depending of the interaction between leukocyte integrins (e.g. LFA1) and intercellular adhesion molecules (e.g. ICAM-1) the leukocytes are bound tightly to the endothelial cell layer.

- The last step is the diapedesis in which the leukocytes migrate through the blood vessel wall towards the infected area ${ }^{62-66}$. 
Figure 2
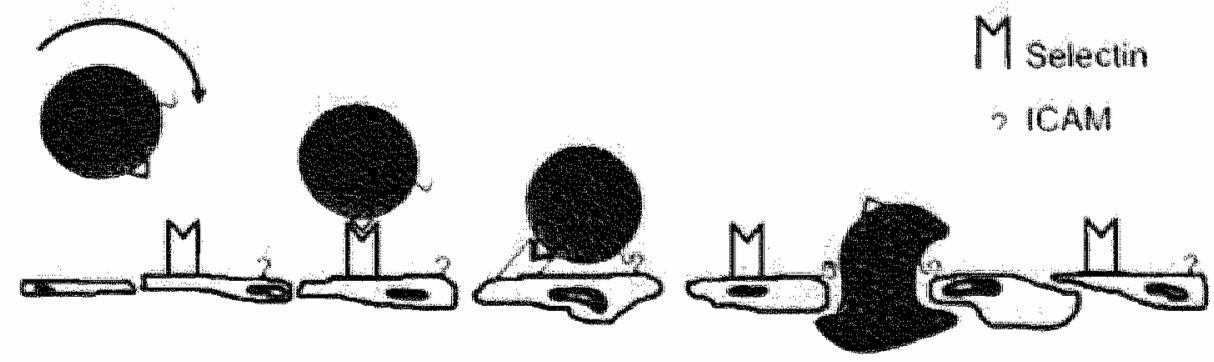

Local release of pro-inflammatory cytokines induce biosynthesis and luminal expression of vascular adhesion molecules as ICAM-1, VCAM and E-selectin ${ }^{66-70}$. E-selectin is known to be of importance in the rolling of leukocytes ${ }^{11}$ in contrast to VCAM and ICAM which have been shown to be important in firm leukocyte endothelial cell adhesion ${ }^{72-74}$. ICAM-I is known to be one of the most important adhesion molecules in the leukocyteendothelium interaction and migration ${ }^{75-81}$. The ICAM-1 molecule, in the human Cluster of Differentiation antigens, CD-54, binds to lymphocyte function associated antigen-1 (LFA-1) CD11a/CD12 and CD-11b/CD12, which is expressed on all lymphoid cells ${ }^{82-85}$. Detection of adhesion molecule expression on endothelial cells is mainly performed on cultured in vitro experiments. In chapters 3 and 5 we show that we are able to determine adhesion molecule expression on endothelial cells with our developed flowcytometric method. Using a double staining, on a single cell suspension, with endothelial markers and adhesion molecules we can easily detect relative expression of adhesion molecules on endothelial cells.

Infiltrated leukocytes migrate into the infected area and interact with the antigen presenting cells to eliminate the infected cells ${ }^{86-88}$. Not orly in inflammatory tissue leukocyte infiltration is important, also infiltration in cancer tissue is thought to be a prognostic factor in a way that high leukocyte counts have a better prognosis ${ }^{89,90}$. This is supported by a study which showed that isolated lymphocytes of colorectal cancer were cytotoxic to cancer cells from the same patient ${ }^{91}$. Moreover numbers of infiltrated leukocytes have a better prognostic outcome in $\mathrm{CRC}{ }^{92-96}$. It is not well understood which leukocyte subsets are responsible for a better prognosis to survival in cancer patients ${ }^{97.98}$. Different carcinomas behave differentially to leukocyte infiltrations. This is emphasized in studies in which some showed positive correlation between T-cell infiltration and prognosis in contrast with others which showed even a negative correlation ${ }^{99}$. Despite the presence of infiltrating cells, cancers continue to grow and metastasize. In chapter 4 we show evidence to different infiltrated leukocyte subsets, relation with angiogenesis and prognostic influences in CRC. 


\section{Relation angiogenesis and leukocyte infiltration}

Endothelial cells, stimulated to proliferate in cancer tissue, show inhibition of adhesion molecule expression on their membranes, suggesting the influence of angiogenic factors on endothelium is stronger than the influence of inflammatory factors $76,100-105$. Some tumors are known to present a high leukocyte infiltration, whereas other carcinomas of a similar organ present a low amount of infiltrated leukocytes. Carcinomas with high numbers of infiltrated leukocytes, in our view, should express high levels of adhesion molecules on their surface and show less angiogenic activity. We show differences in angiogenic activity of carcinomas in chapter 3 . In this chapter we compared two breast carcinomas with each other to angiogenic activity and leukocyte infiltration. A similar result is shown in chapter 4 where we show this inextricable relationship in CRC. Tumors not only stimulate angiogenesis, but indirectly also decrease or even block a proper immune response by inhibition of adhesion molecule expression on the endothelial cells membranes, resulting in an undisturbed tumor growth.

\section{Therapy}

Cancer disease affects many lives in the western world. Between 3-6\% of the gross national product is spent on cancer treatment in western countries ${ }^{106}$. At time of diagnosis normally a lot of cancer tissue has already been formed. This relatively late diagnosis correlates with a poorer survival ${ }^{107-111}$. Progression in cancer detection over the last decades resulted in less mortality of cancer. For instance the intraduction of breast cancer screening resulted in a significant decrease of mortality ${ }^{112-115}$. In colorectal cancer radiologic enhancement, detecting cancer in an earlier stage, showed significant progression in cancer treatment and enhances surgical approaches ${ }^{116-118}$. Next to diagnostic methods, therapeutic approaches improved. Radiotherapy was the first non surgical approach to cure a basal-cell carcinoma of the skin of the nose in 1899 (Thor Stenbeck). Since the introduction of irradiation in rectal cancer tissues treatment to these tumors by consensus has become regularly based ${ }^{119,} 120$. Before rectal cancer resection, irradiation therapy is initiated. A Swedish trial showed a decreased risk of recurrence and local metastasis after pre-operative irradiation "2?. In vitro experiments have shown an inhibition of proliferation and upregulation of adhesion molecules on cultured human umbilical vein endothelial cells after irradiation ${ }^{122}$. Not only in vitro, also in vivo irradiation experiments in mice and rats showed upregulation of adhesion moleculles ${ }^{123-126}$. It is known that irradiation inhibits proliferation of tumor cells and initiates proctitis ${ }^{127,128}$. The better prognostic outcome of pre-operative irradiation might be the cause of the local inflammatory reaction. Therefore the physiological effects of irradiation therapy, which lead to decreased recurrence or local metastasis, need to be studied.

In chapter 5 we describe our study on the influence of irradiation therapy in rectal cancer as well as in normal rectum mucosa. 


\section{References}

1. Ebbell B. The papyrus Eber: The Greatest Egyptian Medical Document. 1937 ;Levin.

2. Shimkin MB. Contrary to Nature. 1977.

3. Bett WR. Historical aspects of cancer. Cancer 1957:1:1-5.

4. Arendshorst WJ, Gottschalk CW. Glomerular ultrafiltration dynamics: historical perspective. Am J Physiol 1985 February;248(2 Pt 2):F163-Fi 74.

5. Wolpert L. Evolution of the cell theory. Philos Trans R SaC Lond B BHol Sci 1995:(1329):227-33.

6. Holash J, Maisonpierre PC, Compton D et al. Vessel cooption, regression, and growth in tunors mediated by angiopoietins and VEGF. Science 1999 June $18 ; 284(5422): 1994-8$.

7. Carmeliet P, Jain RK. Angiogenesis in cancer and other diseases. Nature $2000 ; 407(6801) \times 249+57$.

8. Ferrara N, Henzel WJ. Pituitary follicular cells secrete a novel heparin binding growth factor speeitic for vascular endothelial cells. Biochem Biophys Res Commun 1989 June 15:161(2):851-8.

9. Yancopoulos GD, Davis S, Gale NW, Rudge JS, Wiegand SJ, Holash J. Vascular-specific growth factors and blood vessel formation. Nam 2000 September 14;407(6801):242-8.

10. Hanahan $\mathrm{D}$, Folkman J. Patterns and emerging mechanisms of the angiogenic switch during tumorigenesis, Cell 1996 August 9;86(3):353-64.

11. Hertig A. Angiogenesis in early human chorion and in the primary placenta of the macaque monkey. Contributions to embryology 1935;25:37-81.

12. Folkman J, Cole $\mathrm{P}$, Zimmerman $\mathrm{S}$. Tumor behavior in isolated perfused organs: in witro growth and metastases of biopsy material in rabbit thyroid and canine intestinal segment. Ann Surg 1966 September; 164(3):491-502.

13. Folkman J. Tumor angiogenesis: therapeutic implications. $N$ Engl J Med 1971 ;285(21):1182-6.

14. Gimbrone MA, Jr., Leapman SB, Cotran RS, Folkman J. Tumor dormancy in wivo by prevention of neovascularization. J Exp Med 1972 August 1;136(2):261-76.

15. Skobe M, Rockwell P, Goldstein N, Vosseler S, Fusenig NE. Halting angiogenesis suppresses carcinoma cell invasion. Nat Med 1997 November; $3(111): 1222-7$.

16. Brem $S$, Brem H, Folkman J, Finkelstein D, Patz A. Prolonged tumor dormancy by prevention of neovascularization in the vitreous.Cancer Res 1976 August;36(8):2807-12.

17. Folkman J. Fighting cancer by attacking its blood supply. Sci An 1996September;275(3):150-4

18. Folkman $\mathrm{J}$. What is the evidence that tumors are angiogenesis dependent? $J$ Natl Cancer Inst 1990; 82(1):4-6.

19. O'Reilly $\mathrm{MS}$, Holmgren L, Chen C, Folkman J. Angiostatin induces and sustains dormanoy of human primary tumors in mice. Nal Med 1996 June:2(6):689-92.

20. Folkman J.Angiogenesis in cancer, vascular, rheumatoid and other disease. Nat Med 1995;1(1):27-31.

21. Folkman J, Merler E, A bernathy C, Williams $\mathrm{G}$. Isolation of a tumor factor responsible or angiogenesis. $J$ Exp Med 1971 February 1;133(2):275-88.

22. Folkman J. Tumor angiogenesis: therapeutic implications. $N$ Engl J Med $1971 ; 285(21): 1182-6$.

23. FolkmanJ.Proceedings:Tumor angiogenesisfactor.Concer Res $1974 ; 34(8): 2109.13$.

24. Phillips $P$, Steward IK, Kumar $S$. Tumour angiogenesis factor (TAF) in human and animall tumours. Int $J$ Cancer 1976 May 15;17(5):549-58.

25. Gospodarowicz D, Bialecki H, Greenburg G. Purification of the fibroblast growth factor activity from bovine brain. J Biol Chem 1978 May 25;253(10):3736-43.

26. Dvorak HF, Senger DR, Dvorak AM. Fibrin as a component of the tumor stroma: origins and biological significance. Cancer Metastasis Rev 1983;2(1):41-73.

27. Shing Y, Folkman J, Sullivan R, Butterfield C, Murray J, Klagsbrun M. Heparin affinity: purification of a tumor-derived capillary endothelial cell growth factor.Science 1984 March 23;223(4642):1296-9.

28. Brem $\mathrm{H}_{2}$ Folkman J. Inhibition of tumor angiogenesis mediated by cartilagé. J Exp Med 1975 February 1;141(2):427-39.

29. Peterson HI. Tumor angiogenesis inhibition by prostaglandin synthetase inhibitors. Anticancer Res 1986 March;6(2):251-3. 
30. Mano-Hirano $Y$, Sato $N$, Sawasaki $Y$ et al. Inhibition of tumor-induced migration of bovine capillary endothelial cells by mouse and rabbit tumor necrosis factor. J Natl Cawcer Inst 1987;78(1):115-20.

31. Vermeulex $\mathrm{PB}$, , Gasparini $\mathrm{G}$, Fox $\$ \mathrm{~B}$ et al. Quantification of angiogenesis in solid human tumours: an international consensus on the methodology and criteria of evaluation.

Lur I Cancer 1996;(14):2474-84

32. Vermeulen PB, Fox SB, Dirix LY, Colpaert C, Van Marck EA. Heterogeneity of vascularisation in invasive breast carcinoma. Eur Jancer 2002;38(14):195 I-2

33. Dirix LY, vermetlen PB, Pawinski A et al. Elevated levels of the angiogenic cytokines basic fibroblast growth factor and vascular endothelial growth factor in sera of cancer patients. BrJ Cancer 1997,76(2):238-43.

34. Hannen $\mathbb{E}_{\mathrm{E}}$, van der Laak JA, Kerstens HM et al. Quantification of tumour vascularity in squamous cell carcinoma of the tongue using CARD amplification, a systematic sampling technique, and true colour iriage analysis. Anal Cell Parhol 2001;22(4):183-92.

35. Goddard IC, Sutton $\mathrm{CD}$, Furness $\mathrm{PN}$, Kockelbergh $\mathrm{RC}, \mathrm{O}^{\circ} \mathrm{Byme} \mathrm{KJ}$. A computer image analysis system for microvessel density measurement in solid tumours. Angiogenesis $2002 ; 5(1-2): 15-20$.

36. Padhani AR. Functional MRI for anticancer therapy assessment Eur $J$ Cancer $2002 ; 38(16): 2116-27$

37. Vermeulen PB, Verhoeven D, Hubens $\mathrm{G}$ et al Microvessel density, endothelial cell proliferation and tumour cell proliferation in human colorectal adenocarcinomas. Ann Oncol 1995 January;6(1):59-64.

38. Vermeulen $\mathrm{PB}$, Gasparini $\mathrm{G}$, Fox SB et al. Second international consensus on the methodology and criteria of evaluation of angiogenesis quantification in solid human tumours.

Eut" J Cancer 2002 August;38(12):1564-79.

39. Jain RK, Munn LL, Fukumura D. Dissecting tumour pathophysiology using intravital microscopy. Nat Rev Caricer 2002 April;2(4):266-76.

40. Hobbs SK, Monsky WL, Yuan F et al. Regulation of transport pathways in tumor vessels: role of tumor type and microenvironment. Proc Nal Acad Sci U S A 1998 April 14;95(8):4607-12.

41. Jain RK. Determinants of tumor blood flow: a review. Cancer Res 1988 May 15;48(10):2641-58.

42. Ruoslathit E. Fibronectin and its receptors. Amm Rev Biochem 1988;57:375-413.

43. Chang YS, di TE, McDonald DM, Jones R, Jain RK, Munn LL. Mosaic blood vessels in tumors: frequency of cancer cells in contact with flowing blood.ProcNad Acad Sci 2000 19:97(26):14608-13

44. Folberg R, Flendrix MJ, Maniotis AJ. Vasculogenic mimicry and tumor angiogenesis. An J Pathol 2000 February; $156(2): 361-81$.

45. Hendrix MJ, Seftor EA, Kirschmann DA, Quaranta V, Seftor RE. Remodeling of the microenvironment by aggressive melanoma tumor cells. Ann N Y Acad Sci 2003 May;995:151-61.

46. Hendrix MJ, Seftor EA, Hess AR, Seftor RE. Vasculogenic mimicry and tumour-cell plasticity? lessons from thelanoma. Nat Rev Cancer 2003 June; 3(6):411-21.

47. Folberg $\mathrm{R}$, Maniotis AJ. Vasculogentc mimicry. APMTS 2004 July; $112(7-8) \cdot 508-25$.

48. Ruf W, Seftor EA, Petrovan RJ et al. Differential role of tissue factor pathway inhibitors 1 and 2 in melanoma rasculogenic mimicry. Cancer Res 2003 September 1,63(17):5381-9.

49. Slutrakawa $\mathrm{K}$, Wakasugi $\mathrm{H}_{4}$ Heike $\mathrm{Y}$ et al. Vasculogenic mimicry and pseudo-comedo formation in breast cancer. In J Cancer 2002 June 20;99(6):821-8.

50. Shirakawa $\mathrm{K}$, Kobayashi $\mathbb{H}$, Heike $\mathrm{Y}$ et al. Hemodynamics in vasculogenic mimicry and angiogenesis: of inflanmatory breast cancer xenograft. Cancer Res 2002 January 15;62(2):560-6.

51. Shirakawra $\mathrm{K}$, Furuhata $\mathrm{S}$, Watanabe $\mathrm{I}$ et al. Induction of vasculogenesis in breast cancer models. Br J Cancer 2002 December 2;87(12):1454-61.

52. Sharma $N$, Seftor RE, Seftor EA et al. Prostatic tumor cell plasticity involves cooperative interactions of distinct phenotypic subpopulations: role in vasculogenic mimicry. Prestare 2002 February 15;50(3):189-201.

53. Sood AK, Fletcher MS, Zahn CM et al. The clinical significance of tumor cell-lined vasculature in ovarian carcinona: implications for anti-vasculogenic therapy. Cancer Biol Ther 2002;1(6):661-4.

54. Sun B, Zhang $S$, Zhao $X$, Zhang $W$, Hao $X$. Vasculogenic mimicry is associated with poor survival in patients with mesothelial sarcomas and alveolar thabdomyosarcomas.

In J Oncol 2004;25(6):1609-14.

55. Sun $B$, Zhang $S$, Zhao $X, Z$ Zhang $W$, Hao $X$. Vasculogenic mimicry is associated with poor survival 
in patients with mesothelial sarcomas. Int J Oncol $2004 ; 25(6): 1609-14$

56. Sood AK, Fletcher MS, Zahn CM et al. The clinical significance of tumor cell-lined vasculature in ovarian carcinoma: implications for anti-vasculogenic therapy. Cancer Btol Ther 2002 (6):661 4 .

57. Shirakawa $K$, Wakasugi $H_{\Downarrow}$ Heike $Y$ et al. Vasculogenic minicry and pseudo-comedo formation in breast cancer. Int J Cancer 2002 June 20;99(6):821-8.

58. Nutman T. Clinical Immumology-Principles and Practice. St. Louis: 1996.

59. Albelda SM, Buck CA. Integrins and other cell adhesion molecules. FASEB J 1990;4(11);2868-80.

60. Hahne $M$, Jager $U$, Isenmann S, Hallmann R, Vestweber D. Five twnor necrosis factor-inductble cell adhesion mechanisms on the surface of mouse endothelioma cells mediate the binding of leukoeytes. $J$ Cell Biol 1993 May; $121(3): 655-64$.

61. Mackay $\mathbb{F}$, Loetscher $H$, Stueber D, Gehr G, Lesslauer W. Tumor necrosis factor alpha (TNF-alpha) induced cell adhesion to human endothelial cells is under dommant control of one TNF receptor type, TNF-R55. J Exp Med 1993 May 1;177(5):1277-86.

62. Hemler ME, Elices MJ, Parker C, Takada Y. Structure of the integrin VLA-4 and its cell-cell and cell-matrix adhesion functions. Tmmumol Rev 1990 April;114:45-65.

63. Hynes RO. Integrins: versatility, modulation, and signaling in cell adhesion. Cell 1992 3;69(1):11-25

64. Shimizu Y, Newman W, Gopal TV et al. Four molecular pathways of T cell adhesion to endothelial cells: roles of LFA-1, VCAM-1, and ELAM-1 and changes in pathway hierarchy under different activation conditions. J Cell Biol 1991 June; 113(5):1203-12.

65. Springer TA. Adhesion receptors of the immune system. Nature 1990 August 2;346(6283):425-34.

66. Springer TA. Traffic signals for lymphocyte recirculation and leukocyte emigration: the multistep paradigm. Cell 1994 January 28;76(2):30 $1-14$.

67. Stoolman LM. Adhesion molecules controlling lymphocyte migration. Cell 1989;56(6):907-10.

68. Butcher EC, Williams M, Youngman K, Rott L, Briskin M. Lymphocyte trafficking and regional immunity. Adv Immunol 1999;72:209-53.

69. Osborn L.Leukocyte adhesion to endothelium in inflammation.Cell $\| 99013 ; 62(1): 3-6$

70. Bessa $X$, Elizalde JI, Mitjans F et al. Leukocyte recruitment in colon cancer: role of cell adhesion moleculles, nitric oxide, and transforming growth factor betal. Gastroenterology $2002 ; 122(4): 1122-32$

71. Noman KE, Anderson GP, Kolb HC, Ley K, Enst B. Sialyl Lewis $(x)$ (sLe( $(x)$ ) and an sLe( $x$ ) mimetic, CGP69669A, disrupt E-selectin-dependent leukocyte rolling in vivo.

Blood 1998 January 15;91(2):475-83.

72. Kaplanski $\mathrm{G}$, Marin V, Fabrigoule $M$ et al. Thrombin-activated human endothelial cells support monocyte adhesion in witro following expression of intercellular adhesion molecule-1 (ICAM-1; CD54) and vascular cell adhesion molecule-1 (VCAM-1; CD106), Blood 1998;92(4):1259-67.

73. Yoong KF, McNab G, Hubscher $\mathrm{SG}$, Adams DH. Vascular adhesion protein $₫$ and ICAM-1 support the adhesion of tumor-infiltrating lymphocytes to fumor endothelium in human hepatocellular carcinoma. J Inmunol 1998 April 15;160(8):3978-88.

74. Konstantopoulos K, Kukreti S, Smith CW, McIntire LV. Endothelial. P-selectin and VCAM-I each can finction as primary adhesive mechanisms for T cells under conditions of flow.

JLeukac Biol 1997; 61 (2):179-87.

75. Dirkx AE, Oude Egbrink MG, Kuijpers MJ et al. Tumor angiogenesis modulates leukocyte-vessel wall interactions in vivo by reducing endothelial adhesion molecule expression.

Cancer Res 2003 May:63(9):2322-9.

76. Griffioen AW, Damen CA, Martinotti S, Blijham GH, Groenewegen G. Endothellal intercellular adhesion molecule 1 expression is suppressed in human malignancies: the role of angiogenic factors. Cancer Res 1996 March $11 ; 56(5): 1111-7$.

77. Griffioen AW, Damen CA, Blijham GH, Groenewegen G. Tumor angiogenesis is accompanied by a decreased inflammatory response of tumor-associated endothelinm Blood 1996;88(2):667-73.

78. van de SA, van der Sagg PT. Intercellular adhesion molecule-1. $J$ MolMed 1996January; 74(1): 13-33.

79. Carpen $O$, Pallai $P$, Staunton DE, Springer TA. Association of intercellular adhesion molecule 1 (ICAM-1) with actin-containing cytoskeleton and alpha-actinin. J Cell Blo/ 1992;118(5):1223-34.

80. Sanders VM, Witetta ES. B cell-associated LFA-I and T cell-associated ICAM-1 transiently chuster in the area of contact between interacting cells. Cell Immunol 199 January; $132(1): 45-55$. 
81. Deroanne $C F$, Colige $A C$, Nusgens $B V$, Lapiere CM. Modulation of expression and assembly of vinculin during in vitro fibrillar colllagen-induced angiogenesis and its reversal.

Exp Cell Res 996 May 1;224(2),215-23.

82. Diamond MS, Staunton DE, Marlin SD, Springer TA. Binding of the integrin Mac- $(\mathrm{CD} / \mathrm{b} / \mathrm{CD} 18$ ) to the third immunoglobulin-like domain of ICAM-1 (CD54) and its regulation by glycosylation. Cell 1991 June 14:65(6):961-71.

83. Springer $T A$, Dustin $M L$, et al The lymphocyte function-associated LFA-1, CD2, and LFA-3 molecules: cell adhesion receptors of the immune system. Amu Rev Imwunol 1987,5:223-52.

84. Marlin SD, Springer TA. Purifted intercellular adhesion molecule-1 (ICAM-1) is a ligand for lymphocyte function-assaciated antigen I. (LFA-1). Cell 1987 December 4;51(5):813-9.

85. Springet TA. Adhesion receptors of the immune swstem. Nature 1990 August 2;346(6283):425-34.

86. Dustin ML, Springer TA. T-cell reeeptor cross-linking transiently suimulates adhesiveness through LFA-1. Nature 1989 October 19:341(6243):619-24.

87. Makgoba MW, Sanders ME, Shaw $\mathrm{S}$. The CD2-LFA-3 and LFA-1-ICAM pathways: relevance to T-cell recognition. Imwanol Todoy 1989 December; 10(12):417-22.

88. Hemler ME, Clices MJ, Parker C, Takada Y. Structure of the integrin VLA-4 and its cell-cell and cell-matrix adhesion functions. Inmmunal Rev 1990 April; 114:45-65.

89. An T, Sood U, Pietruk T, Cummings G, Hashimoto K, Crissman JD. In situ quantitation of inflammatory mononuclear cells in ductal infiltrating breast carcinoma. Relation to prognostic parameters. Am J Pathol 1987 July:128(1):52-60.

90. Griffioen AW, Damen CA, Blijham GH, Graenewegen $G$. Tumor angiogenesis is accompanied by a decreased inflammatory response of tumor-associated endothelium. Blood 1996;88(2):667-73.

91. Werkmeister JA, Pihl E, Nind AP, Flannery GR, Nairn RC.Immunoreactivity by intrinsic lymphoid cells in colorectal carcinoma.Br JCancer 1979 December,40(6):839-47

92. Chiba T, Ohtani H, Mizoi T et al. Intraepithelial CD8 + T-cell-count becomes a prognostic factor after a longer follow-up period in human colorectal carcinoma:possible association with suppression of micrometastasis. $B r J$ Cancer 2004 November 1;91(9):171 1-7.

93. Coca S, Perez Piqueras J, Martinez D et al. The prognostic significance of intratumoral natural killer cells in patients with colorectal carcinoma. Cancer 1997 June $15 ; 79$ (12)2320-8

94. Golby SJ, Chinyama C, Spencer J. Proliferation of T-cell subsets that contact tumour cells in colorectal cancer. Clin Exp Immunol 2002 January; 127(1):85-91.

95. Funada $Y$, Noguchi T, Kikuchi R, Takeno S, Uchida Y, Gabbert HE.Prognostic significance of CD\&+ $T$ cell and macrophage peritumoral infiltration in colorectal cancer. Oncol Rep $2003 ; 10(2) \div 309-13$.

96. Khorana AA, Ryan CK, Cox C, Eberly S, Sahasrabudhe DM. Vascular endothelial growth factor, CD68, and epidernal growth factor receptor expression and survival in patients with stage $I$ and Stage HI colon carcinoma: a role for the host response in prognosis. Cancer $2003 ; 97(4) ; 960-8$.

97. Miwa H. Identification and prognostic implications of tumor infiltrating lymphocytes-a review. Acta Med Okaycwna 1984 June;38(3):215-8.

98. Kreider JW, Bartlett GL, Butkiewicz BL. Relationship of tumor leveocytic infiltration to host defense mechanisms and prognosis. Cancer Metastasis Rev 1984;3(1):53-74.

99. Bodey B, Bodey B, Jr. Siegel SE, Kaiser HE. Controversies on the proginostic significance of tumor infiltrating leukocytes in solid human tumors. Anticancer Res 2000 May;20(3A):1759-68.

100. Tromp SC, Oude Egbrink MG. Dings RP et al. Tumor angiogenesis factors reduce leukocyte adhesion in vivo. Int Immwnol 2000 May;12(5):671-6.

101. Griffioen AW, Damen CA, Mayo KH et al. Angiogenesis inhibitors overcome tumor induced endothelial cell anergy. Int J Cancer 1999 January 18;80(2):315-9.

102. Tromp SC, Tangelder GJ, Slaaf DW et al. The role of mast cells and histamine in leukocyteendothelimin interactions in four rat strains. Pfugers Arch $1998 \mathrm{July} ; 436(2): 255-61$.

103. Kitayama J, Nagawa $\mathrm{H}$, Yasuhara $\mathrm{H}$ et al. Suppressive effect of basic fibroblast growth factor on transendothelial emigration of CD4(w) T-lymphocyte. Cancer Res 1994;54(17):4729-33.

104. Zhang $\mathrm{H}$, Issekutz AC. Down-modulation of monocyte transendothelial migration and endothelial adhesion molecule expression by fibroblast growth factor: reversal by the anti-angiogenic agent SU6668. Am I Pathol 2002 June; $160(6): 2219-30$. 
105. Chen $\mathrm{Q}$, Wang WC, Evans SS. Tumor nichowasculature as a barfiet to antitumor immunity. Cancer Imwnut Inmunother 2003 November; $52(11) \cdot 670-9$.

106. Jonsson V, Clausen SR, Hansen MM. Pharmacoeconomic aspects in the treatment of curable and incurable cancer. Pharmacoeconomics 1995 October; $8(4): 275-81$.

107. Kaufmann M. Review of known prognostic variables. Recent Renfts Cancer Res 1996;140:77-87.

108. Abner AL, Collins $\mathrm{L}$, Peiro $\mathrm{G}$ et al. Correlation of tumor size and axillary lymph node involvement with prognosis in patients with T1 breast carcinoma. Cancer 1998 December 15;83(12):2502-8.

109. Bjerkeset $T$, Morild 1, Mork $S$, Soreide $O$. Tumor characteristics in colorectal cancer and their relationship to treatment and prognosis. Dis Colon Recrum 1987 December; 30(12):934-8.

110. Takebayashi Y, Aklyama S, Yamada K, Akiba S, Aikou T. Angrogenesis as an unfavorable prognostic factor in human colorectal carcinoma. Cancer 1996 July $15 ; 78(2): 226-31$.

111. Masaki T, Muto T. Predictive value of histology at the invasive margin in the prognosis of early invasive colorectal carcinoma. J Gastroenterol 2000;35(3):195-200.

112. van Oortmarssen GJ, Habbema J, van der Maas PJ et al. A model for breast cancer screening. Cancer 1990 October 1;66(7):1601-12.

113. Nab HW, Hop WC, Crommelin MA, KJuck HM, Coebergh JW. Inproved proginosis of breast cancer since 1970 in south-eastern Netherlands. Br J Cancer 1994 August;70(2):285-8.

114. Louwman WJ, van Diest PI, van Beek MW et al. Trends in breast cancer aggressiveness before the introduction of mass screening in southeastern Netherlands 1975-1989.

Breast Cameer Res Treat 2002 June; 73(3):199-206.

115. Peer PG, Verbeek AL. [Mass screening for breast cancer in women younger than 50 years; a literature review of the anticipated effect on mortality].

Ned Tijdsch Geneeskd 1991 April 13;135(15):65I-5.

116. van Etten B, van der SJ, Kruyt R, Oudkerk $M$, van der HB, Wiggers T. Ferumoxide-enhanced magnetic resonance imaging techniques in pre-operative assessment for colorectal liver metastases. Eur J Surg Oncol 2002 September;28(6):645-51.

117. Pahlman L. Optimal staging and treatment of localised rectal cancet. Ann Oncol 2002;13 Suppl 4:251-5.

118. Beets-Tan RG, Beets GL, Vliegen RF et al. Accuracy of magnetic resonance imaging in prediction of tumour-free resection margin in rectal cancer surgery. Lancet 200 I February 17;357(9255):497-504.

119. Bru A. [Radiotherapy of cancer of the rectum.]. J Radiol Electrol Arch Electr Medicale 1950;31(11-12):787-8.

120. Stearns MW, Jr., Deddish MR, Quan SH. Preoperative roentgen therapy for cancer of the rectum. Surg Gynecol Obstet 1959 August; 109(2):225-9.

121. Improved surwival with preoperative radiotherapy in resectable rectal cancer. Swedish Rectal Cancer Trial. $N$ Engl J Med 1997 April 3;336(14):980-7.

122. Quarmby $S$, Kumar $P$, Kumar $S$. Radiation-induced normal tissue injury: role of adhesion nolecules in leukocyte-endothelial cell interactions. In I Cancer 1999 July 30;82(3):385-95.

123. Molla M, Gironella M, Miquel $\mathbb{R}$ et al. Relative roles of ICAM-1 and VCAM-1 in the pathogenesis of experimental radiation-induced intestinal inflammation.

Int J Radiat Oncol Biol Phys 2003;57(1):264:73.

124. Molla M, Panes J, Casadevall $M$ et al, Influence of dose-rate on inflanmatory damage and adhesion molecule expression after abdominal radiation in the rat.

In J Rodiat Oncol Biol Phys 1999 November 1;45(4):1011-8.

125. Kan $\mathrm{S}$, Chun $\mathbb{M}$, Jin YM et al. A rat model for radiation-induced proctitis. JKorean Med Sci 2000 December; I 5(6):682-9.

126. Northway MG, Scobey MW, Geisinger KR. Radiation proctitis in the rat. Sequential changes and effects of anti-inflammatory agents. Cancer 1988 November 1;62(9):1962-9.

127. Haboubi NY, Schofield PF, Rowland PL. The light and electron microscopic features of early and late phase radiation-induced proctitis. Am J Gastroenterol 1988 October;83(10):1 $1140-4$.

128. Stift A, Prager $\mathrm{G}$, Selzer $\mathrm{E}$ et al. The early response of $\mathrm{p} 53$-dependent proteins during radiotherapy in human rectal carcinoma and in adjacent normal tissue. In J Oncol 2003November;23(5):1269.75. 


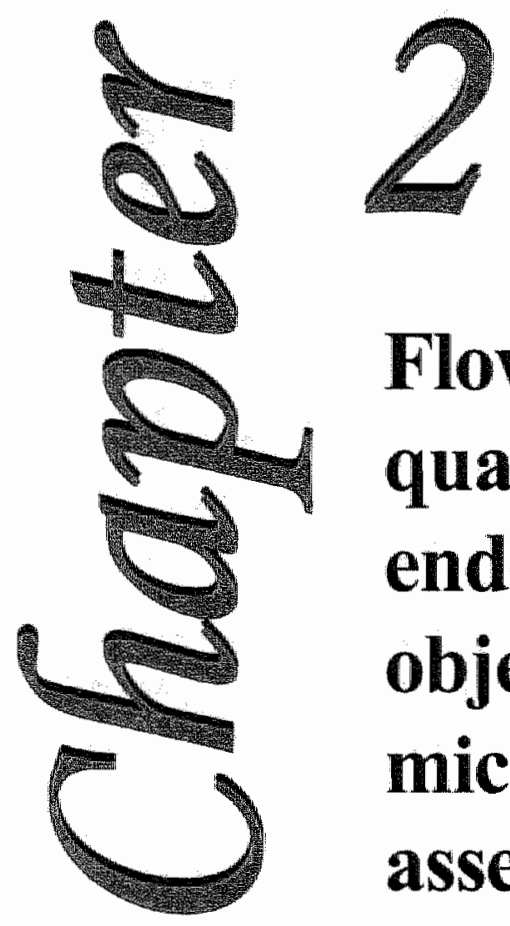

\section{Flow cytometric} quantification of tumour endothelial cells; an objective alternative for microvessel density assessment

CIM Baeten, J Wagstaff, ICL Verhoeven, HFP Hillen and AW Griffioen

Br J Cancer. 2002 Jul 29;87(3):344-7

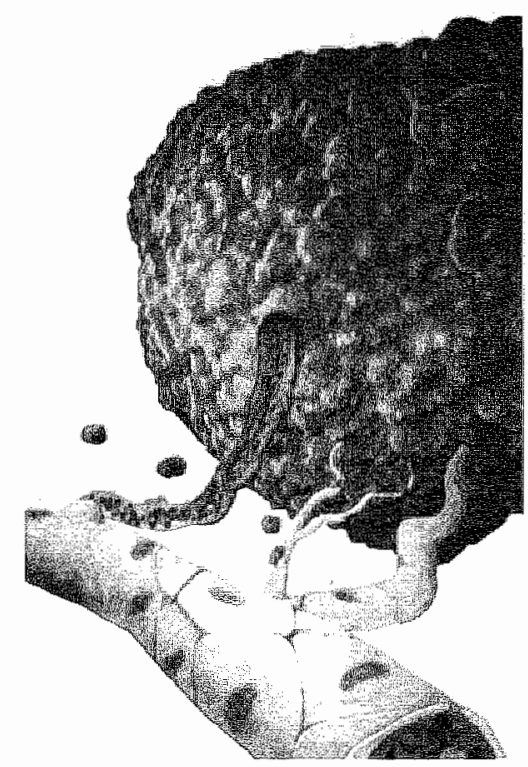




\begin{abstract}
Assessment of microvessel density by immunohistochemical staining is subject to a considerable inter-observer variation, and this has led to variability in correlation between microvessel density and clinical outcome in different studies. In order to improve the method of microvessel density measurement in tumour biopsies, we have developed a rapid, objective and quantitative method using flow cytometry on frozen tissues. Frozen tissue sections of archival tumour material were enzymatically digested. The single-cell suspension was stained for CD31 and CD34 for fJow cytometry. The number of endothelial cells was quantified using light scatter-and fluorescence-characteristics. Tumour endothelial cells were detectable in a single cell suspension, and the percentage of endothelial cells detected in 32 colon carcinomas correlated highly $(r=0.84, P<.001)$ with the immunohistochemical assessment of microvessel density. Flow cytometric endothelial cells quantification was found to be more sensitive especially at lower levels of immunohistochemical microvessel density measurement. The current method was found to be applicable for various tumour types and has the major advantage that it provides a retrospective and quantitative approach to the angiogenic potential of tumours.
\end{abstract}




\section{Introduction}

Angiogenesis is essential for the outgrowth of tumours and metastasis formation (Griffioen and Molema, 2000). It has been recognised that the angiogenic potential of a tumour contributes to the aggressiveness of that tumour and may therefore be of prognostic importance for various cancers. An increasing number of studies have demonstrated that angiogenesis is predictive for the clinical outcome of the disease, in the sense that an increased level of angiogenesis is inversely related with survival (Weidner et al, 1992, 1993). In most of these studies, the angiogenic potential was analysed by immunohistochemical determination of microvessel density (MVD) using antibodies recognising CD31, CD34 or Von Willebrand Factor. This method is currently considered the gold standard for this kind of studies. Although straightforward and routinely performed in most diagnostic laboratories the immunohistochemical MVD measurement has a number of disadvantages. The method is laborious, difficult to quantitate, and suffers from considerable intra- and inter-observer variation. This made an international agreement on performance of MVDanalysis necessary (Vermeulen et al, 1996). It is likely that the difficulties with this method have lead to a substantial number of studies in which no correlation (Brechot et al, 1996; Chandrachud et al, 1997; Hillen et al, 1997) or even an inverse correlation (Sarbia et al, 1996; Delahunt et al, 1997) was found between angiogenesis and the aggressiveness of the tumour. This urged researchers to quantify MVD by using image-analysis software (Kirchner et al, 1996; Wild et al, 2000;). Other methods to measure angiogenesis in patients include detection of circulating levels of angiogenic growth factors and soluble adhesion molecules, magnetic resonance imaging and/or positron emission tomography (van Dijke et al, 1996; Haubner et al, 2001). Major drawbacks of these methods are the costs and the large variation of these measurements in different patients. The current study describes a novel method to efficiently quantify the number of endothelial cells (EC) in frozen tumour biopsies using flowcytometry. The ability to use archival tissue is a major advantage in retrospective fundamental research. 


\section{Materials and methods}

\section{Preparation of single cell suspensions and flow cytometry}

Frozen tumour tissues were obtained from the stocks of the Department of Pathology. Of each tumour two $10,30 \mathrm{and} /$ or $50 \mu \mathrm{m}$ thick $0.5-1 \mathrm{~cm}^{2}$ frozen tissue sections were either directly digested or fixed in $1 \mathrm{ml} 1 \%$ paraformaldehyde (Sigma, Darmstadt, Germany) in phosphate buffered saline (PBS) or $70 \%$ ethanol in water for $1 \mathrm{~h}$ at room temperature prior to digestion. After fixation, the sections were washed twice with $4 \mathrm{ml}$ PBS and centrifuged at $400 \mathrm{~g}$. The sections were digested by incubation in $1 \mathrm{ml}$ of different concentrations $\left(1,5\right.$ and $\left.10 \mathrm{mg} \mathrm{ml}^{-1}\right)$ of collagenase (Life Technologies, Breda, The Netherlands) and dispase (Life Technologies) for time periods of $5-120$ min at $37^{\circ} \mathrm{C}$ during repeated vigorous pipetting. After the digestion, the cells were washed in $10 \mathrm{ml}$ $\mathrm{PBS} / 0.5 \%$ bovine serum albumin (BSA), centrifuged at $400 \mathrm{~g}$ and further processed on ice. Cell preparations were microscopically evaluated for the condition of the single cell suspension. Propidium iodide staining (permeabilisation in $70 \%$ ethanol, two washings and resuspending in $20 \mu \mathrm{g} \mathrm{ml}^{-1}$ propidium iodide in PBS) was used to control for intact cells. Cell pellets were incubated with $20 \mathrm{ml}$ of appropriately diluted primary mouse

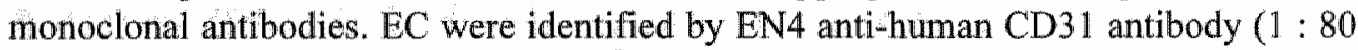
hybridoma supernatant, Monosan, Uden, The Netherlands) and QBEND-10 anti-human CD-34 antibody ( $2 \mu \mathrm{g} \mathrm{ml}^{-1}$, Novocastra, Uden, The Netherlands). After two washings, the cells were incubated with $20 \mathrm{ml}$ biotinylated rabbit antimouse Ig antibodies ( $15 \mu \mathrm{g} \mathrm{ml}$ ', Dako, Uithoorn, The Netherlands) for 1 h. Finally, the cells were stained with phycoerythrin (PE)-conjugated streptavidine $\left(10 \mu \mathrm{g} \mathrm{ml}^{-1}\right.$, Dako) for $30 \mathrm{~min}$. Analysis was performed on a FACS-Calibur (Becton and Dickinson, Mountain View, CA, USA). Both red $(585 \mathrm{~nm})$ and green $(530 \mathrm{~nm})$ fluorescence, forward light scatter and sidescatter were recorded simultaneously of 10000 cells. Analysis of data was performed using CellQuest-software (Becton and Dickinson).

Table 1 Percentages of EC obtained by different procedures of single cell preparation of colon carcinoma tissue

\begin{tabular}{|c|c|c|c|}
\hline \multicolumn{4}{|c|}{ Collagenase and dispase concentration } \\
\hline Digestion time & $1 \mathrm{mg} \mathrm{m}^{-1 \mathrm{n}}$ & $5 \mathrm{mg} \mathrm{ml^{-1/3 }}$ & $10 \mathrm{mg} \mathrm{m}^{-1}$ a \\
\hline $120 \mathrm{~min}$ & Debris" & Debris" & Debris \\
\hline 90 min & 50 & $2.5^{\circ}$ & Debris ${ }^{b}$ \\
\hline 60 min & 70 & $3 \approx$ & 20 \\
\hline $30 \mathrm{~min}$ & L.D. & $9 \cdot$ & $4^{c}$ \\
\hline $15 \mathrm{~min}$ & I.D. & $11:$ & $5:$ \\
\hline $5 \min$ & I.D. & I.D. & 1.D. \\
\hline
\end{tabular}

"Concentration for both collagenase and dispase. "No evaluation due to fragmentationof cells. " Percentage of $\mathrm{CD} 31$-positive EC in the single cell suspension. I.D.=insufficient digestion. The results of one representative experiment out of three independent experiments are shown. 


\section{Results}

EC quantification by flow cytometry

We have reported a technique for isolation and phenotyping of endothelial cells (EC) from tumour biopsies (Griffioen et al, 1996). For reasons of retrospective research we also wanted to develop this method for frozen tissues. We adapted this technique and the starting point of the investigations was the preparation of thick cryo-sections and subsequent digestion with enzymes. In order to find the optimal thickness of the sections (too thin would lead to damage of too many cells and too thick would lead to inappropriate digestion of the tissue), sections of 10,30 and $50 \mu \mathrm{m}$ thickness were prepared. Sections were either directly digested or fixed in $1 \%$ paraformaldehyde or $70 \%$ ethanol at room temperature prior to digestion. It was found that fixation was needed, since less measurable cells were left after omitting the fixation procedure, due to fragmentation. Fixation with paraformaldehyde gave optimal results (not shown). Sections were digested for different time periods in different concentrations of the collagenase/dispase mix. We found that 30 $\mu \mathrm{m}$ thick sections gave optimal results at all enzyme concentrations. The optimal longevity and concentration of the enzyme treatment was observed to be 15 min with $5 \mathrm{mg} \mathrm{ml}^{-1}$ collagenase and $5 \mathrm{mg} \mathrm{ml}^{-1}$ dispase (Table 1). Antibodies to CD31 recognised a distinct subpopulation within the single cell suspension (Figure $\mathbb{I A}, \mathrm{B}$ ), which contains intact and single cells as determined by propidium iodide staining (Figure 1C). The CD31+ cells are of endothelial origin since previous studies, using fresh tissues have demonstrated that these cells are CD105+ and ICAM-2+ and stain positive after Dil-acetylated-LDL incubation (Griffioen et al. 1996).

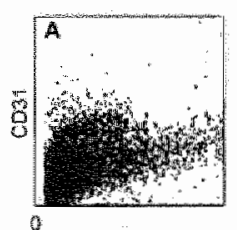

$F \mathrm{FC}$

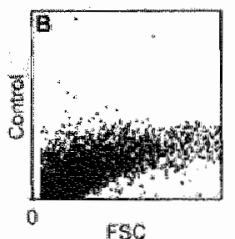

FSC

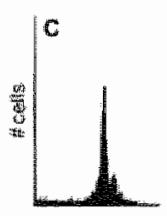

Dis

D

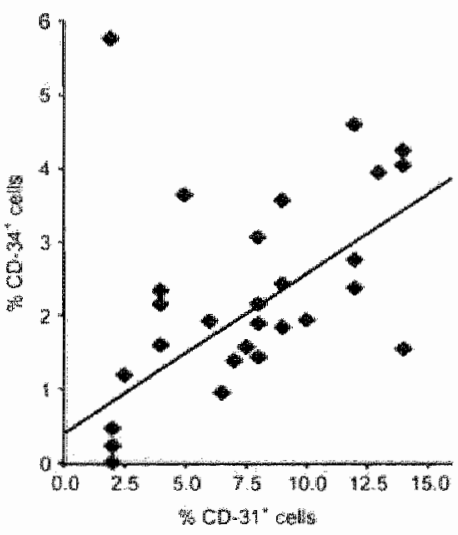

Fignre 1

Identification of tumour EC. (A) Dot-plot of single cell suspension. Forward scatter (FSC) ws indirect CD 1 staining (phycoerythrin, vertical axis). (B) Conjugate control for the CD 31 staining.

(C) Propidium iodide staining, revealing $495 \%$ of cells intact. (D) Positive correlation $(r=0.73, P<.001)$ of flowcytometrically identified EC using CD3! and CD34 antibodies in 32 colon carcinomas. 
The use of CD34 antibodies resulted in generally lower amounts of stained cells, which was similar to the immunohistochemistry data. However, using flow cytometric analysis a high correlation $(r=0.73, \mathrm{P}<.001)$ between the percentages of $\mathrm{CD} 31+$ and $\mathrm{CD} 34+$ cells was observed (Figure 1D). This technique of EC quantification in tumour tissues was applicable for tumours of multiple types and origins. Next to colon carcinoma tissue, breast-, lung-, kidney-, head and neck-, ovarian-and testis carcinomas were successfully analysed (not shown). The analysis of EC percentages in tumour tissues by flow cytometry was found to be highly reproducible. Variation in the percentage of EC obtained by flow cytometry was observed to be less than $5 \%$ of the mean, when six independent measurements were performed on one tumour. For example, one tumour analysed using CD31 antibodies revealed a mean percentage of CD31-positive EC of $12.3 \%$ (s.d. $0.6 \%$, $\mathrm{n}=6$ ). For MVD assessment by immunohistochemistry a variation of $26 \%$ of the mean was observed.
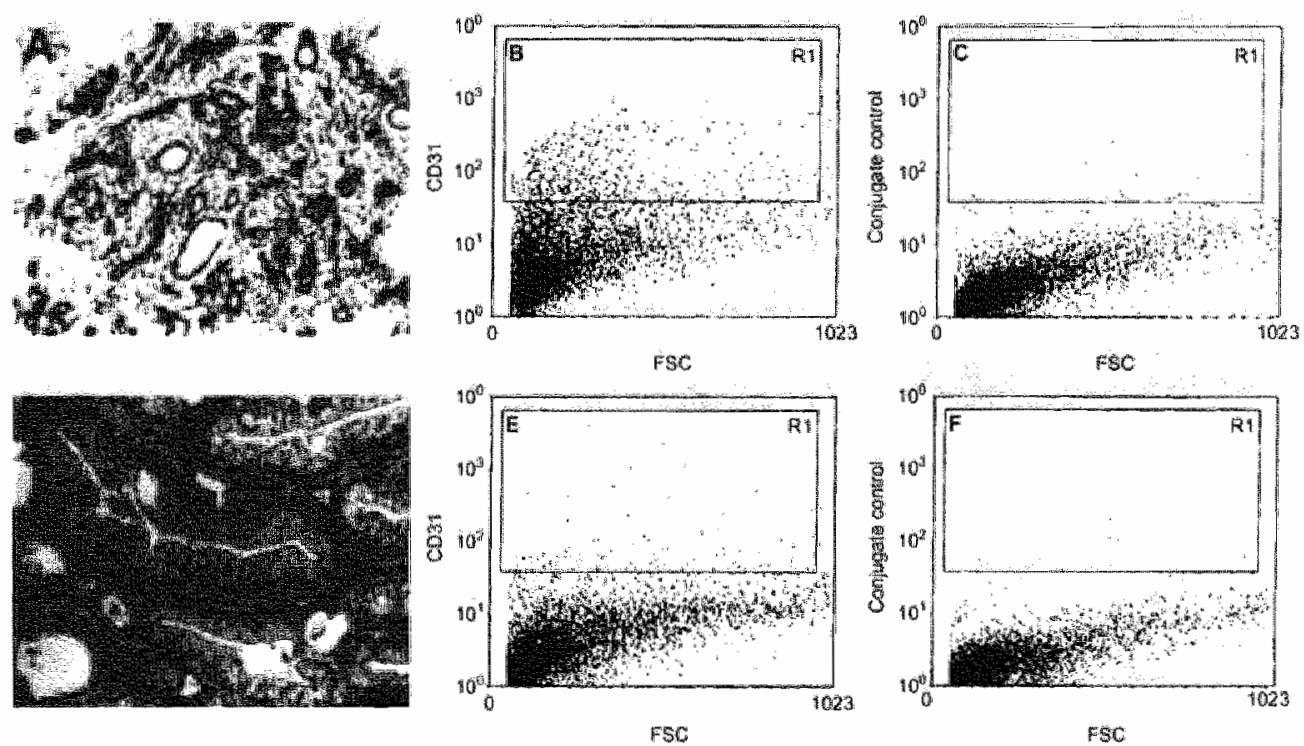

\section{Figure 2}

Immunohistochemistry and flow cytometry and of a colon carcinoma with a high $(\mathrm{A}-\mathrm{C})$ and a low (DE) vessel density. $(A, D)$ Indirect $C D 31$ immunohistochemical staining and counter staining of nuclei with hematoxilin. $(B, E)$ Dot-plots of forward scatter vs indirect $C D 31$ stauning. $(C, F)$ conjugate controls. 
Flow cytometric quantification of EC correlates with immunohistochemical MVD determination

To investigate whether our method correlates with the immunohistochemical measurement of MVD, a series of 32 cryo-preserved human colon carcinoma tissues (four Dukes A, 15 Dukes B, seven Dukes C and six Dukes D) were analysed. Examples of low vascular density in well differentiated colon carcinoma and high vascular density in a poorly differentiated colon carcinoma are shown in Figure 2. A positive correlation between the percentage of EC and immunohistochemical MVD assessment was observed. A high correlation $(\mathrm{F}=0.74, \mathrm{P}=0.001)$ was found when flow cytometric analysis was compared with MVD in vascular hotspots (Figure $3 \mathrm{~A}$ ). An even higher correlation was found when the overall mean MVD was compared $(r=0.84, P<.001$, Figure 3B). Interestingly, in the latter case, the flow cytometric analysis was found to be more sensitive for tissues with low (59\%) MVD measurements. For tissues with high percentages of EC (49\%), a higher correlation with immunohistochemical MVD assessment was observed ( $r=0.93$, $\mathrm{P}<.002$, Figure $3 \mathrm{~B}$ ). A significant correlation with tumour stage was not found. Comparing the different methods, the currently described new flow cytometric technique is most beneficial in the assessment of angiogenesis in tumour tissues.
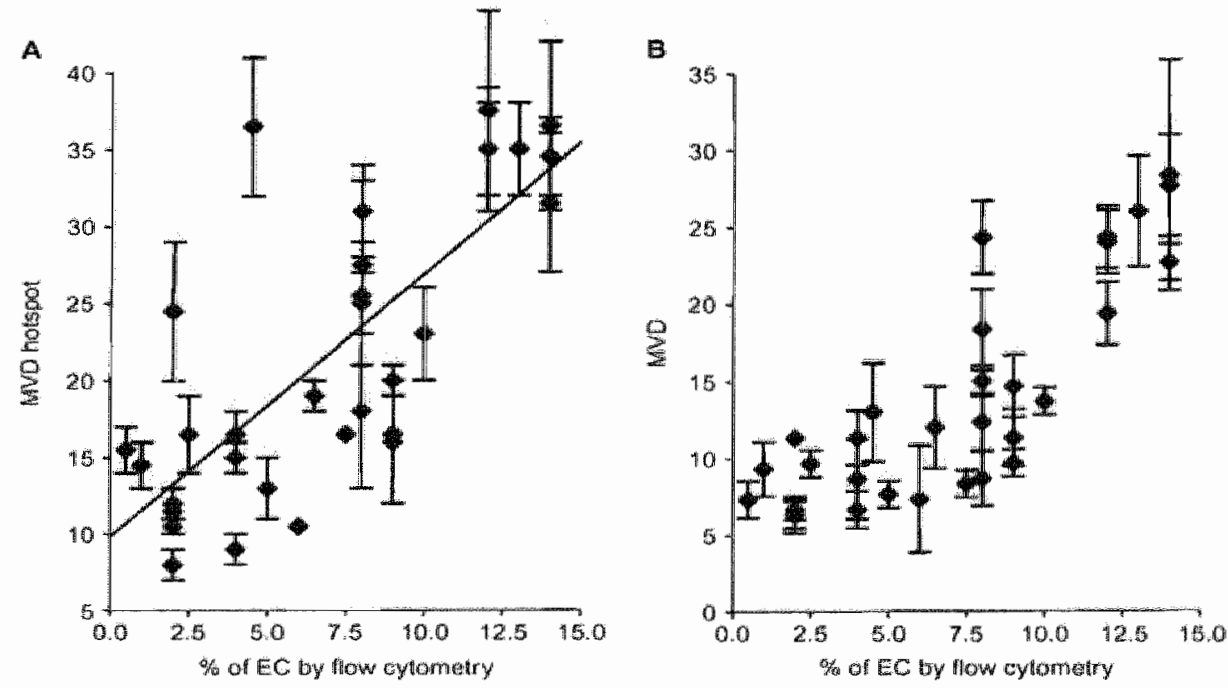

Figure 3

(A) Correlation diagram $(r=0.74, \mathrm{P} 50.001)$ of percentage of llow cylometrically idertified $\mathrm{EC}$ and hotspot MVD measurement (mean number of blood vessels in three hotspots per section). (B) Correlation diagram $(r=0.84, \mathrm{P}<.001)$ of flow cytometrically identified $\mathrm{EC}$ and MVD measurement (mean number of blood vessels per high-power field). The mean results of 32 colon carcinomas are shown. 


\section{Discussion}

The capacity of a tumour to induce new blood vessel formation is of key importance for its outgrowth and spread. The golden standard for analysis of angiogenesis; MVD assessment by immunohistochemistry, has a number of disadvantages (see Introduction). The current method is not subject to these problems. It quantifies the number of $E C$ in frozen tissues accurately and objectively. The high correlation with data obtained by immunohistochemical analysis of MVD proved the specificity of our method. Because the current method was set up to determine the number of EC in an entire tissue section, the data obtained should theoretically be most comparable to the data of the immunohistochemical detection of the total mean number of vessels (Figure 3B). Indeed, we fourid a higher correlation index than with the hotspot countings. In this context two important considerations should be mentioned. Firstly, the size of the blood vessels may be critical. A tissue with a low number of large blood vessels will be scored relatively low by immunohistochemical MVD measurement, whereas, when oxygenation and/or metastasis is concerned, this might be comparable to a higher number of smaller vessels. Enumeration of EC by FACS may level this difference out. Secondly, the nature and composition of the vessel might be critical. Larger vessels may be more mature and consequently contain more extracellular matrix/basal membrane components that can prevent the appropriate digestion and detachment of EC. This may therefore be an intrinsic facilitation of the measurement of angiogenic blood vessels. These two considerations both favour the use of the currently described flow cytometric analysis.

It might be argued that the CD31 antibody also identified other cell types present in the tumour tissues such as leukocytes. However, the immunohistochemistry data did not show staining of leukocytes (see Figure 2). In addition, the leukocyte population has most likely been excluded in the flow cytometric analysis by gating, due to lower scatter characteristics. Therefore, we still favour the use of CD31 antibodies over CD34 antibodies. Within the group of colon carcinoma tissues which was selected for representative cases of all Dukes stages, no correlations were found between percentage of EC and Dukes stage, tumour size or survival. This is most likely due to the study group size. Future studies in large numbers of tumour tissues will provide information on clinical parameters, which was beyond the scope of the present study. The current method is potentially also suitable for analysis of tumour EC phenotype. In future studies the number and phenotype of EC in tumour biopsies before and after chemotherapeutic and antiangiogenic treatment modalities will be subject to investigations. This may reveal fundamental insights into the regulation of angiogenesis or alternatively may provide surrogate endpoints of tumour treatments. 


\section{Acknowledgements}

This work was supported by research grants from the Dutch Cancer Society (UM20012529). We are grateful to Loes van Eijck for expert technical assistance. 


\section{References}

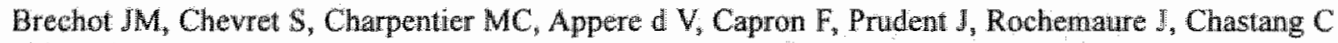
(1996) Blood vessel and lymphatic vessel invasion in resected non small cell lung carcinomia. Correlation with TNM stage and disease free and overall survival. Cancer $78: 2111-2118$

Chandrachud LM, Pendleton N, Chisholm DM, Horan MA, Schor AM (1997) Relationship between vascularity, age and survivall in non-small -cell lung cancer. Br J Cancer 76: $1367-1375$

Delaltunt $\mathbb{B}$, Bethwaite $\mathrm{PB}$, Thornton A (1997) Prognostic significance of microscopic vascularity for clear cell renal cell carcinoma. Br J Urol 80:401 - 404

Grilficen AW Damen CA, Martinotti S, Blijham GH, Groenewegen G (1996) Endothelial ICAM-1 expression is suppressed in human malignancies; role of angiogenic factors. Cancer Res 56: $1111-1117$

Grifficen AW, Molema G (2000) Angiogenesis: potentials for pharmacologic intervention in the treatment of cancer, cardiovascular diseases and chronic inflammation. Pharmacol Rev 52: 237-268

Haubner R, Wester HI, Weber WA, Mang C, Ziegler SI, Goodman SL, SenekowitschSohmidtke R, Kessler H, Schwaiger M (2001) Noninvasive imaging of alpha(v)beta 3 integrin expression using $18 \mathrm{~F}$ - labeled RGDcontaining glycopeptide and positron emission tomography. Cancer Res 61 : $1781-1785$

Hillen HF, Hak LE, Joosten-Achjanie SR, Arends JW (1997) Microvessel density in unknown primary turnors. Int J Cancer 74:81-85

Kirchner LM, Schmidt SP, Gruber BS (1996) Quantitation of angiogenesis in the chick chorioallantoic membrane model using fractal analysis. Microvase Res $51: 2-14$

Sarbia M, Bittinger F, Porschen $\mathbb{R}$, Dutkowski P, Willers R, Gabbert HE (1996) Tumor vascularization and prognosis in squamous cell carcinomas of the esophagus. Anticancer Res 16:2117-2121

van Dijke CF, Braseh RC, Roberts TP, Weidner N, Mathur A, Shames DM, Mann JS, Demsar F, Lang P, Schwickert HC (1996) Manmary carcinoma model: correlation of macromolecular contrast- enhanced MR imaging characterizations of tumor microvasculature and histologic capillary density. Radiology 198: $813-818$

Vermeulen PB, Gasparini G, Fox SB, Toi M, Martin L, McCulloch P, Pezzella F, Viale G, Weidner N, Harris AL, Dirix LY (1996) Quantification of angiogenesis in solid human tumours: an international consensus on the methodology and criteria of evaluation. Eur J Cancer $32 \mathrm{~A}: 2474-2484$

Weidner N, Carroll PR, Flax J, Blumenfeld W, Folkman J (1993) Tumor angiogemesis correlates with metastasis in invasive prostate carcinoma. Am J Pathol 143: $401-409$ 
Weidner N, Folkman J, Pozza F, Bevilacqua P, Allred EN, Moore DH, Meli S, Gasparini G (1992) Tumor angiogenesis: a new significant and independent prognostic indicator in early-stage breast carcinoma. J Natl Cancer Inst 84: $1875-1887$

Wild R, Ramakrishnan S, Sedgewick J, Griffioen AW (2000) Computer assisted digital image analysis for the quantitative assessment of tumor angiogenesis: inhibition by VEGF-toxin conjugate. Microvase Res 59: $368-376$ 



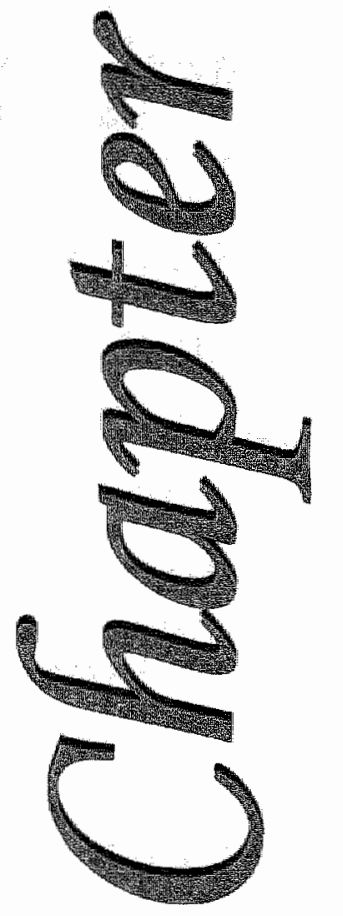

\section{Angiogenic profile of breast carcinoma determines leukocyte} infiltration

Jessica C.A. Bouma-ter Steege, Coen I.M. Baeten, Victor L.J.L. Thijssen, Sietske A. Satijn, Inge C.L. Verhoeven, Harry F.P. Hillen, John Wagstaff, and Arjan W. Griffioen

Clin Cancer Res. 2004 Nov 1;10(21):7171-8.

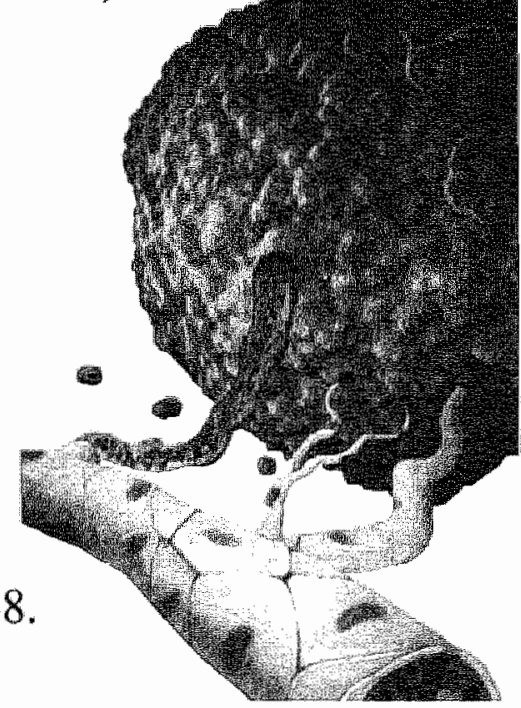




\begin{abstract}
In order to study the relationship between the angiogenic profile and leukocyte infiltration of tumors, single cell suspensions of archival frozen medullary and ductal breast cancer tissues were analyzed by flow cytometry. The amount of leukocytes and endothelial cells (EC) was measured, as well as the expression of intercellular adhesion molecule-1 (ICAM1) on the EC fraction. A significantly higher number (3.2-fold) of infiltrating leukocytes was observed in medullary carcinoma. The composition of this infiltrate was similar to that seen in ductal carcinomas. The more intense infiltrate was explained by the approximately 3 -fold enhanced endothelial ICAM-1 expression in medullary carcinoma. The angiogenic profile of all tumors was assessed by quantitative real-time RT-PCR analysis. VEGF-C and VEGF-D, but not VEGF-A, bFGF, PIGF and angiopoietins-1, -2 and -3 , showed a relatively higher level of expression in ductal carcinoma than in medullary carcinoma. In vitro, both $\mathrm{VEGF}-\mathrm{C}$ and $-\mathrm{D}$ were found to decrease endothelial ICAM-1 expression in the presence of bFGF. These data suggest that in vivo angiogenic stimuli prevent the formation of an effective leukocyte infiltrate in tumors by suppressing endothelial ICAM-1 expression.
\end{abstract}




\section{Introduction}

An intense leukocyte infiltrate in tumors is thought to be a sign of an effective anti-tumor immune response and is consequently often related to an improved clinical outcome (13). We and others have previously demonstrated, both in vitro and in vivo, that leukocyte vessel wall interactions are regulated by tumor derived angiogenic factors (4-8). These factors down-regullate the expression of endothelial adhesion molecules involved in leukocyte interactions, of which intercellular adhesion molecule-1 (ICAM-1) is the most important one (9), ultimately leading to a suppressed infiltration and escape from immune surveillance. To study the relationship between angiogenesis, endothelial cell (EC) phenotype and leukocyte infiltration, we adapted the flow cytometric system which recently was described as a reliable and objective alternative for the assessment of microvessel density (MVD) (10). This method was used to simultaneously determine the level and composition of leukocyte infiltrate in frozen breast cancer tissue, which allows retrospective analysis.

To investigate the leukocyte infiltrate in tumor tissue, we selected breast carcinoma. Among these tumors a distinct type of disease has been identified, namely medullary breast carcinoma, which is defined, among a number of other characteristics, by an intense infiltration of leukocytes $(11,12)$. Interestingly, medullary breast carcinoma has a better clinical prognosis which is thought to be related to this inflammatory infiltrate We compared these rather rare tumors $(5-8 \%$ of breast cancer) with the most common histological diagnosis of breast cancer, which is not otherwise specified (NOS) ductal carcinoma $(60-70 \%$ of breast cancer $)(13)$.

We demonstrate here, using flow cytometry, that a relatively lower level of leukocyte infiltration in ductal type of breast carcinoma than in the medullary type can be explained by the relatively lower level of ICAM-1 expression on tumor vessels in the former case. This suppressed ICAM-1 expression can be explained by a higher expression of angiogenic factors by ductal breast carcinoma tumor cells. This report describes the correlation between angiogenic potential, endothelial adhesion molecules and leukocyte infiltrate in human breast cancer. 


\section{Material and Methods}

\section{Patient characteristics}

Frozen tumor tissues of ductal (not otherwise specified, NOS, $n=14$ ) and medullary breast tumors $(n=9)$, were obtained from the archive of the Department of Pathology. Mean age, tumor size, and percentage of patients with positive lymphnodes were comparable in both groups ( $60 \pm 14.55$ vs $51 \pm 7.97$ years, $21.8 \pm 5.31$ vs $24.2 \pm 13.62$ mm diameter, and $43 \%$ vs $31 \%$ for medullary vs ductal breast carcinoma, respectively).

\section{Preparation of single cell suspensions and FACS analysis}

Single cell suspensions were made as described previously (10). In short, from each tumor, two $30 \mu \mathrm{m}$ thick frozen tissue sections were fixed in $1 \mathrm{ml} 1 \%$ paraformaldehyde (Merck, Darmstadt, Germany) washed with phosphate buffered saline (PBS) and centrifuged. Subsequently, the sections were digested by an incubation in collagenase and dispase (both $5 \mathrm{mg} / \mathrm{ml}$, Life Technologies, Breda, the Netherlands), washed in PBS containing $0.5 \%$ bovine serum albumin (BSA, Sigma, Zwijndrecht, the Netherlands), centrifuged and further processed on ice. Cell pellets were incubated with appropriately diluted EN4 anti-human CD31 (Monosan, Sanbio, Uden, the Netherlands), HI30 antihuman CD45 (common leukocyte marker, Pharmingen, San Diego, CA), T3-4B5 antihuman CD3 (T cell marker, $0.225 \mathrm{mg} / \mathrm{ml}$, DAKO, Glostrup, Denmark), MT310 antihuman CD4 (T helper cell marker, $0.1 \mathrm{mg} / \mathrm{ml}, \mathrm{DAKO}$ ), DK25 anti-human CD8 (cytotoxic T cell marker, $0.05 \mathrm{mg} / \mathrm{ml}, \mathrm{DAKO}$ ), DJ $130 \mathrm{c}$ anti-human CD16 (NK cell and granulocyte marker, $0.2 \mathrm{mg} / \mathrm{ml}$, DAKO) or KP1 anti-human CD68 (macrophage marker, DAKO) antibodies. After the first incubation, the cells were washed and incubated with biotin conjugated rabbit anti-mouse $\operatorname{IgG}(15 \mathrm{mg} / \mathrm{ml}$ DAKO). Subsequently, the cells were washed and incubated with phycoerythrin (PE)-conjugated streptavidine $(10 \mathrm{mg} / \mathrm{ml}, \mathrm{DAKO})$. Finally, the cells were washed and analyzed on a FACS calibur (Becton and Dickinson, Mountain View, CA) using Cell-quest software (Becton and Dickinson). In some experiments propidium iodide (Cabiochem, San Diego, CA) staining was used to control for intact cells (10).

For double staining of the EC with CD31 and ICAM-1 antibodies, the CD31 staining was followed by incubation with FITC conjugated 6.5B5 anti-human CD54 (ICAM-1, DAKO) in the presence of $5 \%$ normal mouse serum. Subsequently the cells were washed and analyzed.

\section{Immunohistochemistry}

Serial cryo-sections $(5 \mu \mathrm{m})$ were made adjacent to the sections used for flow cytometry and mounted onto organosilane coated slides (Starfrost, Germany), fixed in acetone (Merck, Darmstadt, Germany) for 10 minutes at $-20^{\circ} \mathrm{C}$ and subsequently air dried for 16 hours at RT. Endogenous peroxidase was blocked by immersing the slides in $0.3 \% \mathrm{H}_{2} \mathrm{O}_{2}$ in methanol (or PBS in case of CD8 staining) for 30 minutes. Subsequently, the slides were washed in PBS and nonspecific binding was blocked by an incubation with PBS containing 5\% 
BSA for 30 minutes. Sections were washed again and incubated with the primary antibodies (see under FACS analysis) for 1 hour at RT. After washing the slides, biotin-conjugated horse anti-mouse IgG (1:200 dilution, Vector Laboratories, Burlingame, CA) was applied for 1 hour followed by washings and an incubation with freshly prepared avidine-biotinperoxidase complex (Vectastain, Brunschwig Chemie, Amsterdam, the Netherlands) for 30 minutes. Peroxidase activity was detected using diaminobezidine (Sigma, Zwijndrecht, the Netherlands). Slides were counterstained with haematoxillin (Merck, Darmstad, Germany) and mounted in entellan (Merck). MVD was assessed as described previously (17) and leukocyte infiltration was determined by two independent observers in 4 randomly selected high power fields $(200 \mathrm{x})$. Results are expressed as number of vessels $/ \mathrm{mm}^{2}$ (CD31) or leukocytes $/ \mathrm{mm}^{2}$.

\section{RNA isolation and CDNA synthesis}

Total RNA was isolated from ten $20 \mu \mathrm{m}$ thick sections using the RNeasy mini kit (Qiagen, Hilden, Germany) according to the manufacturer's instructions. High quality total RNA could only be isolated from 8 medullary and 8 ductal tissue samples . Possible genomic DNA contamination was removed by on-column DNase treatment with the RNase-free DNase set (Qiagen). The purity and integrity of the RNA was checked by gel electrophoresis according to standard procedures. One ig total RNA was incubated for 5 minutes at $70^{\circ} \mathrm{C}$, and cDNA synthesis was performed for 1.5 hours at $42^{\circ} \mathrm{C}$ with $400 \mathrm{U}$ of M-MLV reverse transcriptase RNase H (Promega, Leiden, the Netherlands) in $20 \mu \mathrm{l}$ of $1 \mathrm{x}$ first strand buffer (Promega), and $1 \mathrm{mM}$ dNTPs in the presence of $10 \mathrm{U}$ RNase inhibitor $\mathrm{rRNasin}$ (Promega) and $0.5 \mu \mathrm{g}$ random primers (Promega). The reverse transcriptase activity was inactivated by incubation at $95^{\circ} \mathrm{C}$ for 5 minutes and following addition of $1 \times T E$ up to a final volume of $50 \mu \mathrm{L}$ the cDNAs were stored at $-20^{\circ} \mathrm{C}$.

\section{Real-time quantitative $R T-P C R$}

The primers used for real-time quantitative PCR (qRT-PCR) were targeted against bactin, cyclophilin $A$ and the following angiogenesis factors (Table 1): vascular EC growth factor (VEGF)-A, VEGF-C, VEGF-D, basic fibroblast growth factor (bFGF), angiopoietin (ang)-1, ang-2, ang-4 and placental growth factor (PIGF). Primers were human specific (checked by the Basic Local Alignment Search Tool, BLAST;

http:/www.ncbi.nlm.nih.gov/BLAST/) and the specific melting point of the amplicons was analyzed using the ABI PRISM 7000® Dissociation curve software (Applied Biosystems, Foster City, CA, USA). All primers were designed to meet several requirements concerning $\mathrm{GC}$-content, annealing temperature and amplicon length and synthesized by Sigma-Genosys (Cambridgeshire, UK). Real-time qRT-PCR was performed on an ABI PRISM 7000@ Sequence Detection System apparatus (Applied Biosystems) using the SYBR@ Green PCR master mix (Applied Biosystems). The PCR reaction was performed in a $25 \mu \|$ volume containing $1.5 \mu \mathrm{l}$ cDNA, $1 \times$ SYBR@ Green PCR master mix (Applied Biosystems), and $400 \mathrm{nM}$ of each primer. The PCR profile was as follows; 10 minutes at $95^{\circ} \mathrm{C}$, followed by 40 cycles of 15 seconds at $95^{\circ} \mathrm{C}$ and 1 minute at $60^{\circ} \mathrm{C}$. Data were analyzed with the Sequence Detection System software (Applied Biosystems). The 
parameter $\mathrm{Ct}$ (threshold cycle) was defined as the cycle number at which the fluorescent signal passed a fixed value (threshold) above baseline. The absolute mRNA copy numbers were calculated from standard curves generated with 10-fold dilution series of precisely quantified cloned template DNA. The copy number of each target gene was normalized to 1 million copies of the housekeeping gene b-actin.

Table 1 Quantitative real-time RT-PCR primers used

\begin{tabular}{lll}
\hline TargetGene & Forward primer(5" to 3 ) & Reverse primer(5 to 3') \\
D-Actin & CATTCCAAATATGATGCATT & CCTGTGTGGACTTGGGAGAG \\
Cyclophilin A & CTCGAATAAGTTTGACTTGTGTT & CTAGGCATGGGAGGGAACA \\
VEGF-A & AAGGAGGAGGGCAGAATCAT & CCAGGCCCTCGTCATTG \\
VEGF-C & CCTGCCCCACCAATTACA & TGGGGTCCACAGCTGGCA \\
VEGF-D & GCAGGAGGAAAATCCACTTG & GGGTGCTGGATTAGATCTTTG \\
Ang-1 & AGCTACCACCAACAACAGTG & CAAAGATTGACAAGGTTTGG \\
Ang-2 & TGCCACGGTGAATAATTCAG & TTCTTCTTTAGCAACAGTGGG \\
Ang-4 & AACAGCGCGCTCGAGAAG & GCTTCGCCTTCTTGCTGA \\
BFGF & CCCGACGGCCGAGTTGAC & CACATTTAGAAGCAGTAATCT \\
PIGF & TGCAGCTCCTAAAGATCCGT & GGGAACAGCATCGCCGCA \\
\hline
\end{tabular}

Ang: angiopoietin; VEGF: vascular endothelial growth factor; bFGF: basic fibroblast growth factor; PIGF: placental growth factor

\section{Cell culture}

Human umbilical vein-derived EC (HUVEC) were harvested from normal human umbilical cords by perfusion with $0.125 \%$ trypsin/ethylenediamine tetra-acetic acid (EDTA). HUVEC were routinely cultured in RPMI-1640 (Life technologies, Breda, The Netherlands) supplemented with $20 \%$ heat inactivated human pooled serum (HS; University Hospital Maastricht), 2 mmol/L L-glutamine (Life technologies, Breda, The Netherlands), $50 \mathrm{ng} / \mathrm{ml}$ streptomycin and $50 \mathrm{U} / \mathrm{ml}$ penicillin (ICN Biomedicals BV, Zoetermeer, The Netherlands) and seeded into gelatin-coated (MERCK Eurolab BV, Amsterdam, The Netherlands) tissue culture flasks at $37^{\circ} \mathrm{C}$ and $5 \% \mathrm{CO}_{2}$. Confluent HUVEC cultures were passed 1:3. For experiments HUVEC in passage 2 or 3 were plated onto fibronectin coated tissue culture plates (Costar Corp., Cambridge, MA). For analysis of the regulation of ICAM-1 expression by VEGF, HUVEC were cultured in fibronectin coated 24 wells tissue culture plates at a concentration of 20,000 cells/well for three days. Cells were stimulated with $10 \mathrm{ng} / \mathrm{ml} \mathrm{bFGF}$ and/or VEGF-C (a kind gift from Dr. K. Alitalo, Helsinki, Finland) and/or VEGF-D (R\&D, Plymouth, MN) in various concentrations. After three days the stimulated wells reached a confluence of $80-90 \%$. HUVEC were trypsinized and harvested, washed in cold PBS and fixed with $1 \%$ paraformaldehyde (Merck, Hamburg, Germany) during 30' and stained for FACS analysis using mouse anti-human ICAM antibody (MEM1.11; Monosan, Uden, The Netherlands). 
Statistical analysis

Correlations between FACS analysis and immunohistochemistry, CD31, ICAM-1 and leukocyte infiltrate were tested using the Spearman correlation test. The Mann-Whitney $U$ test was used to determine the difference between medullary and NOS breast carcinomas. The Student's t-test was used to determine the difference between the in vitro results. $\mathrm{p}$-values $<0.05$ were considered statistically significant and all calculations were performed using SPSS.
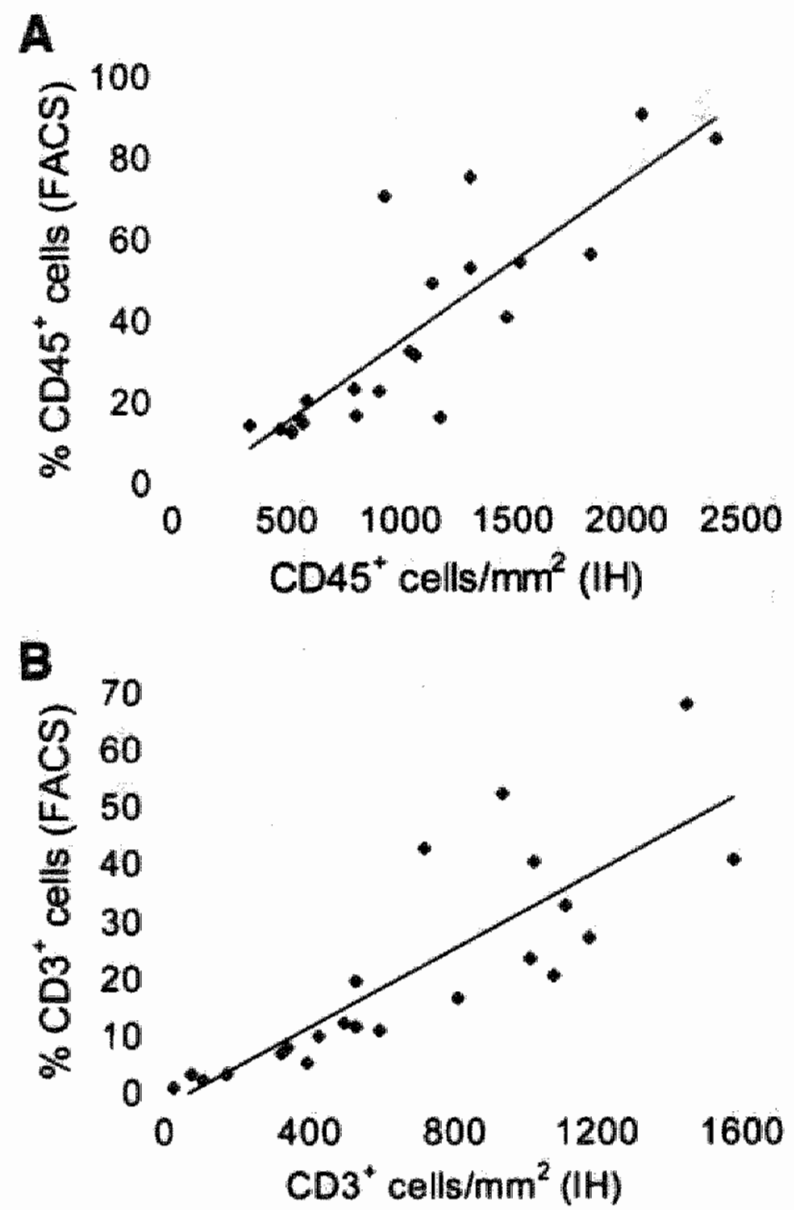

\section{Figure 1}

Detection of leukocyte infiltrate by flow cytometry; correlation with immunohistochemical detection. Immunohistochemical (1H) and FACS analysis values of 23 breast carcinomas are shown using the panleukocyte HI30 anti-CD45 (Spearman's correlation coefficient $r=$ $0.875, P<0.0001, A)$ and the $T 3-4 \mathrm{BS}$ anti-CD3 $\mathrm{T}$ lymphocyte marker (correlation coefficient $r=0.906$, $P<0.0001 ; B)$. 


\section{Results}

Flow cytometric assessment of leukocyte infiltrate in tumors

A recently described method for flow cytometrical detection of $\mathrm{EC}$ in single cell suspensions made of frozen tumor tissues $(10)$, was adapted for quantification and compositional characterization of tumor leukocyte infiltrate. Single color flow cytometry on CD45 (a pan-leukocyte marker) stained single cell suspensions of archival frozen breast cancer tissues easily quantified the total numbers of infiltrating leukocytes. A large variation in the amount of infiltrating white blood cells in these breast carcinoma specimens was found, ranging from $12-91 \%$ of cells. Flow cytometric results were validated and confirmed by simultaneous quantification of infiltrate by conventional immunohistochemical analysis in adjacent $5 \mu \mathrm{m}$ sections of the same tissues. A high correlation between detection of CD45 expressing cells by FACS analysis and immunohistochemistry was found (Figure $1 \mathrm{~A}$, correlation coefficient $\mathrm{r}=0.875, \mathrm{p}<0.0001$ ). Similar results were found for quantification of T lymphocytes after staining with anti-CD3 antibody (correlation coefficient $r=0.906$, $\mathrm{p}<0.0001$, Figure 1B).
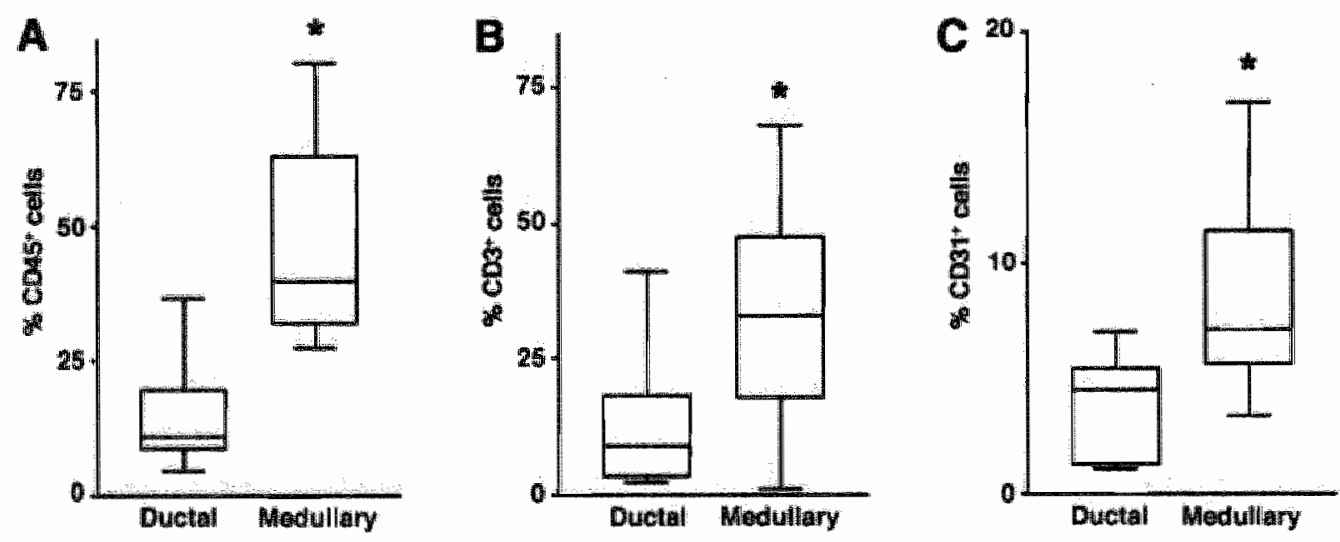

Fügure 2

Enhanced numbers of leukocytes and endothelial cells in medullary breast carcinoma as compared with ductal carcinoma. Medullary breast carcinomas contain significantly more CD45 leukocytes as assessed by FACS analysis $(A ; P<0.001)$ as compared with ductal breast careinomas. Similar results were found for CD3 T lymphocytes $(B ; P<0,004)$ and $C D 31$ endothelial cell $\left(C_{*}, P<0.007\right)$ expressing cells. Data are presented as median number of cells per mm2 with interquartile ranges (boxes) and 5 to 95 percentiles (error bars). * Significance, $\mathrm{P}<0,01$. 
Enhanced leukocyte infiltrate and vascularization in medullary breast carcinoma A characteristic of medullary carcinoma is the intense infiltration with small lymphocytes and plasma cells as compared to ductal carcinoma. Using the above described method this characteristic of medullary carcinoma was readily detected by flow cytometry. A 3.2-fold higher level of infiltration was found in medullary carcinoma (Figure 2A). This enhanced infiltration was also evident in the T lymphocyte subset as detected by CD3 expression (Figure 2B). Immunohistochemical analysis showed similar results: $808 \mathrm{CD} 45^{+}$ cells $/ \mathrm{mm}^{2}$ in ductal carcinoma versus $1436 \mathrm{CD} 45^{+}$cells $/ \mathrm{mm}^{2}$ in medullary carcinoma ( $\mathrm{p}<0.004) ; 533 \mathrm{CD}^{+}$cells $/ \mathrm{mm}^{2}$ in ductal breast carcinoma versus $889 \mathrm{CD}^{+}$cells/mm in medullary breast cancer $(\mathrm{p}<0.003)$. The higher number of T lymphocytes in medullary carcinoma was evident for both helper $\left(\mathrm{CD}^{+}\right)$and cytotoxic $\left(\mathrm{CD} 8^{+}\right) \mathrm{T}$ cell subsets (Table 2). A significantly enhanced number of monocytes/macrophages (CD68 ${ }^{+}$) was also observed to be present in medullary carcinoma as compared to ductal carcinoma. Although a statistically significant difference was not observed for the CD16 expressing leukocyte subset, which consists of granulocytes and NK cells, a clear trend in the same direction was also noted for these cells (Table 2).

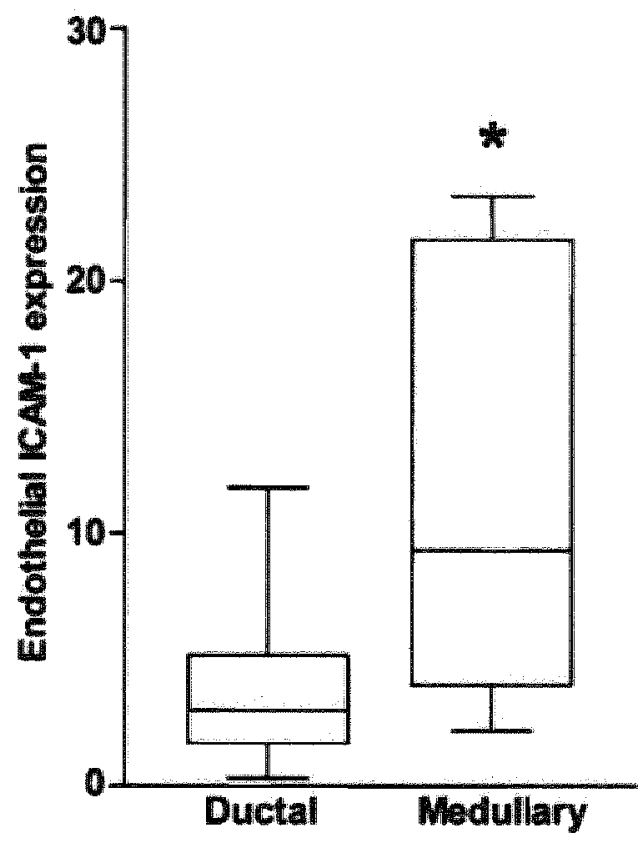

Figure 3

Endothelial ICAM-1 expression is suppressed in ductal breast carcinomas as compared with expression in medullary carcinomas. Mean ICAM1 fluorescence intensity on endothelial cells in medullary breast carcinoma is significantly higher as compared with the expression on endothelial cells in ductal breast carcinoma. Data are presented as mean ICAM-1 thorescence intensity on endothelial. cells with interquartile ranges (boxes) and $\$$ to 95 percentiles (error bars) * Significance, $P<0.01$. 
Table 2 Leukocyte in infiltration in medullary and ductal breast carcinoma determined by immunohistochemistry

\begin{tabular}{lccc}
\hline & Namber of cells & Number of cells & Significance \\
In medullary carcinoma & in ductal carcinoma & (p-value) \\
\hline CD45 (all leukocytes) & $1437 \pm 584^{\text {t }}$ & $809 \pm 341$ & 0.004 \\
CD3 (T lympluocytes) & $888 \pm 416$ & $534 \pm 419$ & 0.030 \\
CD4 (helper T Hymphocytes) & $624 \pm 387$ & $373 \pm 418$ & 0.048 \\
CD8 (cytotoxic T lymphocytes) & $548 \pm 284$ & $323 \pm 214$ & 0.036 \\
CD16 (granolocytes/NK cells) & $793 \pm 321$ & $533 \pm 161$ & 0.063 \\
CD68 )monocytes/macrophages) & $490 \pm 124$ & $343 \pm 146$ & 0.018 \\
\hline
\end{tabular}

statistical significance wass determined using the Mann Whitney U-test "mean number of tumor infiltrating leukocytes/mm² $( \pm \mathrm{SD})$

Next to the infiltrate, the amount of EC was also quantified by flow cytometry according to the earlier described method (10). Interestingly, a significantly higher number of EC was observed in medullary breast carcinoma $(p<0.01$, Figure $2 C)$. This result was confirmed by the classical assessment of microvessel density by CD31 staining and counting of blood vessels in adjacent cryo-sections (medullary 95 vessels $/ \mathrm{mm}^{2}$ versus ductal 58 vessels $/ \mathrm{mm}^{2}, \mathrm{p}<0,02$ ). Also for the detection of $\mathrm{EC}$, a significant correlation
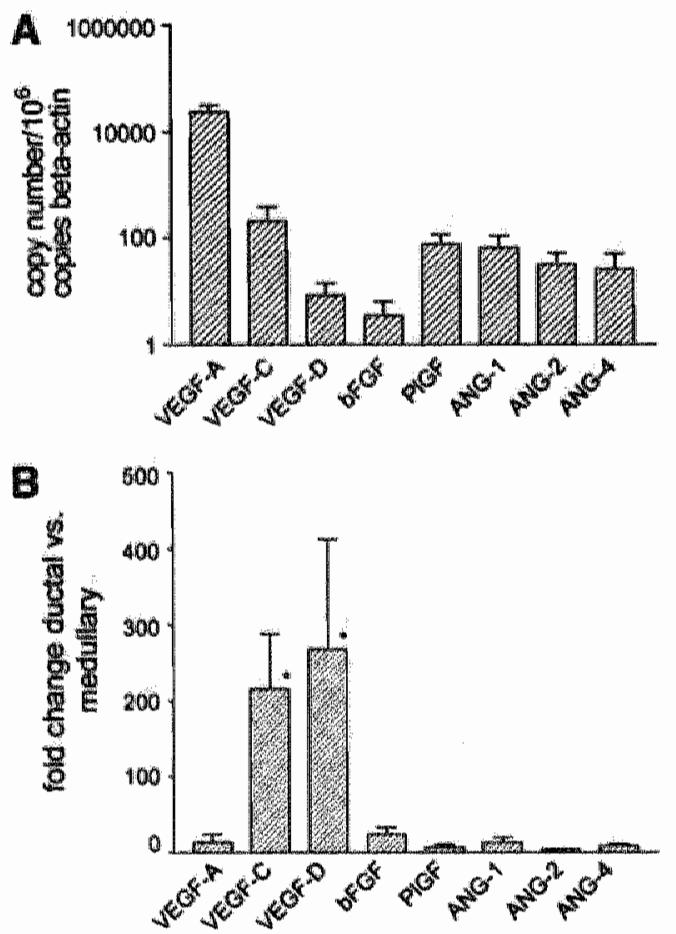

Figure 4

Real-time quantitative RT-PCR analysis of the angiogenic expression profile in ductal and medullary breast carcinoma tissues. $A$, the absolute mRNA copy numbers of the determined factors in medullary tumor tissue normalized to 1 million copies of -actin. $B$, the fold induction of expression in ductal tumor tissues as compared with medullary tumor tissue.. Asterisks represent a statistical significant difference between the two tumor types $(\mathrm{P}<0.05)$. 
between flow cytometric and histochemical techniques was observed $(r=0.658, p<0.0001)$, as was described before in other tissues (10). A low but significant correlation ( $r=0.451$, $\mathrm{p}<0.05$ ) was observed for the amount of $\mathrm{CD} 31^{+}$cells $(\mathrm{EC})$ and $\mathrm{CD} 45^{*}$ cells (leukocytes).

Endothelial ICAM-1 expression is lower in ductal breast carcinoma than in the medullary type

ICAM- 1 is generally accepted to be one of the most important adhesion molecules for infiltration of leukocytes. To investigate the relationship between leukocyte infiltration and endothelial ICAM-1 expression the above described method was applied for double staining with CD31 (phycoerythrin) and ICAM-1 (FITC) antibodies. This approach showed that there was significantly more ICAM-1 present on EC obtained from medullary breast carcinoma as compared to EC from ductal breast carcinona ( $\mathrm{p}<0.01$, Figure 3 ). The ICAM-1 expression on $\mathrm{EC}$ in medullary and ductall breast carcinoma correlated with the amount of leukocyte infiltrate as detected by $\mathrm{CD} 45(\mathrm{r}=0.715, \mathrm{p}<0.001)$ as well as by all used leukocyte subset antibodies.
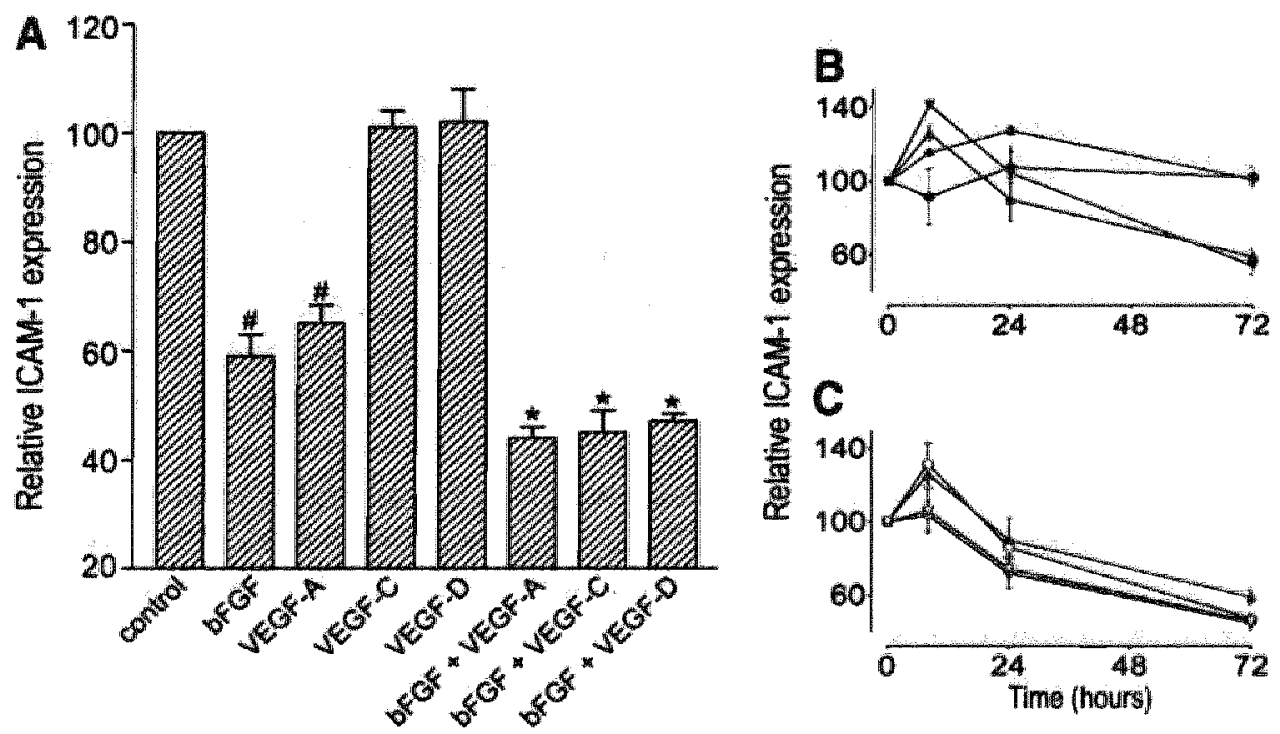

Figure 5

VEGF-C and VEGF-D synergize with $\mathrm{BFGF}$ to down-regulate ICAM-I on endothelial cells. HUVECs were cultured with $10 \mathrm{ng} / \mathrm{mL}$ bFGF, $20 \mathrm{ng} / \mathrm{mL}$ VEGF-A, $400 \mathrm{ng} / \mathrm{mL}$ VEGF $-C$, or $400 \mathrm{ng} / \mathrm{mL}$ VEGF $-D$ or combinations thereof. A. Mean relative endothelial ICAM- 1 expression of four to six independerit experiments (as percentage of ICAM-1 expression of untreated control endothelial cells) is shown ( SD). H represents a statistical significant difference $(P<0.001)$ as compared untreated to control endothelial cells. " represents a statistical significant difference $(P<0.05)$ as compared with HUVECs treated with bFOF allone. $B$, timeresponse curve of $I C A M-1$ regulation by $B F G F, V E G F-A$, VEGF-B, and VEGF-C, as mensured by flow cytometry. $\triangle$ bFGF; VEFG-A; VEGF-C; VEFG-D. C, time-response curve of $\ \mathrm{CAM}-1$ regulation by $10 \mathrm{ng} / \mathrm{mL}$ bFGF in the presence or absence of VEGF-A, VEGF $-B$, or VEGF-C. $\nabla$ bFGF $-V E G F-A$; $\bigcirc$ bFGF VEGF-C; O VEGF-D; - bFGF 
Ductal breast carcinoma is more angiogenic than medullary carcinoma

We have demonstrated before that angiogenic factors downregulate endothelial adhesion molecules such as ICAM-1 (5), leukocyte vessel wall interactions (4), and leukocyte infiltration (14). To see whether there was also a difference in the angiogenic potential between ductal and medullary breast tumors we investigated the expression profile of 8 angiogenic factors by quantitative real-time RT-PCR. Two housekeeping genes were included in the analysis and because there was a strong correlation between the expression levels of both housekeeping genes (correlation coefficient $r=0.965, p<0.001$ ), the expression level of each target gene was normalized only to B-actin expression. VEGF-A was found to be the predominant angiogenic factor in both tumor types while bFGF was expressed at very low levels (Figure $4 \mathrm{~A}$ ). There was no significant difference in expression of both factors between ductal and medullary tumors. Interestingly, the expression of VEGF-C and VEGF-D was found to be at least 200-fold higher in ductal carcinomas (Figure 4B). Angiopoietin-1, -2 and -4 , and PIGF were all expressed at relatively low levels and despite the fact that the only significant differences between the two breast cancer types were observed for VEGF-C and -D, the trend of enhanced expression in ductal breast cancer was noted for all angiogenic factors.

\section{Endothelial ICAM-I regulation by VEGF-A, $-C$ and $-D$}

Since VEGF-C and -D were overexpressed in ductal breast carcinoma, we tested whether these growth factors are involved in the regulation of ICAM-1 in blood vessels, as we have previously published for VEGF-A and bFGF (5). To that end, the effect of these angiogenic proteins on ICAM-1 was investigated using cultured EC. Unlike VEGF-A, VEGF-C and $-D$ alone had no effect on ICAM-1 expression on these cells (Figure 5). However, in combination with $10 \mathrm{ng} / \mathrm{ml} \mathrm{bFGF}$, a significant synergistic downregulation of ICAM-1 expression was observed (Figure 5A).

Since earlier reports by us and others have demonstrated a bi-phasic response of ICAM1 expression by $\mathrm{bFGF}$, with an upregulation after 16-24 hours and a marked downregulation after longer time points, and also a transient upregulation by VEGF, we performed a temporal study with both VEGF-C and -D in comparison with VEGF-A and bFGF. The bi-phasic response as observed for bFGF and VEGF-A was not present using VEGF-C and $-D$. At best a transient upregulation can be observed for VEGF-C (Figure 5B). In combination with bFGF VEGF-C and -D act similarly as VEGF-A (Figure 5C). 


\section{Discussion}

A flow cytometric approach was used to reliably quantify and identify the composition of the leukocyte infiltrate in archival frozen breast tumor tissues. This retrospective study indicated that the relatively rare medullary carcinoma of the breast, which is widely known to be characterized by an intense infiltration, has on average a 3.2-fold increased leukocyte infiltrate as compared to ductall (not otherwise specified, NOS) breast carcinoma. The enhanced infiltrate in medullary carcinoma is composed of similar leukocyte subsets as present in ductal breast carcinoma. The demonstration that endothelial expression of ICAM-1, which is the most important adhesion molecule for leukocyte extravasation (both necessary and sufficient (9)), is lower in ductal carcinoma suggests that the absence of adhesion molecules on the tumor vessels is the possible reason for the low level of infiltration as compared to medullary carcinoma. In previous studies we have extensively demonstrated in in vitro and in vivo models that the process of tumor angiogenesis downregulates leukocyte vessel wall interactions by suppression of endothelial adhesion molecules, such as ICAM-1, VCAM-1, E-selectin and CD34 (15-17). Moreover, tumor $\mathrm{EC}$ were shown to be relatively unresponsive to pro-inflammatory cytokines, a process that we have called EC anergy, and which is mediated through different mechanisms $(5,18)$. Finally, it has been demonstrated that these phenomena are mediated through exposure of EC to angiogenic growth factors $(5,6)$. The present study is the first to show the difference in angiogenic potential between ductal and medullary breast carcinoma. This difference involves a significantly higher expression of VEGF-C and -D $(19,20)$ in ductal breast cancer cells as compared to medullary breast cancer cells. Both these VEGFs have been described to induce proliferative responses in EC either alone or in combination with other stimuli $(21,22)$. In our studies, both growth factors alone did not regulate ICAM-1 expression on HUVEC. Interestingly, in combination with $\mathrm{bFGF}$, and possibly also with other growth factors (not tested), VEGF-C and -D synergistically downregulated ICAM-1. Thus the angiogenic stimulation of endothelium in ductal carcinoma suppresses the expression of adhesion molecules leading to the prevention of leukocyte infiltration. It is known that leukocyte infiltration can positively influence the prognosis of cancer $(1,14)$ and the present results may therefore serve as an explanation for the better prognosis of medullary over ductal carcinoma.

Although tumor infiltrating leukocytes can contribute to the anti-tumor immune response, there are also reports describing a role of immune cells in promoting tumor growth by the production of angiogenic factors. The presence of tumor associated macrophages, known to produce angiogenic factors such as VEGF, was correlated to vascular grade and to clinical outcome in breast cancer (23-25). Similarly, in the present study we observed a higher MVD and leukocyte (and macrophage) infiltration in medullary carcinoma as compared to ductal carcinoma. Nevertheless, medullary carcinoma has a better prognosis (13). This apparent discrepancy might also be explained by the comparison of two different tumor types in the present study. 
An explanation for the apparent contradiction of a stronger pro-angiogenic profile and a lower MVD may lie in the presence of the sequential steps within the process of the angiogenesis cascade. In the presence of a fully developed and dense vascular bed the angiogenic switch will be 'off'. This genetic change can be accomplished in minutes to hours while formation of new blood vessels, a process that will take days or longer, will always lag behind. If the latter is true, the assessment of MVD in tumors may just reveal the opposite of angiogenic potential. This may explain the difficulty of linking MVD to prognosis in many previous reports. In addition, this also places previous reports in the literature, describing an inverse relationship between MVD and prognosis, in new perspective $(26,27)$.

Next to the differential expression of ICAM-1 on the endothelium in these tumors, we also found that there is a correlation between the number of EC and the number of leukocytes in the tumor tissues. It is evident that also the amount of blood vessels can contribute to the level of infiltration by leukocytes.

We favor the view that the exposure of tumor blood vessels to higher concentrations of angiogenic growth factors, results in the suppressed adhesion molecule expression in ductal carcinomas. Since we have demonstrated previously that ICAM-1 expression, and consequently the leukocyte infiltrate, is regulated by angiogenic factors such as VEGF and $\mathrm{bFGF}$, the potential of medullary and ductal breast tumors to produce various angiogenic factors was investigated. VEGF-A was found to be the predominant angiogenic factor, of which mRNA expression was detected at high levels in both tumor types. All other angiogenic factors were expressed at relatively low levels. However, while all angiogenic factors showed a trend of overexpression in ductal breast carcinoma, we did find a marked overexpression of both VEGF-C and VEGF-D in ductal carcinomas. We suggest that the enhanced expression of angiogenic factors is responsible for the suppression of ICAM- 1 in ductal carcinoma EC.

The angiogenic profile was determined on total RNA from a whole tissue section. The problem then arose as to whether the increased expression of these angiogenic factors could be explained by differences in the leukocyte infiltrate. A number of factors make this explanation unlikely: 1) although leukocytes can be producers of angiogenic factors, the medullary carcinomas were found to have lower expression of these factors. 2) most factors were found to be equally expressed, indicating that not all factors follow this trend, and the differences found in VEGF-C and $-\mathrm{D}$ expression may be specific for these factors. 3) if the different amounts of leukocytes in the two tumor types is assumed to generate differences in the real time $\mathrm{qRT}$ RPCR, than the factors of 2-3 difference in infilitration can never explain the 200-fold difference in cytokine expression. 4) for prognosis it may be considered irrelevant where these cytokines come from, as long as they contribute to a more aggressive growth characteristic of the tumor.

In line with our observations, Zhang et all. (1) recently demonstrated that the absence of intratumoral $T$ cells in ovarian carcinoma was associated with increased expression of VEGF and a significantly worse clinical outcome. We are aware of the fact that VEGF$\mathrm{C}$ and $-\mathrm{D}$ are claimed to be mainly involved in lymphangiogenesis $(28,29)$ which might explain the difference in clinical outcome between medullary and ductal breast cancer. 
However, a recent study reported the absence of lymphangiogenesis and intratumoral lymph vessels in metastatic breast cancer (30). Together with the observation that VEGF. $C$ and -D downregulated endothelial ICAM-1 expression we suggest that in ductal breast cancer VEGF-C and -D are involved in the downregulation of the tumor infiltrate.

In conclusion, we favor the view that the measurement of a large number of angiogenic factors, which we called angiogenic profiling, is a necessary tool in determining the prognosis of cancer. Not only to have a better insight into the angiogenic potential than by measuring MVD, but also to understand anti-tumor immune responses. It is suggested, but remains to be investigated, whether angiogenic profiling may help to predict the success of immunotherapy as an anti-cancer strategy.

\section{Acknowledgements}

The current research was supported by grants to $\mathrm{AWG}$ from the Dutch Cancer Society (UM 2001-2529), the Dutch Science Foundation (NWO) - Stichting Technische Wetenschappen (MPG-5456), and by a grant from Reell Precision Manufacturing BV, Elsloo, The Netherlands. 


\section{References}

1. Zhang, L., Conejo-Garcia, J. R., Katsaros, D., Gimotty, P. A., Massobrio, M., Regnani, G., Makrigiannakis, A., Gray, H., Schlienger, K., Liebman, M. N., Rulbin, S. C., and Coukos, G. Intratumoral $T$ cells, recurrence, and survival in epithelial ovarian cancer. N.Engl I Med, 348: 203-213, 2003.

2. Funada, Y, Noguchi, T., Kikuchi, R, Takeno, S., Uchida, Y, and Gabbert, H. E. Prognostic significance of CD84 T cell and macrophage perifumoral infiltration in colorectal cancer. Oncol:Rep, 10:309-313, 2003.

3. Femandez Acenero, M. J., Galindo-Gallego, M., Sanz, J., and Aljama, A. Prognostic influence of tumor-associated eosinophilic infiltrate in colorectal carcinoma. Cancer, 88: 1544-1548, 2000.

4. Dirkx, A, oude Egbrink, M. G. A., Kuipers, M., Van de Niet, S. T., Heijnen, V. V. T., Bouma-ter Steege, J. C. M., Wagstaff, J., and Griffioen, A. W. Tumor angiogenesis modulates leukocytevessel wall interactions in vivo by reducing endothelial adhesion molecule expression. Cancer Res., 63: 2322*2329, 2003.

5. Griffioen, A. W., Damen, C. A., Blijham, G. H., and Groenewegen, G. Tumor angiogenesis is accompanied by a decreased inflammatory response of tumor associated endothelium. Blood $_{1,88:} 667-673,1996$.

6. Tromp, S. C, oude Egbrink, M. G, A., Dings, R. P. M., Van Velzen, S., Slaaf, D. W, Hillen, H. F. P., Tangelder, G. J., Reneman, R. S., and Griffioen, A. W. Tumor angiogenesis factors reduce leukocyte adhesion in vivo. Int. Immunol, 12:671-676, 2000.

7. Kuzu, I., Bicknell, R., Fletcher, C. D., and Gatter, K. C. Expression of adhesion molecules on the endothelium of normal tissue vessels and vascular tumors. Lab.Invest., 69:322-328, 1993 .

8. Melder, R. J., Koenig, G. C., Witwer, B. P., Safabakhsh, N., Murn, L. L., and Jain, R. K. During angiogenesis, vascular endothelial growth factor and basic fibroblast growth factor regulate natural killer cell adhesion to tumor endothelium. Nature Med., 2: 992-997, 1996.

9. Reiss, $Y_{\text {., Hoch, }}$., Deutsch, U., and Engellhardt, B. T cell interaction with ICAM-1-deficient endothelium in vitro: essential role for ICAM-1 and ICAM-2 in transendothelial migration of T cells. Eur.J.linmunol, 28: 3086-3099, 1998.

10. Baeten, C. I. M., Wagstaff, J., Verhoeven, I. C. L., Hillen, H. F. P., and Griffioen, A. W. Flow cytometric quantification of tumor endothelial cells; an objective alternative for microvessel. density assessment. Brit.J.Cancer, 87: 344-347, 2002.

11. Tamiolakis, D., Simopoulos, C., Cheva, A., Lambropoulou, M., Kotini, A., Jivannakis, T., and Papadopoulos, N. Immunophenotypic profile of tumor infiltrating lymphocytes in medullary carcinoma of the breast. Eur.J.Gynaecol.Oncol., 23: 433-436, 2002.

12. Yakirevich, E., lizhak, O. B., Rennert, G. Kovacs, Z. G., and Resnick, M. B. Cytotoxic phenotype of tumor infiltrating lymphocytes in medullary carcinoma of the breast. Mod.Pathol., 12: 1050-1056, 1999.

13. Bloom, H. J., Richardson, W. W., and Field, J. R. Host resistance and survival in carcinoma of breast: a study of 104 cases of medullary carcinoma in a series of 1,411 cases of breast cancer followed for 20 years. Br.Med.J., 3: 181-188, 1970.

14. Menard, S., Tomasic, G., Casalini, P., Balsari, A., Pilotti, S., Cascinelli, N., Salvadori, B., Colnaghi, M. 1., and Rilke, F. Lymphoid infiltration as a prognostic variable for early-onset breast carcinomas. Clin.Cancer Res., 3:817-819, 1997.

15. Griffioen, A. W., Damen, C. A., Martinotti, S., Blijham, G. H., and Groenewegen, G. Endothelial ICAM-1 expression is suppressed in human malignancies; role of angiogenic factors. Cancer Res., 56: 1111-1117, 1996.

16. Griffioen, A. W., Relou, I. A. M., Gallardo Torres, H. I., Damen, C. A., Martinotti, S, De Graaf; J. C., Zwaginga, J. J, and Groenewegen, $G$. The angiogenic factor bFGF impairs leukocyte adheston and rolling under flow conditions. Angiogenesis, 2: 45-50, 1999. 
17. Hellwig, S. M. M., Damen, C. A., Van Adrichem, N. P. H., Groenewegen, G, Bhinam, G H. and Griffioen, A. W. Endothelial CD34 is suppressed in human malignancies: role of angiogenic factors, Cancer Letters, 120:203-211, 1997.

18. Guenzi, E, Topolt, K, Comali, E., Lubeseder-Martellato, C., Jorg, A, Matzen, K., Zietz, C., Kremner, E., Nappi, F., Schwemmle, M., Hohenad, C., Barillari, G. Tschachler, E., Monini, P., Ensoli, B., and Sturzl, M. The helical domain of GBP-1 mediates the inhibition of endothelial cell proliferation by inflammatory cytokines. EMBO J., 20: 5568-5577, 2001.

19. Jeltsch, M., Kaipainen, A., Joukov, V., Meng, X. J., Lakso, M., Rauvala, H., Swartz, M., Fukumura, D., Jain, R. K., and Alitalo, K. Hyperplasia of lymphatic vessels in VEGF-C transgenic mice. Science, $276: 1423-1425,1997$.

20. Orlandini, M., Marconcini, L., Ferruzzi, $R$., and Oliviero, $S$. Identification of a c-fos-indweed gene that is related to the platelet- derived growth factor/vascular endothelial growth factor family. Proc.Natl.Acad.Sci.U.S.A, 93: 11675-11680, 1996.

21. Shin, H. Y., Smith, M., Toy, K., Williams, P., Bizios, R., Gerritsen, M. VEGF-C mediates cyclic pressure-induced endothelial cell proliferation. Physiol Genomics, $11: 245-251,2002$.

22. Marconcini, L., Marchio, S., Morbidelli, L., Cartocci, E, Albini, A., Ziche, M., Bussolino, F.s and Oliviero, S. c-fos-induced growth factor/vascular endothelial growth factor D induces angiogenesis in vivo and in vitro. Proc.Natl.Acad.Sci.U.S.A, 96:9671-9676, 1999.

23. Leek, R.D., Hunt, N., Landers, R., Lewis, C., $\mathbb{R}$ oyds, J., and Harris, A. Macrophage infiltration is associated with VEGF and EGFR expression in breast cancer. J.Pathol., 190:430-436, 2000.

24. Leek,R.D., Lewis, C., Whitehouse, R., Greenall,M., Clarke,J., Harris, A. Association of macrophage infiltration with angiogenesis and prognosis in invasive breast carcinoma.

Cancer Res., 56: 4625-4629, 1996.

25. Sivridis, E., Giatromanolaki, A., Papadopoulos, I., Gatter, K., Harris, A., and Koukourakis, M. Thymidine phosphorylase expression in normal, hyperplastic and neoplastic prostates: correlation with tumour associated macrophages, infiltrating lymphocytes, and angiogenesis. Br.J.Cancer, 86: 1465-1471, 2002.

26. Vincent-Salomon, A., Carton, M., Zafrani, B., Freneaux, P., Nicolas, A., Massemin, B., Fourquet, A., Clough, K., Pouillart, P., and Sastre-Garau, X. Long term outcome of small size invasive breast carcinomas independent from angiogenesis in a series of 685 cases.Cancer: $249-256,2001$.

27. Sarbia, M., Bittinger, F., Porschen, R., Dutkowski, P., Willers, R., and Gabbert, H. E. Tumor vascularization and prognosis in squamous cell carcinomas of the esophagus.

Anticancer Res., 16:2117-2121, 1996.

28. Cao, Y., Linden, P., Farnebo, J., Cao, R., Eriksson, A., Kumar, V., Q1, J. H., Claesson-Welsh, L., and Alitalo, $K$. Vascular endothelial growth factor $C$ induces angiogenesis in vivo.

Proc.Natl.Acad.Sci.U.S.A, 95: 14389-14394, 1998.

29. Nagy, J. A., Vasile, E., Feng, D., Sundberg, C., Brown, L. F., Detmar, M. J., Lawitts, J. A, Benjamin, L., Tan, X., Mansea, E. J., Dworak, A. M., and Dvorak, H. F. Vascular permeability factor/vascular endothelial growth factor induces lymphangiogenesis as well as angiogenesis. J.Exp.Med., 196: 1497-1506, 2002.

30. Willians, C. S., Leek, R. D., Robson, A. M., Banerji, S., Prevo, R., Harris, A. L., and Jackson, D. G. Absence of lymphangiogenesis and intratumoural lymph vessels in human metastatic breast cancer. J.Pathol., 200: 195-206, 2003. 


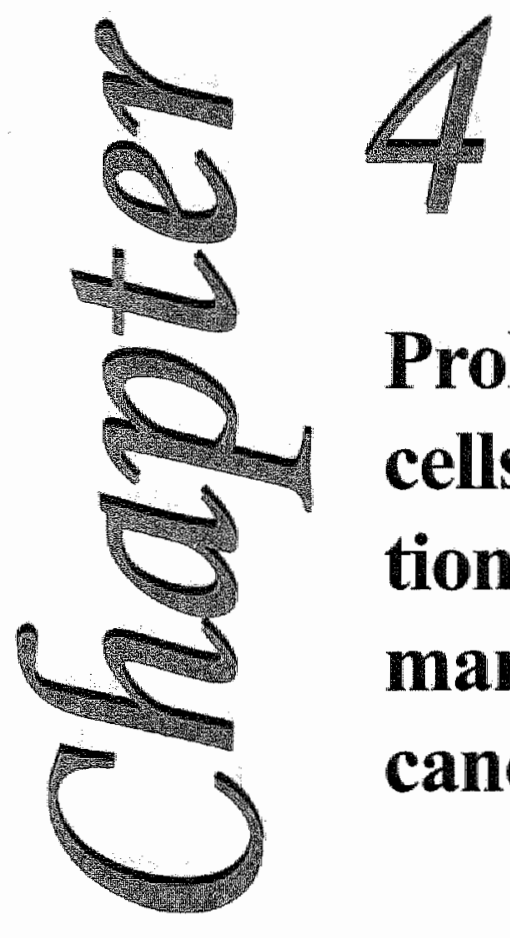

\section{Proliferating endothelial cells and leukocyte infiltra- tion are related prognostic markers in colorectal} cancer

Coen I.M. Baeten, Karolien Castermans, Harry F.P. Hillen \& Arjan W. Griffioen

Submitted for publication

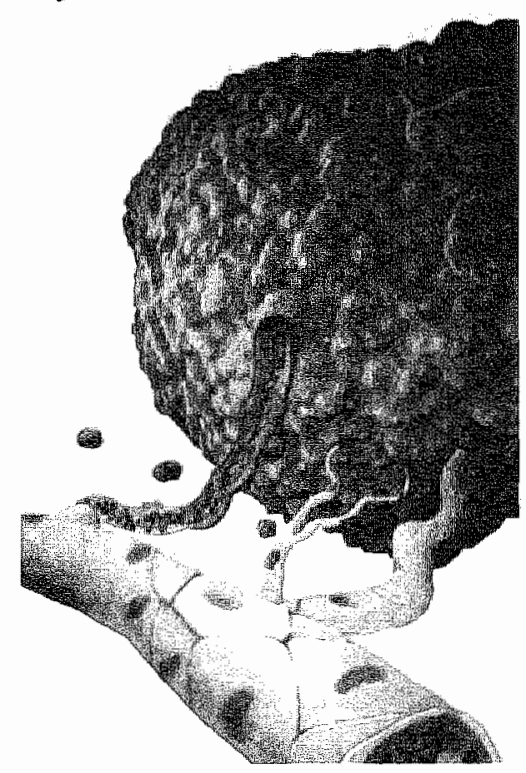




\begin{abstract}
Background \& aims

Leukocyte infiltration in tumors is dependent on angiogenic potential. In this study we aimed to retrospectively investigate the angiogenic potential in archival colorectal carcinoma (CRC) tissues and its relationship to amount and composition of the inflammatory infiltrate.
\end{abstract}

\title{
Methods
}

In tumor tissues of 117 CRC patients with a 12 year follow-up, micro vessel density (MVD) and proliferating endothelial cells (EC) were assessed by CD31/CD34 double staining with the proliferation marker Ki-67. Leukocyte infiltration was determined using $\mathrm{CD} 45, \mathrm{CD} 3, \mathrm{CD} 8, \mathrm{CD} 16, \mathrm{CD} 20$ and $\mathrm{CD} 68$ antibodies in peritumoral, tumor stroma and intratumoral areas.

\section{Results}

Proliferating ECs, but not MVD, is correlated to Dukes stage and survival in CRC $(p<0.05)$. This parameter correlated significantly with the expression of vascular endothelial growth factor $(\mathrm{r}=0.82 ; \mathrm{p}<0.012)$. The number of inflammatory cells in the tumor stroma $\mathrm{a}_{4}$ and cells infiltrated into the tumor cell nests, but not of peritumoral leukocytes, predicted patient survival. This was most obvious for $T$ lymphocytes $(C D 3 ; p<0.05)$ and polymorphonuclear cells (CD16; $\mathrm{p}<0.04)$. We found a significant relationship between angiogenesis parameters and infiltrated leukocytes $(r=-0.70 ; p<0.02)$. Combination of high numbers of infiltrated leukocytes and low amounts of proliferating ECs demonstrated to be an improved prognostic value compared to either parameter alone $(p<0.006)$.

\section{Conclusions}

We found a correlation between the intrinsic tumor parameters of ongoing angiogenesis and leukocyte infiltration with prognosis and survival in $\mathrm{CRC}$. These findings have a potential impact on therapeutic applications for both anti-angiogenesis as well as immunotherapy. 


\section{Introduction}

Colorectal cancer (CRC) is a common form of cancer in Western countries. The best available prognostic indicator of CRC is tumor stage, based on the Dukes classification, but this is not sufficient to predict the outcome of disease accurately. Several other parameters have been proposed to improve prognostic criteria, among which are angiogenic potential and infiltration by inflammatory cells $(1-3)$. Since it is now evident that these two phenomena are interrelated, the current study was performed to assess the value of both phenomena for the prognosis in CRC.

Angiogenesis is essential for tumor growth and metastasis, and is regulated by tumor cells through the production of pro-angiogenic factors such as vascular endothelial cell (EC) growth factors (VEGFs) and fibroblast growth factors (FGFs), and angiostatic factors such as platelet factor-4, thrombospondin-1, angiostatin and endostatin( $4 ; 5)$. Measurement of angiogenesis is commonly performed by the assessment of microvessel density (MVD) (6). This parameter is controversial since it might not be a reliable indicator of ongoing angiogenesis. It has been suggested that angiogenesis is best evaluated through detection of proliferating ECs (7).

The presence of immune cells in tumors is generally seen as a favorable prognostic parameter. This is evident for leukocyte subsets, including T-lymphocytes, PMNs and macrophages (8-12). However, for tumor associated macrophages adverse effects have been described $(13 ; 14)$. Tumor infiltration by leukocytes is regulated by a number of inflammatory cytokines, the combination of which presumably determines amount and composition of the infiltrate. In addition, infiltration is also affected by regulators of angiogenesis. Both inhibitory and stimulatory effects were found for VEGF and other angiogenic growth factors during angiogenesis (15-17). In the current study, a large set of archival CRC tumor samples, for which a 12-year clinical follow-up was available, was analyzed for angiogenesis parameters and leukocyte infiltration. We show that angiogenesis and leukocyte infiltration are interrelated. Several leukocyte subsets as well as proliferating ECs are prognostic factors in colorectal cancer. 


\section{Materials and methods}

\section{Patients and tissues}

Tumor tissues from 117 patients diagnosed with colorectal cancer (CRC) between 1979 and 1982 were collected from the tissue bank of the Department of Pathology, Maastricht University, and used for these studies. The tissues were from patients that were enrolled in two independent studies, one of which was a study on the beneficial effect of 'notouch' surgery ( 96 patients), and one was a study on the impact of preoperative radiotherapy (21 patients; 10 of whom received preoperative radiotherapy) $(18 ; 19)$. None of these patients received any postoperavtive therapy. For all patients clinical follow up was at least 12 years.

The mean age of the patient group $(\mathrm{n}=117)$ at time of diagnosis was 68.1 years (range 29-87) and the mean overall survival time of the total patient population was 5.8 years (range 0.1-12.8). The mean tumor diameter was $46.3 \mathrm{~mm}$ (range 5-120). Other patient data are summarized in Table 1.

Table 1. Clinical data on the $117 \mathrm{CRC}$ patients

\begin{tabular}{|c|c|c|c|c|}
\hline & & H of patients & $\%$ of group & tumor size (mm) \\
\hline \multirow[t]{2}{*}{ Gender } & Male & 59 & $50.4 \%$ & 47 \\
\hline & Female & 58 & $49.6 \%$ & 45 \\
\hline \multirow[t]{4}{*}{ Dukes stage } & $A$ & 2 & $2 \%$ & 35 \\
\hline & $\mathrm{B}$ & 72 & $62 \%$ & 49 \\
\hline & $\mathrm{C}$ & 32 & $27 \%$ & 44 \\
\hline & $\mathrm{D}$ & 11 & $9 \%$ & 38 \\
\hline \multicolumn{5}{|c|}{ Primary location } \\
\hline & ascending colon & 18 & $15 \%$ & 52 \\
\hline & transverse colon & 16 & $14 \%$ & 45 \\
\hline & descending colon & 32 & $27 \%$ & 42 \\
\hline & rectosigmoid & 47 & $40 \%$ & 48 \\
\hline & unknown & 8 & $8 \%$ & 41 \\
\hline \multicolumn{5}{|c|}{ Recurrence of metastasis } \\
\hline & positive & 69 & $59 \%$ & 48 \\
\hline & negative & 48 & $41 \%$ & 44 \\
\hline
\end{tabular}

Recurrence or metastasis within follow up period of 12 years 


\section{Immunohistochemistry}

Adjacent serial sections of $4 \mu \mathrm{m}$ were made from the 117 paraffin embedded colon tumor tissues. The sections were put on organosilane coated object slides (Starfrost, Germany) and air-dried for 48 hours at room temperature. After rehydration, endogenous peroxidase was blocked by incubation in $0.3 \% \mathrm{H}_{2} \mathrm{O}_{2}$ in methanol for 30 minutes. The slides were microwaved for 10 minutes in citrate buffer ( $\mathrm{pH} \mathrm{6.0)}$ and cooled down for 30 minutes. After rinsing with PBS, the slides were blocked for non-specific antibody binding with 5\% BSA in PBS. Primary antibodies polyclonal rabbit anti-human Ki-67 (NeoMarker, Freemont, CA.;1:200), and monoclonal antibodies to CD3 (1:50, DAKO, Glostrup, Denmark), CD8 (1:100, Novocastra, Valkenswaard, the Netheriands), CD16 (1:50, NeoMarker), CD20 (1:1000, DAKO), CD68 (1:100, DAKO) and VEGF (1:100 Santa Cruz, CA) were properly diluted and applied on the sections for a 1 hour incubation at room temperature.

After washing with PBS, the slides were incubated in polyclonal biotin-labeled swine anti-rabbit IgG (DAKO) or rabbit anti-mouse Ig (DAKO) for 30 minutes. After a subsequent incubation with avidine-biotin complex HRP (DAKO) for 30 minutes, the slides were developed with diaminobenzidine (DAB, Sigma, Zwijndrecht, the Netherlands). The slides were either counterstained with haematoxylin (Merck, Darmstadt, Germany) or incubated for 1 hour with a secondary cocktail of primary CD31 (1:100) and CD34 (1:50, DAKO, Monosan; QBEND-10) antibodies against ECs. After washing with PBS the slides were incubated in biotin-labelled Goat anti mouse IgG (DAKO, Glostrup, Denmark) for $1 / 2$ hour. After incubation with avidine-biotin complex AP (DAKO) for 30 minutes, the slides were developed with alkaline phosphatase.substrate KIT III (Vector Laboraties, Inc., Burlingame, CA). After treatment of the slides with insulmount to protect alkaline phsphatase from bleaching, the slides were mounted in entellan (Merck).

\section{Analysis}

MVD was assessed as described previously by two independent observers in four randomly selected high power fields (200x), the results are shown as number of vessels/ $\mathrm{mm}^{2}(20)$. Next to angiogenesis measurement by MVD, ongoing angiogenesis by proliferating ECs was determined in the same four randomly chosen fields and presented as the number of proliferating $\mathrm{EC} / \mathrm{mm}^{2}$. VEGF expression in tumor cells was determined at $200 \mathrm{x}$ magnification for intensity and density of tumor cells, as described before (21). To differentiate between location of leukocyte infiltration, we enumerated stained leukocytes (i) in peritumoral areas outside the tumor but directly at the tumor host interface, (ii) in areas of tumor stroma, and (iii) as infiltrated into the nests of tumor cells (referred to as 'intratumoral'), directly in contact with the tumor cells. All leukocyte subsets were determined in all three areas by counting in four randomly chosen fields. Peritumoral leukocytes were scored at low magnification $(40 \mathrm{x})$ and ranged from 0 (absent) to 4 (heavy) infiltration ( $0=$ no infiltration, $1=<1 \%$ of the cells, $2=$ between 1 and $5 \%$ of 
cells, $3=$ between $5 \%$ and $20 \%, 4=>20 \%$ of cells $)$. Similar procedure $(0-4$ range $)$ was used for stromal leukocyte infiltration, at $100 \mathrm{x}$ magnification. Intratumoral leukocyte infiltration, leukocytes in direct contact with tumor cells, was scored at $200 \mathrm{x}$ magnification. Data and presented as the number of leukocytes $/ \mathrm{mm}^{2}$.

\section{Statistical analysis}

All statistical analysis was done with SPSS software. We used Mann-Whitney, student'sT, Pearson, Spearman, Log Rank tests, results were considered statistically significant when $\mathrm{p}<0,05$.
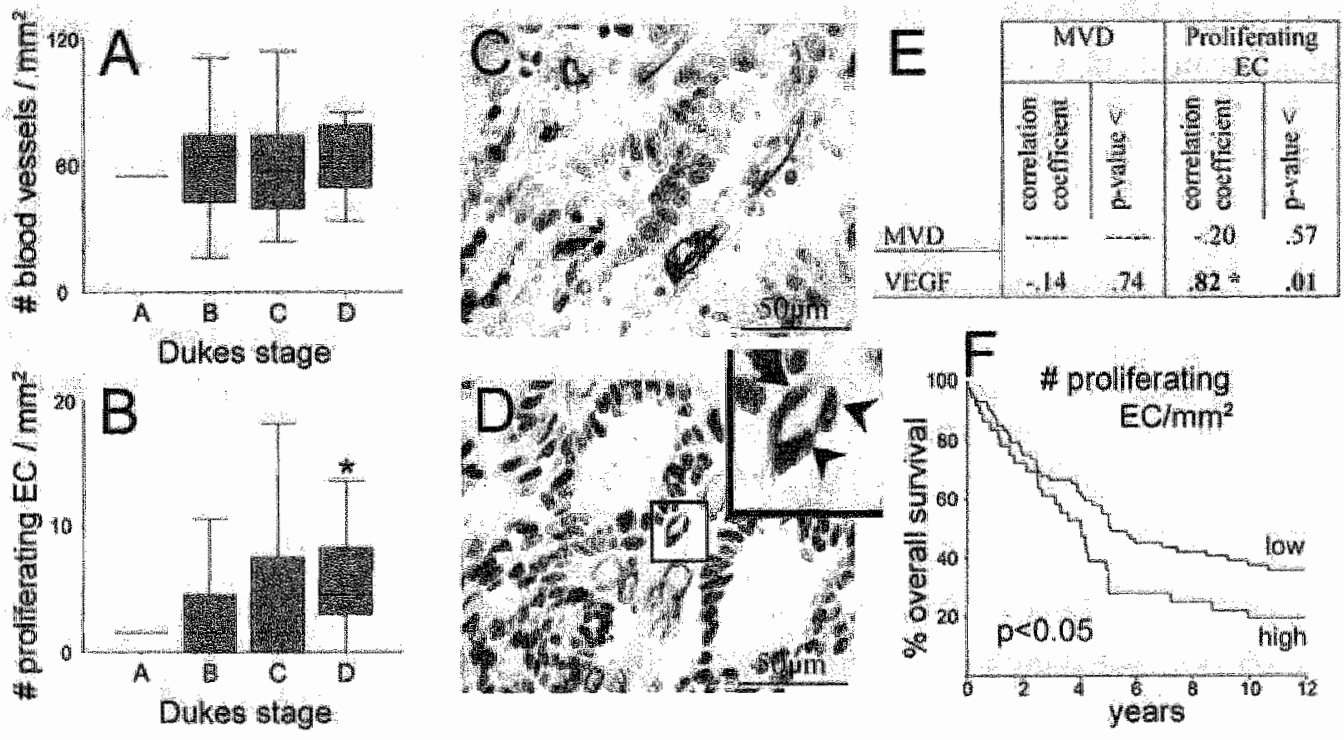

\section{Figure 1.}

Angiogenic parameters in CRC.

Relationship between MVD (A) and proliferating ECs (B) to Dukes stage (* respresents statistical difference from Dukes $\mathrm{B}$ value, $\mathrm{p}<0.05$ ). C, D. CD3 1/34 (blue) and $\mathrm{ki}-67$ (brown) double staining of CRC tissues. Note the higher amount of proliferating $\mathrm{ECs}$ in figure $\mathrm{D}$ as compared with $\mathrm{C}$, whereas equivalent amounts of bloodvessels are present (scalebars $50 \mu \mathrm{m}$ ). E. Correlation (and significance) between VEGF, MVD and proliferating ECs. F. The Kaplan Meter curve is shown for patients with proliferating ECs above or below the mean walue. A significantly favorable prognosis is found in patients with lower counts of proliferating ECs (Log Rank: $p<0.05$ ). 


\section{Results}

The number of proliferating endothelial cells but not microvessel density (MVD) is a prognostic factor in $C R C$

Microvessel density (MVD) was measured in 117 CRC tissue samples. MVD did neither correlate with grade/differentiation, size or localization, Dukes stage of the tumor (Figure 1A). Measurement of the number of proliferating endothelial cells (EC), a parameter that presumably reflects ongoing angiogenesis (7), did result in a significant correlation with Dukes stage (Spearman's rho test; $p<0.05$, Figure 1B). For reference, two tissues with equivalent MVD levels but with largely differing numbers of proliferating $\mathrm{ECs}$ are shown (Figure 1C and D). Correlations of proliferating ECs with tumor grade/ differentiation, size or localization were not found (data not shown). Next to these vascular parameters, the expression of vascular endothelial cell growth factor (VEGF) was assessed immunohistochemically. High expression of VEGF correlated with the presence of proliferating ECs $(r=0.82 ; p<0.012$, Figure $1 \mathrm{E}$ ) but not with MVD, supporting the fact that the number of proliferating ECs reflects ongoing angiogenesis better than MVD. The amount of proliferating ECs also strongly correlated with the number of proliferating tumor cells $(r=0.56 ; p<0.001)$, suggesting that rapid tumor cell turnover is associated with a higher angiogenic potential.

To determine the prognostic value of the angiogenesis parameters, patients were divided into groups with high and low numbers of proliferating cells and MVD. With a cut off point at 3.6 proliferating $\mathrm{EC} / \mathrm{mm}^{2}$ (mean value), this parameter already showed a favorable 5 -year survival rate of $48 \%$ in patients with low numbers of proliferating ECs (versus $29 \%$ in patients with high numbers of proliferating ECs; $p<0.05$, Figure 1F). This observation extended over a period up to 12 years where these values were $37 \%$ and $20 \%$, respectively. Since a minor subgroup of the patients ( 10 patients) received preoperative radiotherapy, we analyzed whether the results of this subgroup biased the overall data. We were able to exclude a bias of the data (not shown). Classification in high or low MVD (cut off point, mean value; 61.1 blood vessels $\left./ \mathrm{mm}^{2}\right)$ measurements did not show differences in survival $(\mathrm{p}<0.52$, not shown).

\section{Intratumoral leukocyte infiltration is a prognostic factor in $C R C$}

To investigate the patterns of leukocyte infiltration, all tissues were stained for CD45 (pan-leukocyte), CD3 (T lymphocytes), CD8 (cytotoxic T cells), CD16 (PMNs), CD20 (B lymphocytes) and CD68 (macrophages). We counted the number of these subsets in the peritumoral-, stroma]- and intratumoral areas. In all three areas the composition of the inflammatory infiltrate was comparable, with a major representation of macrophages and PMNs. There were no apparent correlations between the extent and type of leukocyte infiltration. As for the angiogenesis parameters, the minor subgroup of patients that received preoperative radiotherapy did not influence the results. In $35 \%$ of the samples peritumoral 
areas were found to be heavily infiltrated by leukocytes. This infiltration was present in a patchy pattern. No significant correlation was found between the amount of peritumoral infiltration and grade/differentiation, size, localization, Dukes stage or survival (not shown). Leukocyte infiltration within the tumor was found in all CRC samples. Most of these leukocytes were present in the tumor stroma, while in $50 \%$ of samples also intratumoral infiltrating leukocytes were detected (Figure 2). The amount of stromal and intratumoral leukocytes are highly correlated $(C D 3, r=0.74 ; C D 8, r=0.70 ; C D 16, r=0.71 ; C D 20, r=0.60$; $\mathrm{CD} 68, \mathrm{r}=0.39, \mathrm{p}<0.001$ for all subsets).

Intratumoral leukocyte infiltration, as assessed by CD 45 staining, decreased with Dukes stage. The pattern of leukocyte subsets in the infiltrate was similar for the Dukes stages (Table 2).

Table 2. Quantification and composition of the leukocyte infiltrate for the different Dukes stages.

\begin{tabular}{lrrrr}
\hline Dukes stage & $\mathrm{A}^{\mathrm{*}}$ & $\mathrm{B}$ & $\mathrm{C}$ & $\mathrm{D}$ \\
\hline $\mathrm{CD} 45^{\circ}$ & $(7)$ & 10.7 & 6.19 & 3.64 \\
\hline CD3 & $(0 \%)$ & $31 \%$ & $22 \%$ & $31 \%$ \\
CD8 & $(57 \%)$ & $6 \%$ & $7 \%$ & $16 \%$ \\
CD16 & $(11 \%)$ & $20 \%$ & $19 \%$ & $16 \%$ \\
CD20 & $(0 \%)$ & $1 \%$ & $2 \%$ & $3 \%$ \\
CD68 & $(60 \%)$ & $38 \%$ & $68 \%$ & $43 \%$ \\
\hline
\end{tabular}

" number of leukocytes infiltrated between the tumor cells (intratumoral) $\mathrm{CD} 45^{+} \mathrm{cells} / \mathrm{mm}^{2}$.

${ }^{b}$ amount of leukocytes in the indicated subsets as percentage of $\mathrm{CD}_{4} 5^{+}$cells.

"values for Dukes A staged tumors between brackets because this subgroup only represents 2 cases.

The correlation between the number of intratumoral leukocytes and Dukes stages suggested a relationship with survival. Kaplan-Meier curves indeed show that there is a significant difference in survival between subgroups with high and low leukocyte infiltration levels for both CD3 $(\mathrm{p}<0.05)$ and CD16 ( $<<0.04$ )(Figure 3A and C). For CD8 (Figure $3 \mathrm{~B}$ ) and CD20 (data not shown) only a trend to significant difference was observed. In contrast, CD68 showed no correlation with survival or clinical parameters.

Due to the high correlation between stromal and intratumoral leukocyte populations (see above), similar relationships were found for the presence of stromal leukocytes. Also the Kaplan-Meier curves show significant results when the patient groups is separated on basis of leukocyte subsets in CRC stroma (Figure 3D-F). 

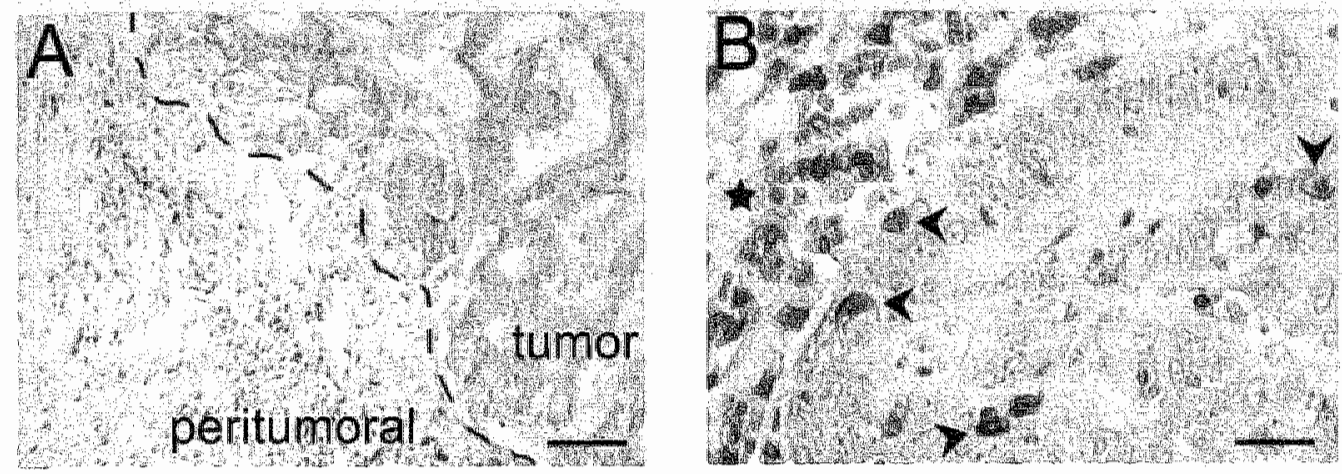

Figure 2.

Lewkocyle infiltration in CRC.

A. CD45 staining of a Dukes B staged tumor at the tumor host interface, showing the intense infiltration by leukocytes in the peritumoral area. The dashed line indicates the tumor border. Scale bar represents $100 \mu \mathrm{m}$. B. A higher magnification of a Dukes B staged tumor at an intratumoral area, indicating the difference between leukocyte infiltration in the tumor stroma and in between the tumor cell nests. Stromal leukocytes area is marked by arrow heads and leukocytes infiltration between the tumor cells is marked with arrows. Scalebar represents $20 \mu \mathrm{m}$.

\section{Relationship between angiogenesis and leukocyte infiltration}

We previously described that ongoing angiogenesis in tumors prevents the infiltration of leukocytes $(1 ; 16)$. We investigated whether this process is present in the human CRC tissues. As shown in Figure 1E, ongoing angiogenesis as measured by proliferating EC is correlated with the expression of VEGF, suggesting a causal relationship. We found that both the number of proliferating ECs and the expression of VEGF correlated inversely with the number of infiltrated leukocytes as measured by CD45 (proliferating ECs $\mathrm{r}=$ $0.7, p<0.024$; VEGF $r=0.431, p<0.05$ ). Kaplan-Meier survival analysis of patient groups separated by both parameters into 4 groups (Figure 4), led to a markedly increased 5year survival of $62 \%$ in the group with low number of proliferating ECs and dense leukocyte infiltration, versus $18 \%$ in the group with high numbers of proliferating ECs and low infiltration, $p<0.0061)$. This result extended over the period up to 12 years $(p<0.0067)$. This result indicates that ongoing angiogenesis and leukocyte infiltration are related, and that the combination of these two parameters as a prognostic factor is a more reliable predictor of survival. 


\section{Discussion}

Several earlier studies report on the prognostic value of angiogenic parameters in colorectal cancer (CRC). Since it has been described frequently to associate with prognosis and clinical outcome in many tumor types, microvessel density was assessed in most of these studies. Interestingly, although several studies do report a prognostic value for vessel density (22-25), a relatively (as compared to studlies in e.g. breast- and lung carcinoma) large percentage of studies reported the absence of any prognostic value for microvessel density $(26-29)$, or even an inverse relationship (30;31). In all these studies different immunohistochemical protocols were used to identify microvessels, including detection with CD31 (25;32), CD34 (33), Factor VIII related peptide von Willebrand factor (24), or CD105 (34). Independent on the detecting antibody, these studies report that a prognostic value of microvessel density is or is not present. It is therefore questioned whether vessel density is a measure of angiogenesis. Indeed, other studies report on alternative angiogenesis parameters that do predict patient outcome, such as expression of angiogenic growth factors $(35 ; 36)$ or angiogenesis inhibitors (37), color Doppler vascularity index (38) or MR imaging $(39 ; 40)$. These parameters are supposedly more physiological measurements and therefore more reliable indicators of functional vascularity or ongoing angiogenesis. In the current study, we have measured ongoing angiogenesis in CRC by
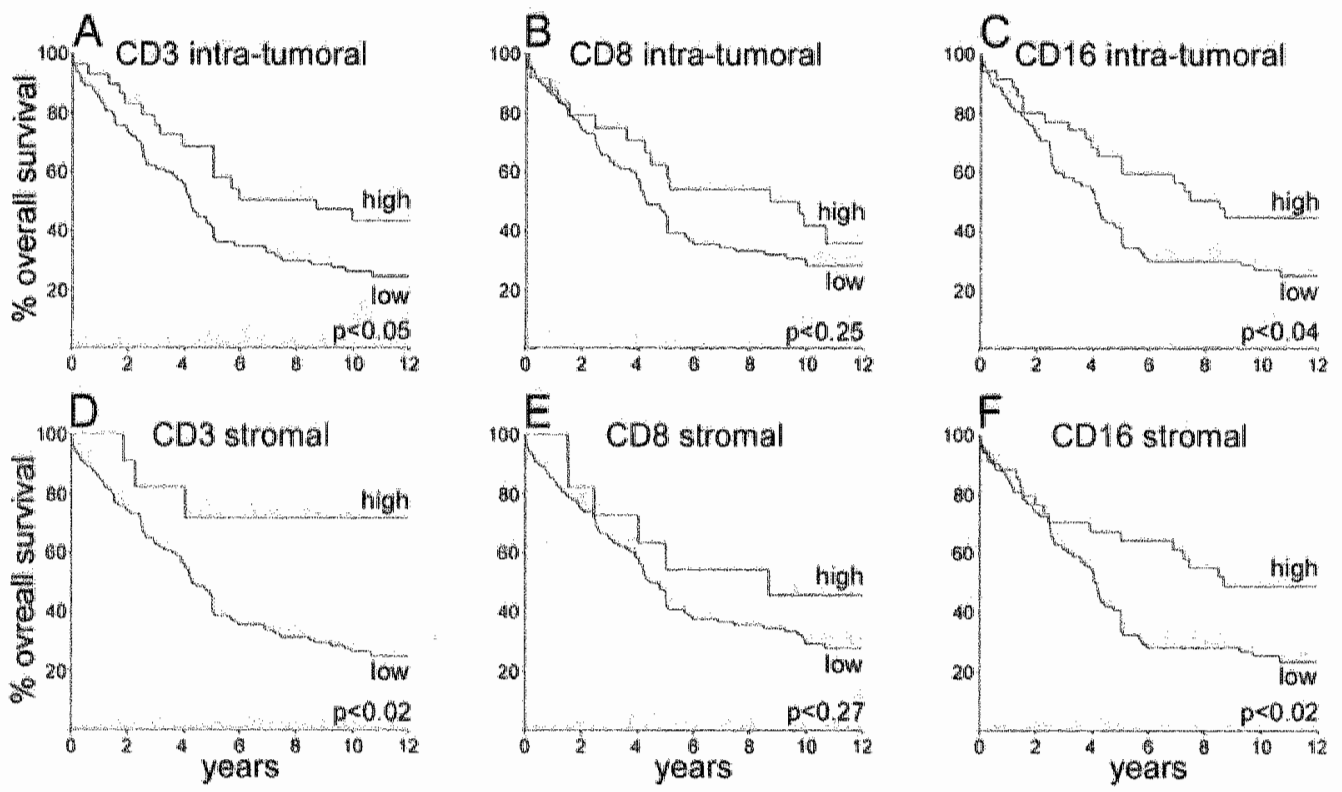

Figure 3 .

Relationship between leukocyte infultration and patient survival.

Kaplan Meier curves of patient groups separated on basis of high or low infiltration by CD3, CD 8 and CD 16 leukocyte subsets. Curves represent leukocyte counts areas within the tumors. Panels $\mathrm{A}-\mathrm{C}$ represent leukocyte counts within the tumor cell nests in $\mathrm{CRC}$, whereas panels $\mathrm{D}$-F represent leukocyte scores in the stroma of CRC. Significance was assessed by Log Rank tests. 
enumerating the number of proliferating endothelial cells (EC) in sections double stained for endothelium with both CD31 and CD34 antibodies, which we found to stain all ECs in $\mathrm{CRC}$, and $\mathrm{Ki}-67$, a proliferation marker. We show that the number of proliferating $\mathrm{ECs}$ (positively correlated to the expression of VEGF and thus to ongoing angiogenesis), but not microvessel density, is correlated with Dukes stage. Only in a few studies a patient follow-up was available to report on survival characteristics $(25 ; 32 ; 33)$. For the patient group of our study a 12-year follow-up was available, which made a meaningful correlation to survival possible. We found that a high number of proliferating ECs predicts shorter survival.

Next to proliferating ECs we also found that leukocyte infiltration is a prognostic factor in CRC. We studied the presence of inflammatory cells allong the invasive margin (tumorhost interface) as well as intratumorally in the cancer stroma and infiltrated into the cancer cell nests. We found that the number of infiltrated $T$ lymphocytes as well as PMNs displayed a significant impact on prognosis and survival. In contrast, we did not determine a significant relationship between the amount of peritumoral infiltrate and clinical outcome.

Inflammatory infiltrate is generally interpreted as an indication of the host's immune reponse against the tumor. Most studies report on leukocyte infiltrate as a whole or as single subsets of $\mathrm{T}$ lymphocytes (41), CD4 $+\mathrm{T}$ cells (42), CD8 $+\mathrm{T}$ cells (43), PMN/ natural killer cells $(10 ; 44)$, eosinophils $(45 ; 46)$ or macrophages (11), to have a favorable impact on prognosis.

Our finding indicated that intratumoral leukocytes have the most significant impact on patient survival as compared to those in the tumor periphery. This result confirms earlier data obtained from studies in CRC $(8 ; 43)$. These studies described that the beneficial effect of intratumoral $\mathrm{CD} 8^{+} \mathrm{T}$ cells becomes apparent after longer survival times. This made the authors hypothesize that the effect is mediated by suppression of distant micrometastases rather than suppression of growth of the primary tumor. Our study, having also a fairly long patient follow-up period, indicates a clear trend of a prognostic impact of $\mathrm{CD} 8^{+} \mathrm{T}$ cells. The fact that we see a larger effect on the total population of $\mathrm{T}$ lymphocytes, suggests that also by $\mathrm{CD}^{+} \mathrm{T}$ cells survival curves would indicate differences. This is very likely to be the case since it has been described that a reduction in CD4* $\mathrm{T}$ Jymphocyte infiltration in $\mathrm{CRC}$, is associated with recurrence of disease, most likely due to lack of specific cytokine release (42). We also found a significant correlation between the amount of PMNs and survival. This finding is interesting since these immune cells can be considered the first line of defence against cancer.

Infiltration of tumors by leukocytes also has been correlated with poor clinical outcome. These reports indicate that cancer can be caused or promoted by infectious agents that induce chronic inflammation (47;48). Especially the role of tumor associated macrophages is controversial. Although several studies have indicated the beneficial effect on patient survival $(11 ; 12 ; 49 ; 50)$, other studies indicate that they play an active role in enhancing tumor progression and metastatic capacity through their ability to produce VEGF and chemokines to promote angiogenesis and tissue remodeling as well as to deliver direct effects on the tumor cells leading to growth and migration (13;21;51-54). In the current 

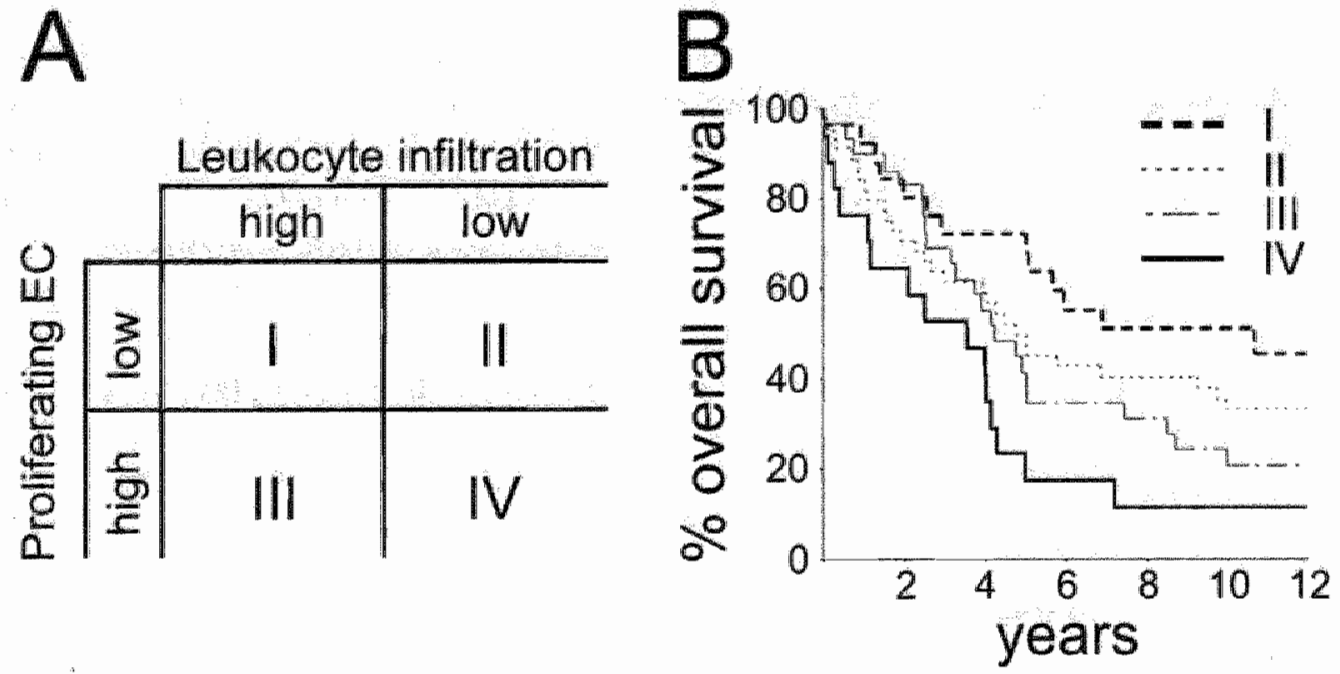

Figure 4.

Improved survival by combining leukocyte infiltration and angiogenesis parameters.

A. The patient group divided according to both leukocyte infiltration and proliferating ECs into 4 groups.

B. Kaplan Mejer survival curves of the patient groups as clefined in panel A. Five-year survival is best in the group with high numbers of infiltrated leukocytes and low numbers of proliferating $\mathrm{ECs}$ (group I) and worst in the group with low numbers of infiltrated leukacytes and high numbers of proliferating ECs (group IV, $\mathrm{p}<0.0061)$.

study we did not even see a trend towards any correlations with patient data or survival. This may be due to the specific attraction of macrophages by tumor-produced chemoattractants, such as colony stimulating factor- 1 and $\mathrm{CC}$ chemokine ligand-2, which have been described to play an important role in infiltration of breast-, ovarian- and prostate cancer (54-56).

Considering the results of the current study on angiogenic potential and leukocyte infiltration, we favor the view that these observations are interrelated. We have previously demonstrated that ongoing angiogenesis impairs leukocyte-vessel wall interactions, due to downregulation of vascular adhesion molecules or EC anergy to inflammatory signals $(2 ; 16)$. Very recently we have reported on the inverse relationship between angiogenic potential and leukocyte infiltration. This study was carried out in breast carcinoma. We found that medullary breast carcinoma, which is heavily infiltrated by inflammatory cells, has a lower angiogenic profile, causing a higher vascular intercellular adhesion molecule1 expression and is therefore heavily infiltrated by inflammatory cells. This in contrast to ductal breast cancer which is a highly angiogenic tumor (1). We now show this inverse relationship in CRC. 
In conclusion, the current study describes the impact of both angiogenic potential and leukocyte infiltration on the prognosis of $\mathrm{CRC}$, in a large group of patients of which a 12year follow-up was available.

\section{Acknowledgements}

Grant support: The current research was supported by a generous grant (to HFPH and AWG) from the Coenegracht Stichting 


\section{References}

1. Bouma ter $S t e g e ~ J C$, Baeten $C_{3}$, Thijssen VL ef ol Angiogenic profile of breast carcinoma determines leukocyte infiltration. Clin Cancer Res2004;10(21):7171-8

2. Dirkx $A E$, Oude Egbrink MG, Kuijpers MJ et al. Tumor angiogenesis modulates leukocyte-vessel wall interactions in wivo by reducing endothelial adhesion moleculeex pression. Cancer Res $2003 ; 63(9): 2322-9$

3. Zhang $L$, Conejo Garcia JR, Katsaros $D$ et al. Intratmoral $T$ cells, recurrence, and surwival in epithelial ovarian cancer. NEngl J Med 2003;348(3):203-13.

4. Czubayko F, Liaudet-Coopman ED, Aigner A ef al. A secreted FGF-binding protein can serve as the angiogenic switch in human cancer. Nat Med 1997; 3(10):1137-40

5. Zheng $\mathrm{S}, \mathrm{Han} \mathrm{MY}$, Xiao ZX er al. Clinical significance of vascular endothelial growth factor expression and neovascularization in colorectal carcinoma. World J Gastroenterol 2003,9(6):1227-30.

6. Vermeulen PB, Gasparini $\mathrm{G}$, Fox $\mathrm{SB}$ et al. Quantification of angiogenesis in solid human tumours: an international consensus on methodology and criteria of evaluation Eur $J$ Cancer 1996;32(14):2474-84.

7. Vermewlen PB, Gasparini G, Fox SB et al. Second international consensus on the methodology and. criteria of evaluation of angiogenesis quantification in solid human tumours.

Eur J Cancer 2002;38(12):1564-79.

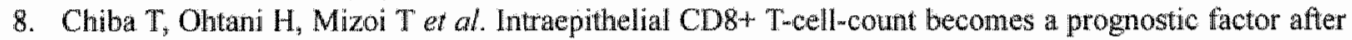
a longer follow-up period in human colorectal carcinoma: possible association with suppression of micrometastasis. Br J Cancer 2004;91(9):1711-7.

9. Golby SI, Chinyama C, Spencer J. Proliferation of T-cell subsets that contact tumour cells in colorectal cancer. Clin Exp Immuno/ 2002; 127 (1):85-91.

10. Coca $S_{;}$Perez-Piqueras J, Martinez D er al. The prognostic significance of intratumoral natural killer cells in patients with colorectal carcinoma. Cancer 1997;79(12):2320-8.

11. Funada $Y$, Noguchi $T$, Kikuchi $R$ et al. Prognostic significance of CD $8+T$ cell and macrophage peritumoral infiltration in colorectal cancer. OncolRep2003; 10(2):309-13

12. Khorana AA, Ryan CK, Cox C et al. Vascular endothelial growth factor, CD68, and epidermall growth factor receptor expression and survival in patients with Stage II and Stage III colon carcinoma: a role for the host response in prognosis. Cancer 2003;97(4):960-8.

13. Leek RD, Lewis CE, Whitehouse $R$ et al. Association of macrophage infiltration with angiogenesis and prognosis in invasive breast carcinoma. Cancer Res 1996;56(20):4625-9.

14. Lewis CE, Leek $R$, Harris $A$ et al. Cytokine regulation of angiogenesis in breast cancer: the role of tumoreassociated macrophages.J Leukoc Blol1995;57(5):747-51.

15. Melder RJ, Koenig GC, Witwer BP ef al. During angiogenesis, vascular endothelial growth factor and basic fibroblast growth factor tegulate natural killer cell adhesion to tumor endothelium.

Nat Med 1996:2(9):992-7.

16. Griffoen AW, Damen CA, Blijham GH er al. Tumor angiogenesis is accompanied by a decreased inflammatory response of tumor-associated endothelium. Blood 1996;88(2):667-73.

17. Kuzu I, Bicknell R, Fletcher CD et al. Expression of adhesion molecules on the endothelium of momal tissue vessels and vascular tumors. Lab Irwest 1993;69(3):322-8.

18. Wiggers T, Jeekel J, Arends JW et al. No-touch isolation technique in colon cancer: a controlled prospec tive trial. Br J Surg 1988;75(5):409-15.

19. de Bruine AP, Wiggers T, Beek C et al. Endocrine cells in colorectal adenocarcino mas: incidence, hormone profile and proghostic relevance. Int J Cancer $1993 ; 54(5): 765-71$.

20. Hillen HF, Hak LE, Joosten-Achjanie SR et al. Microvessel density in unknown primary tumors. Int J Camcer 1997;74(1):81-5.

21. Salvesen HB, Akslen LA. Significance of tumour-associated macrophages, vascular endothelial growth factor and thrombospondin- 1 expression for tumour angiogenesis and prognosis in endometrial carcinomas. In J Cancer 1999;84(5):538-43.21.

22. Vermeulen $\mathrm{PB}_{3}$ Verhoeven $\mathrm{D}$, Hubens $\mathrm{G}$ et al. Microvessel density, endothelial cell proliferation and tumour cell proliferation in human colorectal adenocarcinomas. Ann Oncol 1995;6(1):59-64. 
23. Bhatavdekar JM, Patel DD, Chikhlikar PR et al Overexpression of CD44: a useful independent predictor of prognosis in patients with colorectal carcinomas. Amn Sug Oncol 1998,5(6),495-501.

24. Choi HJ, Hyun MS, Jung GJ et al. Tumor angiogenesis as a prognostic predictor in colorectal carcinoma with special reference to mode of metastasis and recurrence. Oncology $1998,55(6), 575,81$.

25. Giatromanolaki A, Stathopoulos GP, Tsiobanou E et al Combined role of tumor angogenesis, bol 2 , and p 53 expression in the prognosis of patients with colorectall carcinoma. Cancer 1999,86(8):1421-30

26. Bossi $P$, Viale $G$ Lee AK et al. Angiogenesis in colorectal tumors: microvessel quantitation in adenomas and carcinomas with clinicopathological correlations. Cancer Res 1995:55(21):5049-53.

27. Fox SH, Whalen GF, Sanders MM et al. Angiogenesis in normal tissue adjacent to colon cancer. J Surg Oncol 1998;69(4):230-4.

28. Akagi $K_{\text {, }}$ Keda $Y$, Sumiyoshi $Y$ et al. Estimation of angiogenesis with anti-CD 105 immunostaining in the process of colorectall cancer development. Surgery 2002; 131 (1 Suppl):S109-S113.

29. Pietra N, Sarli L, Cauruana $\mathrm{P}$ et al. Is tumour angiogenesis a proginostic factor in patients with colorectal cancer and no involved nodes? Eur I Surg 2000;166(7):552-6

30. Mooteri $S$, Rubin D, Leurgans $S$ ef al. Tumor angiogenesis in primary and metastatuc colorectal cancers. Dis Colon Rectum 1996;39(10):1073-80.

31. Abdalla SA, Behzad F, Bsharah S et al. Prognostic relevance of microvessel density in colorectal tumours. Oncol Rep 1999;6(4):839-42.

32. Vermeulen $P B$, Van den Eynden GG, Huget $P$ et al. Prospective study of intratumoral microvessel density, p53 expression and survivall in colorectal cancer. Br.J Cancer 1999;79(2):316-22.

33. Yoshimura $\mathrm{H}$, Chikamoto $\mathrm{A}$, Honda $\mathrm{T}$ et al. Relationship between microvessel quantification and induc ibility of endogenous tumor necrosis factor in colorectal adenocarcinoma Amicancer Res2000;20:629-33.

34. Li C, Gardy R, Seon BK et al. Both high intratumoral microvessel density determined using CD 105 antibody and elevated plasma levels of CD 105 in colorectal cancer patients correlate with poor prognosis. Br.J Cancer 2003;88(9):1424-31.

35. Saito S. Tsuno N, Nagawa $H$ et al. Expression of platelet-derived endothelial cell growth factor correlates with good prognosis in patients with colorectal carcinoma. Cancer 2000;88(1):42-9.

36. Kaio E, Tanaka $S$, Oka $S$ et al. Clinical significance of thrombospondin-1 expression in relation to vascular endothelial growth factor and interleukin-10 expression at the deepest invasive tumor site of advanced colorectal carcinoma. Int J Oncol 2003;23(4):901-11.

37. Maeda K, Nishiguchi Y, Kang SM et al. Expression of thrombospondin-I inversely correlated with tumor vascularity and hematogenous metastasis in colon cancer. Oncol Rep 2001;8(4):763-6.

38. Chen CN, Cheng YM, Liang JT et al. Color Doppler vascularity index can predict distant metastasis and survival in colon cancer patients. Cancer Res 2000;60(11):2892-7.

39. de Lussanet QG, Backes WH, Griffioen AW et al, Gadopentetate dimeglumine versus ulltrasmall superparamagnetic iron oxide for dynamic contrast-enhanced MR imaging of tumor angiogenesis in human colon carcinoma in mice. Radiology 2003;229(2):429-38.

40. Tuncbilek N, Karakas HM, Altaner S. Dynanic MRI in indirect estimation of microvessel density, histologic grade, and prognosis in colorectal adenocarcinomas. Abdom Imaging 2004;29(2):166-72.

41. Prall F, Duhrkop $T$, Weirich $V$ er al. Prognostic role of CD8 + tumor-infiltrating lymphocytes in stage III colorectal cancer with and without microsatellite instability. Hum Pothol 2004;35(7):808-16.

42. Ali AA, McMillan DC, Matalka II et al. Tumour T-lymphocyte subset infiltration and tumour recur rence following curative resection for colorectal cancer. Eur J Surg Oncol 2004,30(3):292-5.

43. Naito Y, Saito K, Shiiba K et al. CD8 + T cells infiltrated within cancer cell nests as a prognostic factor in human colorectal cancer. Cancer Res 1998;58(16):349 1-4

44. Balch CM, Riley LB, Bae YJ et al. Patterns of human tumor-infiltrating lymphocytes in 120 human cancers. Arch Surg $1990 ; 125(2): 200-5$.

45. Fernandez-Acenero MJ, Galindo-Gallego M, Sanz J et al. Prognostic influence of tumor-associated cosinophilic infilltrate in colorectal carcinoma. Cancer $2000 ; 88(7): 1544-8$.

46. Pretlow TP, Keith EF, Cryar AK et al. Eosimophil infiltration of human colonic carcinomas as a prognos tic indicator. Cancer Res 1983;43(6):2997-3000.

47. Coussens LM, Werb Z. Inflammatory cells and cancer: think different! $J \operatorname{Exp}$ Med 2001;193(6):F,23-F26. 
48. Coussens LM, Werb Z. Inflammation and cancer. Nontwe 2002;420(6917) $860-7$.

49. Shimura $\mathrm{S}$, Yang $\mathrm{Q}$, Ebara $\mathrm{S}$ et al. Reduced infiltration of tumor-associated macrophages in human prostate cancer: association with cancer progression. Cancer Res 2000;60(20):5857-61.

50. Migite T, Sato E, Saito K et al. Differing expression of MMPs-1 and -9 and urokinase receptor between diffuse and intestinal type gastric carcinoma, Int J Cancer 1999;84(1):74-9.

51. Torisu $\mathrm{H}$, Ono $\mathrm{M}, \mathrm{Kiry}$ H et al. Macrophage infiltration conrelates with tumor stage and angiogenesis in human malignant melanoma: possible involvement of TNFalpha and IL-Ialpha. Int J Cancer $2000 ; 85(2): 182-8$

52. Fujimoto J, Sakaguchi $\mathrm{H}$, Aoki l et al. Clinical implications of expression of interleukin 8 related to angiogenesis in uterine cervical cancers. Cancer Res 2000;60(10):2632-5.

53. Led AH, Happerfield LC, Bobrow LG et al. Angiogenesis and inflammation in invasive carcinoma of the breast. J Chi Pathol 1997;50(8);669-73.

54. Lin EY, Poltard JW. Role of infiltrated leucocytes in tumour growth and spread. Be J Cancer 2004;90(11):2053-8.

55. Lin EY, Gouon-Evans V, Nguyen AV et al. The macrophage growth factor CSF-1 in mammary gland development and tumor progression. I Mammory Gland Biol Neoplasia 2002;7(2):147-62.

56. Ueno T, Toi M, Saji H er al. Significance of macrophage chemoattractant protein-l in macrophage recruitment, angiogenesis, and survival in human breast cancer. Clin Cancer Res 2000;6(8):3282-9. 

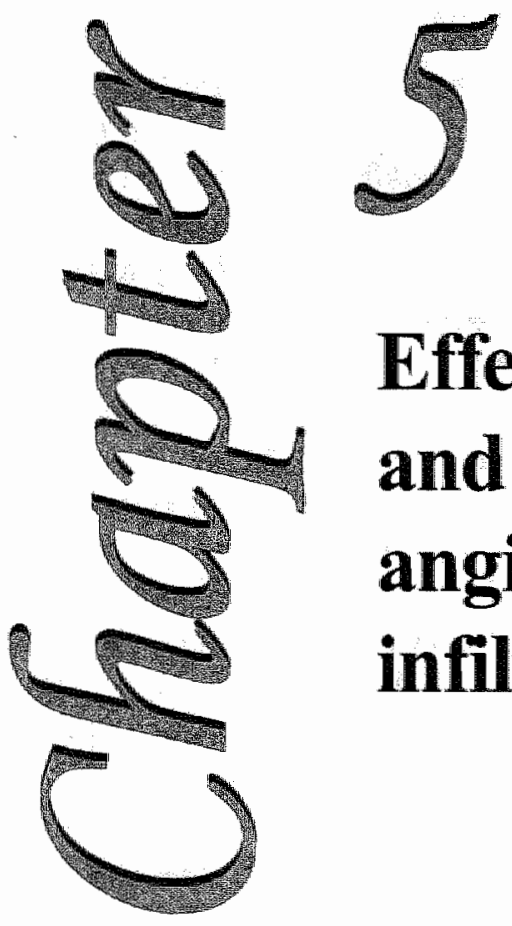

\section{Effects of radiotherapy and chemotherapy on angiogenesis and leukocyte infiltration in rectal cancer}

CIM Baeten, K Castermans, F Hillen, G Lammering, HFP Hillen, AW Griffioen, CGMI Baeten

Submitted for publication

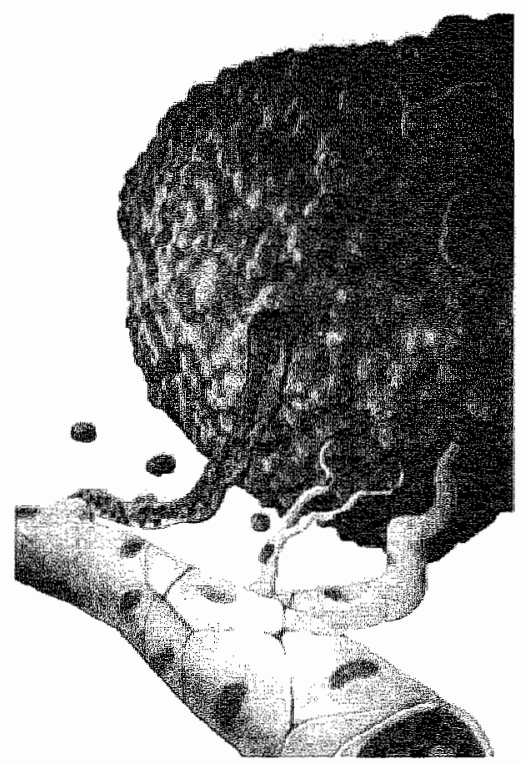




\section{Abstract}

\section{Introduction}

Radiotherapy is used as a pre-surgical treatment of rectal carcinomas in order to reduce tumor volume and to improve prognosis. Angiogenesis and leukocyte infiltration are related processes and important prognostic factors in rectal cancer. The biological effects of irradiation on these parameters in rectal carcinomas and normal mucosa are largely unknown. Thus, we were interested to study the influence of radiotherapy on angiogenesis and leukocyte infiltration in rectal carcinomas and normal rectal mucosa.

\section{Methods}

Biopsies of rectal carcinoma and normal rectal mucosa were studied in 34 patients prior to and after short course radiotherapy or long course radio-chemotherapy. We measured MVD and leucocyte infiltration in the biopsies using immunohistochemical staining. With flowcytometric analysis we determined the percentage of leukocytes and endothelial cells (EC) and measured the relative adhesion molecule expession on $\mathrm{EC}$. Furthermore we selected 10 patients, 5 with short course and 5 with long course therapy and determined the angiogenic $m$ RNA profile of these patients by qRT-PCR.

\section{Results}

We found in rectal carcinoma tissue a significant decrease in $M V D$, proliferating tumor cells and proliferating EC after radiotherapy treatment (RTX) $(\mathrm{p}<0.001)$. In contrast, no significant decrease could be detected in normal rectal mucosa. After RTX an increase in adhesion molecule expression on $\mathrm{EC}$ for normal as well as carcinoma tissue $(\mathrm{p}<0.05)$ and as a result an enhanced leukocyte (CD45, CD3, CD8, CD16 and CD20 subsets) infiltration could be demonstrated $(\mathrm{p}<0.05)$. CD68 did not show significant elevated levels. After short course radiotherapy no significant enhanced levels of angiogenic cytokines were determined in normal as well as rectal carcinoma specimen, in contrast to long course radiochemotherapy, where bFGF was significantly upregulated $(\mathrm{p}<0.05)$.

\section{Discussion}

Radiotherapy inhibits the proliferation of tumor cells as well as proliferating EC, increases the expression of adhesion molecules and as a result increases leukocyte infiltration. Supposedly this immunological tumor response reduces local recurrence and metastasis of rectal cancers. 


\section{Introduction}

Rectal cancer is a curable and frequently occurring malignancy in the western countries. The incidence of rectal cancer in the Netherlands is 46 per 100.000 a year. Exact location, size and invasiveness of rectal carcinomas are important for clinical staging ${ }^{1-3}$. Depending on clinical staging, rectal carcinomas are first treated with radiotherapy alone or in combination with chemotherapy, in order to improve local control or to also reduce the tumor volume, respectively. Importantly, a Swedish trial demonstrated for the first time, that a short course ( $5 \times 5 \mathrm{~Gy}$ ) of radiotherapy given preoperatively not only improved local control, but also overall survival ${ }^{4}$. In addition, a randomized trial performed in the Netherlands also clearly highlighted the significant benefit of this neoadjuvant treatment compared to a surgical TME resection alone, however no overall survival advantage has been reported so far ${ }^{5.6}$. For locally advanced rectal carcinoma with a predicted resection margin of less than $2 \mathrm{~mm}$ a 6-week course of radiotherapy combined with chemotherapy is commonly used ${ }^{7}$. These chemotherapeutics, like Capecitabine (oral 5-FU) have been introduced concomitantly, because it has been shown to further improve the local control of the radiotherapy ${ }^{8}$. In the Netherlands patients with rectal carcinoma are diagnosed and treated according to a national consensus protocol based on several of these important studies ${ }^{4-6,8,9}$.

It is well known, that radiotherapy induces cell damage, up-regulates leukocyte infiltration and inhibits tumor proliferation ${ }^{10,11}$. We and others have shown that angiogenesis and intra-tumoral leukocyte infiltration are important prognostic parameters in CRC ${ }^{12}$. 13. In addition, we were able to demonstrate that angiogenesis and leukocyte infiltration are inversely related ${ }^{14}$. An increase in adhesion molecule presentation on endothelial cell membranes resulted in an upregulation of leukocyte infiltration in vivo ${ }^{15}$. In active proliferating endothelium, however, as found in tumor blood vessels, the adhesion molecule exposure was lowered and as a result, this mechanism was inextricable related to the amount of leukocyte infiltration ${ }^{14,}, 15$.

It has been demonstrated in in vitro studies that irradiation inhibits proliferation of EC, upregulates adhesion molecule expression and induces leukocyte infiltration ${ }^{16-15}$. In in vivo models, irradiation induced the up-regulation of adhesion molecule expression on $\mathrm{EC} 20$. ${ }^{21}$. Unfortunately, in humans, not much is known about the in vivo intra-tumoral endothelial cell behavior after radiotherapy. It is unclear, if radiotherapy will effect proliferation of EC directly or indirectly, e.g. by damaging tumor cells leading to a lower angiogenic cytokine release.

The radiotherapy of rectal cancer is not only affecting the rectal cancer tissue itself, but also normal mucosa by initiating direct pathological changes ${ }^{22}$. Furthermore, an indirect radiation-induced enhancement of inflammatory cytokine release has also been described, leading to an upregulation of adhesion molecules on EC as well as an enhanced adhesion molecule expression leading to higher numbers of infiltrated leukocytes ${ }^{16,21,23,24}$. F urther studies showed that infiltration of leukocytes in normal mucosa tissue after irradiation can cause proctitis or colitis $11,20,25$. There have been reports about an increase of 
polymorphonuclear cells in colorectal tissue after irradiation, though others could not confirm that granulocytes are fully responsible for this inflammatory reaction to irradiation 26.28

Here we investigate, for both human rectal cancer and normal rectal epithelium, the influence of short course radiotherapy and long course radio-chemotherapy on proliferating $E C$, adhesion molecule expression, angiogenic profile and the relations with leukocyte infiltration.

Table 1. Patient data

\begin{tabular}{|c|c|c|c|c|}
\hline & & $\begin{array}{l}\text { Male } \\
\text { mean (st dev) }\end{array}$ & $\begin{array}{l}\text { Female } \\
\text { mean (st dev) }\end{array}$ & $\begin{array}{l}\text { Total } \\
\text { mean (st dev) }\end{array}$ \\
\hline \multicolumn{2}{|l|}{ Patients (H) } & 25 & 9 & 34 \\
\hline \multicolumn{2}{|l|}{ Age(years) } & $68.56(10.18)$ & $77.0(6.95)$ & $70.79(10.07)$ \\
\hline \multirow[t]{4}{*}{ Tumor( $(4) \mathrm{T}=\mathrm{I}$} & 0 & 1 & $\mathbb{1}$ & \\
\hline & $\mathrm{T}=2$ & 6 & 1 & 7 \\
\hline & $T=3$ & $\mathbb{1 6}$ & 3 & 19 \\
\hline & $T=4$ & 3 & 4 & 7 \\
\hline \multirow[t]{3}{*}{ Nodes(H) } & $N=0$ & 15 & 6 & 21 \\
\hline & $N=\mathbb{1}$ & 5 & 2 & 7 \\
\hline & $N=2$ & 5 & 1 & 6 \\
\hline \multirow[t]{2}{*}{ Metastasis (牛) } & $M=0$ & 23 & 8 & 31 \\
\hline & $M=1$ & 2 & 1 & 3 \\
\hline \multicolumn{2}{|l|}{ No therapy (H) } & 1 & 1 & 2 \\
\hline \multicolumn{2}{|l|}{$\mathrm{RTX}^{\mathrm{s}}(4)$} & 17 & 4 & 21 \\
\hline \multicolumn{2}{|l|}{$\mathrm{RTX}^{\mathrm{L}}(\mathrm{t})$} & 7 & 4 & 11 \\
\hline \multicolumn{2}{|l|}{ "Tumor" sate (mon) } & $52(19.11)$ & $36.4(20.3)$ & $48.4(20.1)$ \\
\hline \multicolumn{2}{|c|}{$\begin{array}{l}\text { CFA lewel betore surgical } \\
\text { resection (ng/ml) }\end{array}$} & $56.52(137.45)$ & $12.28(16.51)$ & $44.46(\| 18.52)$ \\
\hline \multicolumn{2}{|c|}{ Location "ab ani" (nm) } & $92.9(29.5)$ & $110(44)$ & $97.1(33.6)$ \\
\hline \multicolumn{5}{|c|}{ Tumor differentiation } \\
\hline & Well & 3 & 0 & 3 \\
\hline Mo & lerate & 9 & 5 & 14 \\
\hline Modera & -less & 4 & 1 & 5 \\
\hline & Less & 3 & 1 & 4 \\
\hline Un & nown & 6 & 2 & 8 \\
\hline
\end{tabular}




\section{Material and Methods}

\section{Patients}

Consecutive patients with rectal cancer admitted between august 2003 and may 2005 in the surgical departments of the academic hospital Maastricht and the affiliated St.Jans hospital in Weert, were included in this study. Inclusion criteria were biopsy proven rectal cancer, distal tumor margin within $20 \mathrm{~cm}$ from the anal verge, indication for radiotherapy and written informed consent. At diagnosis, two biopsies were taken endoscopically from the rectal lesions and two biopsies from the adjacent normal rectal mucosa (within $3 \mathrm{~cm}$ from the tumor), snap frozen and stored at $-80^{\circ} \mathrm{C}$. All patients received routinally preoperative diagnostics and radiotherapy. After radiotherapy subsequent tumor and nomal rectal tissue biopsies (within $3 \mathrm{~cm}$ ) were obtained from the surgical operation specimen and also stored at $-80^{\circ} \mathrm{C}$.

\section{Radiotherapy}

The indication for radiotherapy was routinely based on $\mathrm{CT}$ and MRI imaging according to national protocol guidelines. An MRI- based predicted circumferential resection tumor margin of $>2 \mathrm{~mm}$ from the fascia has been defined as an indication for short term radiotherapy (RTX'; 5 fractions of 5 gray within 1 week), at which surgical resection took place within a week after RTXS. Consequently, a circumferential resection margin of less than $2 \mathrm{~mm}$ was defined as an indication for long course radiotherapy (RTX, 28 fractions of 1,8 gray within 6 weeks) in combination with chemotherapy (capecitabine 5 -FU dosis $825 \mathrm{mg} / \mathrm{m}^{2}$, twice a day during 6 weeks radiotherapy). After RTX ${ }^{\mathrm{L}}$, the surgical resection took place within six weeks after the last radiotherapy fraction.

\section{Immunohistochemistry}

Adjacent serial sections of $4 \mu \mathrm{m}$ were made from the obtained frozen material, fixed with $1 \%$ paraformaldehyde and stored $-20^{\circ} \mathrm{C}$. Endogenous peroxidase was blocked by incubation in $0,3 \% \mathrm{H}_{2} \mathrm{O}_{2}$ in methanol for 30 minutes and a-specific antibody binding was blocked with $5 \%$ BSA in PBS. The primary antibodies $\mathrm{Ki}-67$ (rabbit anti human; NeoMarker, Freemont, CA.;1:200), CD31 (DAKO, Glostrup, Denmark; 1:100), CD34 (Qbend-10, Monosan; 1:50), CD3 (1:50, DAKO Cytomation, Glostrup, Denmark), CD8 (1:100, Novocastra, Valkenswaard, the Netherlands), CD16 (1:50, NeoMarker), CD20 (1:1000, DAKO), CD68 (1:100, DAKO) were properly diluted and incubated for 1 hour at $20^{\circ} \mathrm{C}$. Dependent to primary antibody the slides were incubated in biotin-labelled Swine anti rabbit $\operatorname{IgG}$ (DAKO) or Rabbit anti mouse $\lg$ (DAKO) for $1 / 2$ an hour, followed by incubation with avidine-biotin complex HRP (DAKO) for half an hour and finally the slides were developed with diaminobenzidine (DAB)(Sigma, Zwijndrecht, the Netherlands). 
The slides were either counterstained with haematoxylin (Merck, Darmstadt, Germany) or subsequently used for double staining. When double stained a secondlary cocktail of primary antibodies against endothelial cells CD31 (1:100) and CD34 (1:50) (DAKO, Monosan; QBEND-10) was added for 1 hour. After washing with PBS the slides were incubated in biotin-labelled Goat anti mouse IgG (DAKO, Glostrup, Denmark) for $1 / 2$ hour and afterwards incubated with avidine-biotin complex AP (DAKO) for half an hour. The slides were developed with alkalic phosphatase substrate KIT III (vector laboraties inc., Burlingame, CA) and covered with imsolmount (Merck).

\section{Analysis}

MVD was assessed by two independent observers in 4 randomly selected high power fields (200x), the results are shown as number of vessels $/ \mathrm{mm}^{2}$. Also angiogenesis (\# of proliferating EC/mm ${ }^{2}$ ), proliferating epithelail cells (\# of proliferating epithelial cells $/ \mathrm{mm}^{2}$ ) and proliferating tumor cells (\# of proliferating $\mathrm{TC} / \mathrm{mm}^{2}$ ) were determined in the the same randomly chosen fields. All leukocyte subsets were determined intra- tumoral in 4 random chosen fields for endoscopic biopsies, because of surface size 5 random chosen fields were used in operation specimens. Intra-tumoral leukocyte infilltration were scored at $400 \mathrm{x}$ magnification and presented as \# of leukocytes $/ \mathrm{mm}^{2}$.

\section{Preparation of single cell suspensions and flowcytometric analysis}

Single cell suspensions were made as described previously ${ }^{29}$. In short, from each biopsy, two $30 \mu \mathrm{m}$ sections were fixed in $1 \mathrm{ml} 1 \%$ paraformaldehyde (Merck, Darmstadt, Germany). The sections were digested by incubation in collagenase and dispase (both 5 $\mathrm{mg} / \mathrm{ml}$, Life Technologies, Breda, the Netherlands) for 15 minutes at $37^{\circ} \mathrm{C}$. After digestion, which was microscopically checked, the cells were washed and incubated with CD31 (1:80; DAKO), CD34 (1:80; Monosan), CD45 (1:200; DAKO) for 1 hour $\left(4^{\circ} \mathrm{C}\right)$. The suspension was incubated with biotin conjugated rabbit anti-mouse $\mathrm{IgG}(15 \mu \mathrm{g} / \mathrm{ml}$ DAKO$)$ for 1 hour $\left(4^{\circ} \mathrm{C}\right)$ and subsequently incubated with phycoerythrin (PE)-conjugated streptavidine $(10 \mu \mathrm{g} / \mathrm{ml}, \mathrm{DAKO})$ for 30 minutes $\left(4^{\circ} \mathrm{C}\right)$.

For double staining firstly the $\mathrm{EC}$ staining was performed as described above, followed by a two hour incubation of the sample with FITC conjugated (ICAM-1, VCAM-1 or Eselektin) in the presence of $5 \%$ normal mouse serum $\left(4^{\circ} \mathrm{C}\right)$. The cell suspensions were washed and analyzed on a FACS calibur (Becton and Dickinson, Mountain View, CA) using Cell-quest software (Becton and Dickinson). Propidium iodide (Calbiochem, San Diego, CA) staining was used to control for intact cells. 
$q R T-P C R$

Out of 10 patients, 5 patients received $\mathrm{RTX}^{\mathrm{S}}$ and 5 patients received RTX', RNA before as well as after therapy was isolated. Total RNA was isolated from the suspensions using the RNeasy RNA isolation kit (Qiagen) according to the supplier's protocol. Possible genomic DNA contaminations were removed by DNAse treatment (Qiagen). Primers to b-actin, VEGF-A, bFGF, PIGF, ANG-1 and ANG-2 were used to detect angiogenic profile of the tissue samples.

\section{Statistics}

For statistical analysis SPSS (version 11) was used. Mann-whitney, Wilcoxon signed ranks test, Pearson and Spearman tests were examined. We considered p-value $<0.05$ as significant. 


\section{Results}

\section{Patients}

We collected rectal carcinoma and normal mucosa tissues before and after radiation treatment of 34 patients (Table 1). All short course radiotherapy $\left(\mathbb{R T X}^{\mathrm{s}}\right)$ patients received surgery in the week following the last fraction of radiotherapy. The long course radiochemotherapy patients ( $\mathrm{RTX}^{\mathrm{L}}$ ) was always given in combination with chemotherapy (capecitabine (5-FU)) and surgery was performed 6 weeks after the last irradiation. Two patients did not recieve radiotherapy because these patients showed constipation complications. No significant differences were found between $\mathrm{RTX}^{\mathrm{S}}$ and $\mathrm{RTX}^{\mathrm{L}}$ patients for age (respectively 71.1 years (stdev 11.2); 69.6 years (8.4)), CEA levels (49.6 (stdev 139.5); 34.1 (stdev 88.5)), localisation "ab ani" (97mm (stdev 34); $94 \mathrm{~mm}$ (stdev 37)) or tumor size (48.0mm (stdev 20.0); 48,0 mm (stdev 23.0).

\section{Angiogenic parameters in rectal cancer}

The amount of proliferating tumor cells (TC)/ $\mathrm{mm}^{2}$ was significantly reduced after RTX for both $\mathrm{RTX}^{\mathrm{S}}$ and $\mathrm{RTX}^{\mathrm{L}}$ (Figure 1A, respectively; $\mathrm{p}<0.001$ and $\mathrm{p}<0.045$ ). Also MVD (Figure 1B, RTX ${ }^{\mathrm{S}}$ course $\mathrm{p}<0.028 ; \mathrm{RTX}^{\mathrm{L}} \mathrm{p}<0.05$ ) and moreover the number of proliferating endothelial cells (EC)/ $\mathrm{mm}^{2}$ after RTX was remarkably lower (Figure 1C, RTX ${ }^{\mathrm{S}}$ and RTX $\mathrm{p}<0.001$ ). As a result a high correlation comparing the number of proliferative $\mathrm{EC}$ with the number of proliferative TC before $(r=0.701 ; \mathrm{p}<0.01)$ and after RTX $(r=0.398 ; \mathrm{p}<0.05)$ was established. The two patients who did not receive any RTX (constipation complications) showed similar results in endoscopically taken biopsies and surgical resection specimen (Figure 1A, B, C and D). For MVD, proliferating TC and proliferating EC no correlation with tumor differentiation, tumor size, tumor location, CEA-levels or TNMstage could be determined.

Interestingly, the percentage of EC, as measured by flow cytometry ${ }^{29}$, was significantly increased after RTX (Figure 1D, p $<0.037$ ). The percentage of EC measured before both RTX correlated with the immunohistochemical determined MVD ( $r=0.241 ; p<0.05)$, whereas this correlation could not be found after both RTX $(r=0.17 ; \mathrm{p}=0.37)$.

We found that vascular endothelial growth factor-A (VEGF-A) was the most abundantly expressed gene compared to other angiogenic genes (up to 300 times higher than bFGF; Figure IE). RTX ${ }^{8}$ showed an upregulation of all genes after RTXs, in contrast with RTX ${ }^{\mathrm{L}}$ where some genes show downregulation (Figure IF). Interestingly an upregulation of bFGF $\left(\mathrm{p}<0.05\right.$ ) and trends to upregulation for Ang- 1 and Ang-2 were found in the RTX ${ }^{\mathrm{L}}$ group. None of the genes correlated with proliferating $\mathrm{EC}$ or $\mathrm{TC}$, nor with adhesion molecule expression. 

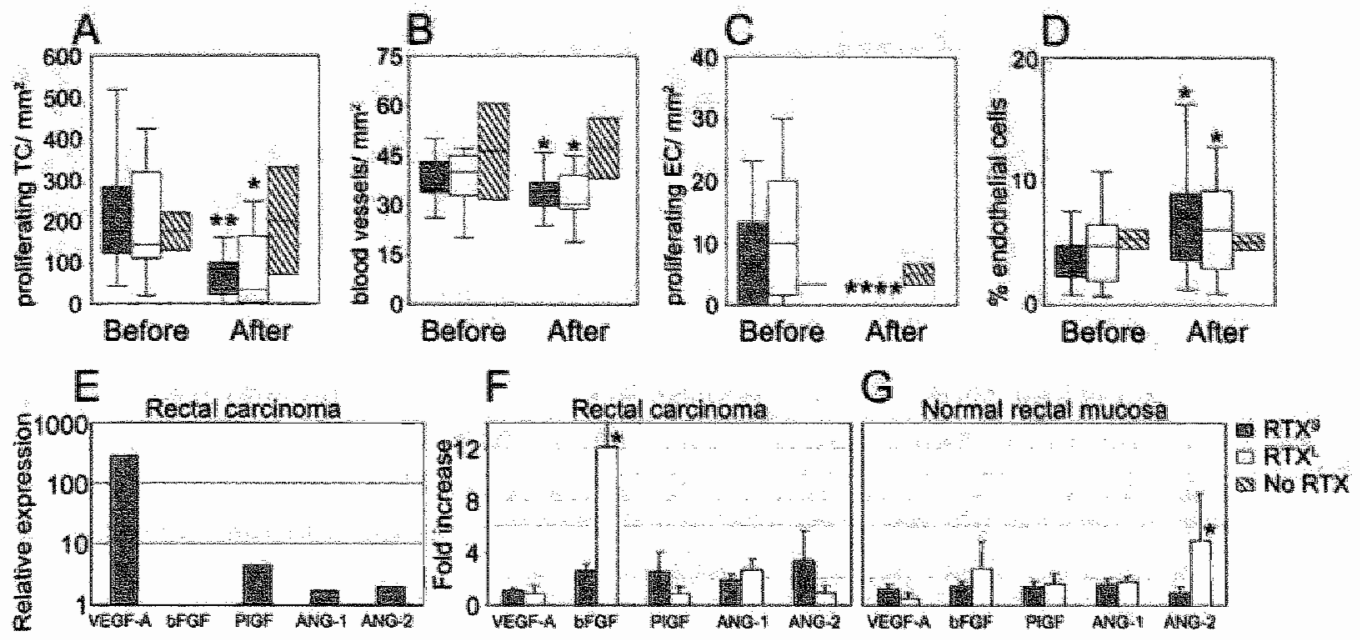

\section{Figare 1.}

Angiogenic parameters in rectal cance:

Figure $\mathrm{A}, \mathrm{B}$ and $\mathrm{C}$ represent respectively the immunolistochemistry results of proiliferating tumor cells (TC), MVD and proliferating endotheliall cells (EC).

The percentage of endothelial cells in a tumor tissue before and after therapy measured by flowcytometric analysis is shown in figure $D$. The relative expression of the angiogenic factors is shown in figure $\mathbb{E}$. The fold increase in expression of angiogenic mRNA levels of tissues measured after RTX are shown in rectal carcinoma and normal rectal mucosa (respectively Figure F and G). After RTX' only bFGF expression is significantly higher expressed $(* 0<0.05)$ in rectal carcinoma, whereas in normal rectal mucosa ANG-2 is significantly upregulated (* $\mathrm{p}<0.05$ ).

\section{Leukocyte infiltration in rectal carcinoma}

Analysis of flowcytometric determined CD45 positive cells showed a significant upregulation after $\mathrm{RTX}^{\mathrm{s}}$ radiotherapy (Figure $2 \mathrm{~A}, \mathrm{RTX}^{\mathrm{S}} \mathrm{p}<0.046 ; \mathrm{RTX}^{\mathrm{L}} \mathrm{p}<0.34$ ). Interestingly, CD45 correlated with tumor differentiation in a way that poorly differentiated tumors showed less infiltration $(r=0.437 ; p<0.05)$. We did not find any relation with leukocyte subsets and other clinical parameters as tumor size, location, CEA-levels or TNM-stage. For all subsets, except $C D 20$, determined by immunohistochemistry, we found a significant upregulation after $\mathbb{R T X}^{\mathbb{S}}$ (Figure 2, CD3 $\mathrm{p}<0.001 ; \mathrm{CD} 8 \mathrm{p}<0.001 ; \mathrm{CD} 16 \mathrm{p}<0.01$; CD20 $\mathrm{p}=0.354$; and $\mathrm{CD} 68 \mathrm{p}<0.001)$. After RTX ${ }^{\mathrm{L}}$ we found an enthanced numbers of infiltrated T-cells (Figure 2B, CD3 p $<0.005$ ) and macrophages (Figure 2F, CD68, p<0.04), but not for cytotoxic T-cells (CD8), PMN's (CD16) and B-cells (CD20).

Interestingly only $\mathrm{CD} 20$ showed a correlation with tumor differentiation and tumor size (respectively $\mathrm{r}=0.466$ and $\mathrm{r}=0.365$; both $\mathrm{p}<0.05$ ). All other clinical parameters did not show significance with any leukocyte subset.

In the biopsies taken before both RTX significant correlations were found between the percentages of $C D 45$ positive cells, measured by flowcytometry, and the microscopically analysed CD3 $(r=0.27 ; p<0.05), C D 8(r=0.248 ; p<0.05), C D 16(r=0.361 ; p<0.01)$ and $\mathrm{CD} 20$ ( $\mathrm{r}=0.347 ; \mathrm{p}<0.01$ ). After both RTX similar results were found (data not sliown). 
Leukocyte infiltration is inextricable related to adhesion molecule expression on $\mathrm{EC}$. Therefore we measured adhesion molecule expression on EC. The relative expression of ICAM-1, VCAM and E-selectin on EC (respectively Figure $3 \mathrm{~A}, \mathrm{~B}$ and $\mathrm{C}$ ) was upregulated by therapy. After RTXs a significant upregulation of ICAM-1 was found $(p<0.05)$, with a trend of significance for VCAM. Interestingly, E-selectin expression showed a significant upregulation after $\operatorname{RTX}^{\mathrm{L}}(\mathrm{p}<0.01)$. ICAM-1 as well as VCAM showed clear trends, though no significance was reached (respectively $p=0.09$ and $p=0.06$ ).

\section{Angiogenic potential of a tumor is related with the amount of infiltrated leukocytes} In previous studies we showed that endothelial cell behavior can predict the amount of leukocyte infiltration in tumor tissue ${ }^{14}$. The total amount of ICAM-1, VCAM and Eselectin expression in a tissue correlated with the amount of flowcytometric determined CD45 cells $(r=0.354 ; p<0.05)$. Interestingly, after both RTX no significant correlation between adhesion molecule expression and leukocyte infiltration was found $(r=0.265$; $\mathrm{p}=0.136$ ).

Correlating adhesion molecule expression with immunohistochemical determined leukocytes before both RTX, significance with CD20 and CD68 positive cells was found (respectively $\mathrm{r}=0.359, \mathrm{r}=0.392$ both $\mathrm{p}<0.05$ ). There was neither significant correlation between other subsets, nor a significant correlation after both RTX with any leukocyte subset (data not shown).
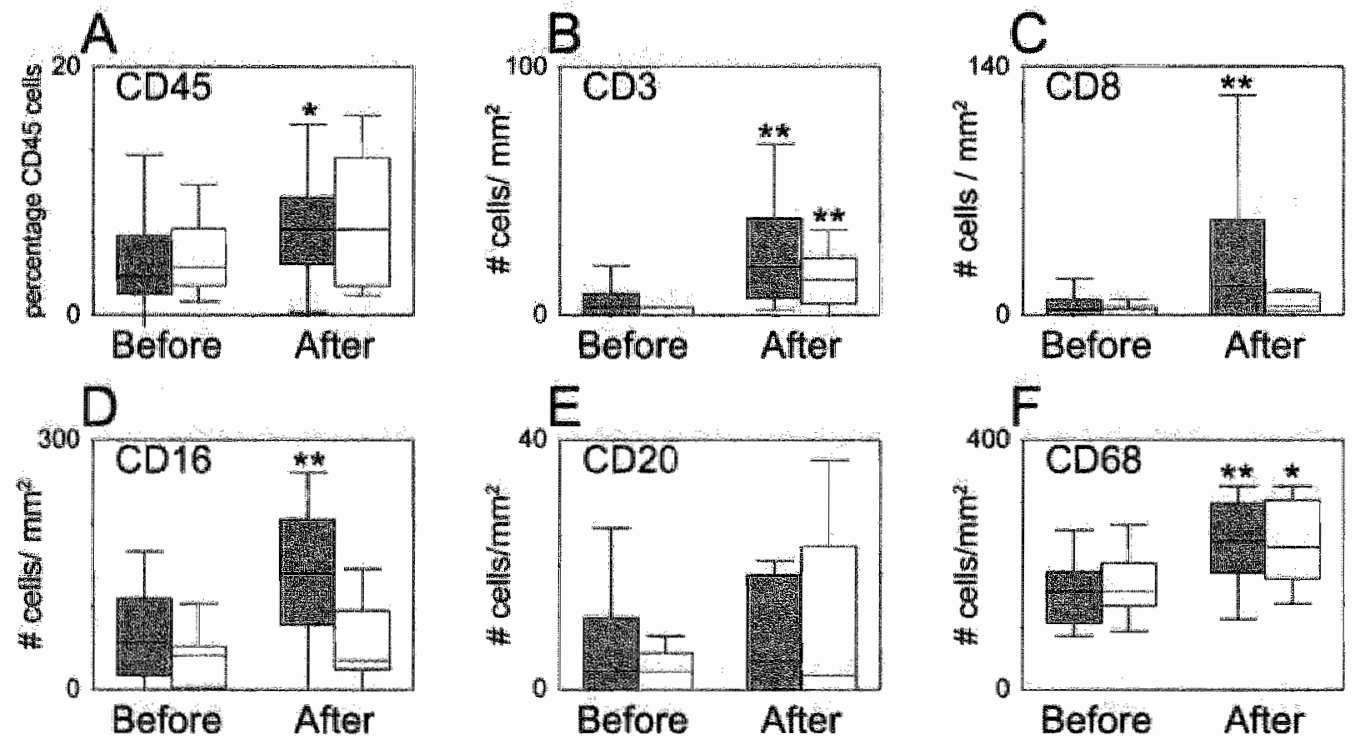

RTXs $\quad$ RTRX

Figure 2.

Lewkocyte imfiltration in rectal cancer.

The left upper panel shows the measured percentage of $C D 45$ positive cells before and after irradiation therapy. Imnunohistochemistry results for $\mathrm{CD} 3, \mathrm{CD} 8, \mathrm{CD} 16, \mathrm{CD} 20$ and $\mathrm{CD} 68$ are shown in respectively $\mathrm{B}, \mathrm{C}, \mathrm{D}, \mathrm{E}_{*}$ and $\mathrm{F} .{ }^{*} \mathrm{p}<0.05 ; *{ }^{*}<<0.001$ 


\section{Angiogenesis in normal rectal mucosa}

No differences in MVD and proliferating EC were found after RTX (MVD; RTX', $\mathrm{p}<0.238$; $\mathrm{RTX}^{\mathrm{L}}, \mathrm{p}<0.217$; proliferating $\mathrm{EC}$; $\mathrm{RTX}^{\mathrm{s}}, \mathrm{p}<0.076$; $\mathrm{RTX}^{\mathrm{L}}, \mathrm{p}<0.332$ ), in contrast to the amount of proliferating epithelial cells (RTX', $<<0.001$; RTX ${ }^{\mathrm{L}}, \mathrm{p}<0.088$ ). The percentage of EC showed no significant difference after RTX (both RTX; $\mathrm{p}<0.265$ and RTX $^{\mathrm{L}} ; \mathrm{p}<0.300$ ). A correlation was established between the immunohistochemic determined MVD and flowcytometric measured percentage of $\mathrm{EC}(\mathrm{r}=0.378 ; \mathrm{p}<0.04)$. ICAM-1 expression on EC was upregulated after RTX' $(p<0.001)$, in contrast to VCAM and E-selectin (data not shown). After RTX ${ }^{\mathrm{L}}$ (radio-chemotherapy) an upregulation of both ICAM-1 and VCAM on EC was found (respectively $p<0.001$ and $p<0.023$ ), but not for E-selectin ( $p<0.367)$. After RTX ${ }^{\mathrm{s}} \mathrm{mRNA}$ expression is enhanced for several angiogenic factor in normal rectal mucosa tissue. This upregulation of expression showed a trend after RTX ${ }^{\mathrm{S}}$ (Figure 1G), in contrast to the RTX ${ }^{\mathrm{L}}$, where we found a significant upregulation of ANG-2 $(p<0.02)$ and a trend for bFGF $(p<0.073)$.

\section{Leukocyte infiltration in normal mucosa}

After RTX ${ }^{s}$ higher amounts of CD3 infiltrated leukocytes were found (Figure 4A, $p<0.009$ ), in contrast to $\mathrm{RTX}^{\mathrm{L}}(\mathrm{p}<0.08$ ). Significantly higher numbers of PMN's (CD16) were present after therapy, for both $\mathrm{RTX}^{\mathrm{S}}$ and $\mathrm{RTX}^{\mathrm{L}}$ (Figure $4 \mathrm{~B}$, respectively $\mathrm{p}<0.005 ; \mathrm{p}<0.002$ ). Interestingly, a clear trend $(\mathrm{N}=2)$ to enhanced levels of $\mathrm{CD} 16$ was found in the untreated patients, suggesting an inflammatory reaction (data not shown). In contrast to the detection of B-lymphocytes and CD8 positive cells, which showed overall low amounts of positive cells (no significant upregulation was found for both after therapy), a high number of infiltrated macrophages (CD68) was found. A strong significant increase in the amount of macrophages was detected after RTXS and RTX ${ }^{L}$ (Figure $4 C$, respectively $p<0.001 ; p<0.005)$. Examples of immunohistochemical staining to the amounts of infil-
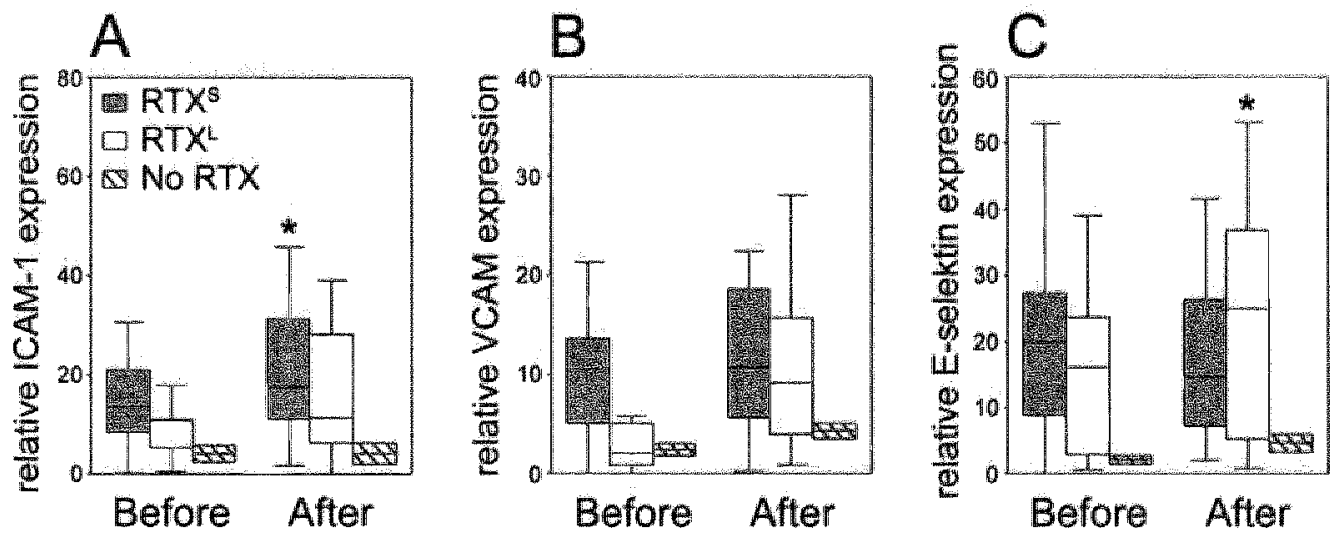

Figure 3.

Adhesion molecule expression on endothelial cells in rectal cancer.

Effects of RTX on adhesion molecule expression are shown as relative expression in figure $E_{5} F$ and $G$. * $\mathrm{p}<0.05$ vs before $\mathrm{x}$-ray; * $\mathrm{p}<0.001$ ws before irradiation 
trated macrophages after both RTX are shown in Figure 4D (untreated normal rectal mucosa), Figure $4 \mathrm{E}\left(\mathrm{RTX}^{\mathbb{S}}\right.$ in normal rectal mucosa) and Figure $4 \mathrm{~F}$ ( $\mathrm{RTX}^{\mathbb{L}}$ in normal rectal mucosa). An increased percentage of flowcytometric measured CD45 cells was determined after RTX $\left(\mathrm{RTX}^{\mathbb{S}} \mathrm{p}<0.001\right.$; $\left.\mathrm{RTX}^{\mathrm{L}} \mathrm{p}<0.049\right)$. Therefore a high correlation between the flowcytometric measured CD45 cells and immunohistochemic determined numbers of leukocytes was found $(\mathrm{CD} 3 \mathrm{r}=0.321, \mathrm{p}<0.046, \mathrm{CD} 8 \mathrm{r}=0.259 ; \mathrm{p}<0.042, \mathrm{CD} 16$ $\mathrm{r}=0.342 ; \mathrm{p}<0.007, \mathrm{CD} 20 \mathrm{r}=0.087 ; \mathrm{p}<0.520, \mathrm{CD} 68 \mathrm{r}=0.688 ; \mathrm{p}<0.031$ ).

\section{Comparisons between rectal tumor tissue and adjacent normal rectal mucosa}

Before both RTX, lower amounts of blood vessels within normal rectal mucosa as compared to tumor mucosa were found $(p<0.02)$. This higher MVD in rectal carcinomas is likely to be a result of a significantly higher endothelial cell (EC) proliferation rate $(\mathrm{p}<0.0001)$. In contrast to the results before both RTX, no significant differences were found between normal rectum mucosa and rectal carcinoma for MVD and proliferating EC after both RTX (respectively $p<0.364$ and $p<0.708$ ). Leukocyte infiltration showed high correlations between normal and rectal carcinoma tissue before both RTX (CD45, $r=0.661 \mathrm{p}<0.001$ ). After RTX a significant higher increase to infiltrated leukocytes was found in rectal mucosa $(\mathrm{p}<0.001)$. Correlations between adhesion molecule expression before and after both RTX were not found (data not shown). Before both RTX was initiated a significantly lower angiogenic gene expression in normal rectal mucosa as compared to rectal cancer tissue of the same patients was found, in contrast to the results after both RTX where no significant differences were found (data not shown).

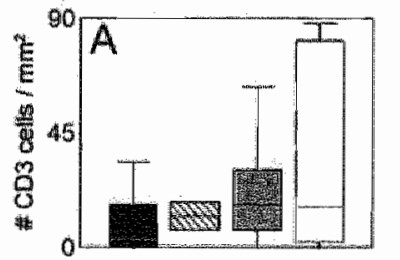

Nornal mucosa before RTX

NoRTX

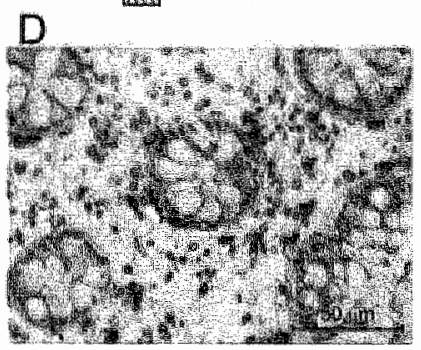

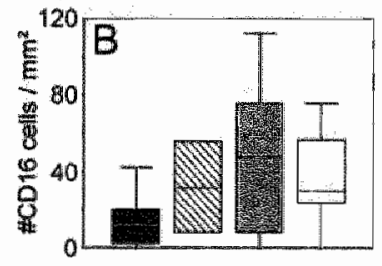

Normal mucosa after RTX $X^{s}$

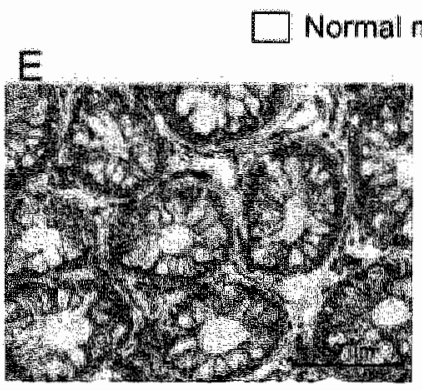

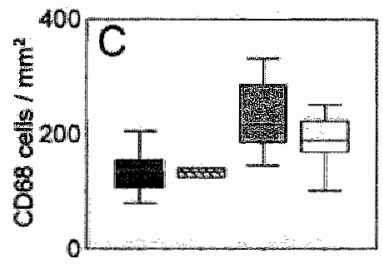

ucosa after RTX

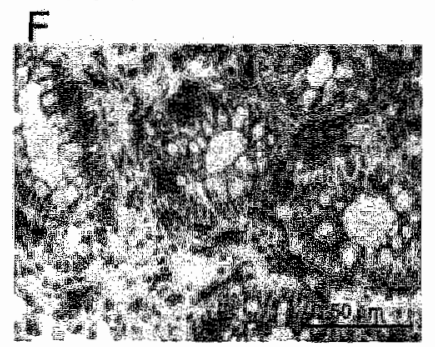

Figure 4.

In/luences of RTX on normal rectal mucosa.

Panel A, B and C show the boxplot result of amounts of leukoeytes $/ \mathrm{mm}^{2}$. Significantly more infiltrated leukocytes were measured after $\mathrm{RTX}^{\mathrm{s}}(\mathrm{S})$ as well as RTX ${ }^{\mathrm{L}}(\mathrm{L})$ therapy (respectively panel A: (S) $p<0.009$; panel B: (S) $p<0.005$, (L) $p<0.002$; panel $C$ : (S) $p<0.001$, (L) $p<0.005$ ). Figure $D, E$ and $F$ are examples of macrophage infiltration of respectively before treatment, after $\mathrm{RTX}^{\mathrm{s}}$ and $\mathrm{RTX}^{\mathrm{L}}$. 


\section{Discussion}

Radiotherapy is mostly used in treatment of trectal carcinomas. Although several studies have shown that radiotherapy and radio-chemotherapy can significantly reduce the size of a cancer mass, and lower the propability for metastasis and recurrence, not much is known about the physiological responses of endothelial cells (EC) to this therapy ${ }^{30,31}$. In our study we obtained from each rectal carcinoma patient an endoscopical biopsy of the cancer lesion and a biopsy of the normal rectal mucosa. Both tissue biopsies were taken before and after therapeutic interference; therefore we were able to determine the therapeutic effect of radio- or radio-chemotherapy on each patient. Two patients were not treated with radiotherapy, but directly operated due to complications, the measured values of the surgical specimen were almost equal to the endoscopically taken biopsies, indicating that the used methods are accurate.

We found MVD to be significantly decreased after RTX ${ }^{\mathrm{L}}$, whereas RTX ${ }^{\mathrm{S}}$ showed a trend and the adjacent normal rectal mucosa showed no significant decrease after RTX. A study to glioma in mice showed a decrease in MVD after $5 \times 5$ gray radiotherapy, a similar result as our findings in rectal carcinomas ${ }^{32}$. Next to MVD measurement in rectal carcinomas, the number of proliferating endothelial cells (EC) and proliferating tumor cells (TC) were determined, both showed a lower amount of proliferation after RTX. As TC proliferate, blood vessels need to extend by proliferation to supply mutrients to the tumor cells, as a logical result we found a high correlation between proliferating $\mathrm{EC}$ and proliferating TC. A correlation between proliferating EC and proliferating epithelial cells was not found in normal rectal mucosa, probably because the epithelial cell layer is constantly rebuilt and therefore no extension of vasculature is needed. Next to immunohistochemical angiogenesis determination, flowcytometric analysis, as described before, was performed ${ }^{29}$. Interestingly, we found an increase of EC after RTX in contrast with a decrease in MVD (figure 1). Because no proliferating EC were found after RTX, the higher percentage of EC cannot be a result of proliferation. An explanation for this apparent paradox can be the higher sensitivity of surrounding cells for the treatment and therefore the higher loss, especially in $\mathrm{RTX}^{\mathrm{L}}$ treatment, leading to a relative higher percentage of EC in the single cell suspensions. After both $\mathrm{RTX}^{\mathrm{S}}$ and $\mathrm{RTX}^{\mathrm{L}}$ no proliferating $\mathrm{EC}$ were found in rectal carcinoma, in contrast to the angiogenic mRNA profile, which was overall increased after RTX. Endothelial cells respond accurate to an angiogenic call ${ }^{33}$, we therefore suggest that the inhibitory effect of RTX must be a direct effect on $\mathrm{EC}$ and not an indirect result of decreased angiogenic cytokine release. We measured up to 1000 fold higher VEGF-A gene expression in contrast to other angiogenic stimuli, indicating current trials to anti-VEGF-A treatment can be an effective target ${ }^{34,35}$. Although the current study did not use anti-VEGF-A treatment the intratumoral-measured levels of VEGF-A were equal after treatment, suggesting VEGF-A is not only released by active cells.

Inhibition of proliferating EC is highly related, as we have also shown in previous studies, with adhesion molecule expression ${ }^{14}$, 15 . In correspondence to these earlier reports we 
also found that the adhesion molecules ICAM-1 and VCAM-1 are upregulated within a week $\left(\mathrm{RTX}^{\mathrm{s}}\right)$, in contrast with E-selectin which showed a significant increase after RTX (Figure 3) ${ }^{36}$. It is not known whether the adhesion molecule expression shows a peak or stays level between the RTX $\mathrm{RT}^{\mathrm{S}}$ and $\mathrm{RTX}^{\mathrm{L}}$ periods. From in vitro experiments it is known that ICAM-I and VCAM can be maximal upregulated within 48 hours and are persistently upregulated over a longer time period ${ }^{37-39}$. Therefore we think that after RTX $^{s}$ in rectal carciniomas the adhesion molecule expression stays level. In contrast to ICAM-1 and VCAM, E-selectin has been shown to have a delayed or even no upregulation on endothelial cells in vitro after radiotherapy, though these studies did not measure the expression of E-selectin over 12 weeks ${ }^{39,40}$. Normal rectal mucosa showed a similar upregulation of adhesion molecules on endothelial cells as the carcinoma lesion, and this might clarify inflammatory reactions in normal rectal mucosa after irradiation.

The relationship between leukocyte infiltration and adhesion molecule expression on $\mathrm{EC}$ in tumor tissues was, next to earlier reports, also found in this study ${ }^{14}$. Interestingly this relationship was only found in the tissue samples before RTX. After RTX the physiological environment is probably disturbed (high angiogenic potentials, inhibited EC proliferation), there is an increase in leukocyte infiltration (CD45), but this does not relate to the significantly higher upregulation of adhesion molecules, and there fore no correlating results are found. Upregulation of adhesion molecules can occur rapidly in response to stimuli, as stated before ${ }^{21,36}$. ICAM-1 expression and leukocyte adhesion occur concurrently 16,20 , interestingly the infiltration of leukocytes into ischemic area shows a delayed response $11,41,42$.

In our rectal carcinomas study significant upregulation of especially CD3, CD8 and CD16 infiltrated leukocytes was found after RTX ${ }^{\mathrm{s}}$ (Figure 2), in contrast to macrophages, which were upregulated after RTX ${ }^{\mathrm{L}}$. Similar results were found in normal rectal mucosa, though we did not find a significant upregulation of infiltrated CD8 cells (Figure 4). The increased amounts of infiltrated leukocytes are an indication to an active anti-tumor reaction ${ }^{43-45}$. The enhanced leukocyte infiltration after RTX in normal rectal mucosa is a result of the upregulated adhesion molecule expression and causes proctitis and colitis in rats ${ }^{11,25,21}$. Radiation treatment is used to reduce tumor volume and the risk of local metastasis and recurrence. Reducing proliferation of cells is probably not enough to protect recurrence or local metastasis. The effectiveness of radiation is probably a combination of proliferation inhibition and a local immune response. Radiotherapy or radio-chemotherapy inhibit EC proliferation, upregulate adhesion molecule expression and as a result enable infiltration of leukocytes in tumor tissue. Tumor cells left behind after potentially curative surgical resection will be targeted by infiltrated leukocytes and as a result a decrease of local recurrence is accomplished.

The findings of our studies will support the ideas of combined modality treatment in rectal cancer. The combination of radiotherapy and angiogenesis inhibitors is an interesting field for future studies. One has to keep in mind that angiogenesis inhibition can only be effective when supplied before radiotherapy has started. After radiotherapy the bloodsupply to the tumor is disturbed, irradiation directly affects endothelial cells and angiogenesis inhibitors will probably not have any additional effect anymore. Another additional 
combination therapie next to radiotherapy is the combination of an anti-angiogenic compound with immunotherapy (activated leukocytes) to further decrease local recurrence or metastasis in rectal carcinoma by a direct inflammatory effect. In conclusion radiation therapy reduces $M V D$, inhibits proliferating endothelial cells (EC) and inhibits proliferating tumor cells. Radiotherapy has a direct inhibitory effect on the proliferation of EC and thus can't be interpreted as a side effect of decreased angiogenic profile. The inhibition of proliferating EC results in higher adhesion molecule expression, leading to an enhanced leukocyte infiltration. This immunological response as a result of the enhanced levels of infiltrated leukocytes might reduce the risk of local recurrence and metastasis of rectal cancers.

\section{Acknowledgements}

Dr. H. Verkooijen, Dr.WS Kwee and the dept. of gastroenterology St. Jans Gasthuis Weert for their support. 


\section{Reference List}

1. Beets-Tan RG, Beets GL, Borstlap AC, Oei TK, Teune TM, von Meyenfeldt MF, van Engelshoven JM: Preoperative assessment of local tumor extent in advanced rectal cancer: CT or high-resolution MRIT Abdom lmaging 2000,25:533-541.

2. Beets-Tan RG, Beets GL, Vliegen RF, Kessels AG, Van BH, De BA, won Meyenfeldt MF, Baeten

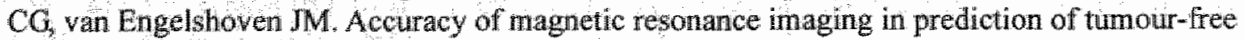
resection margin in rectal cancer surgery. Lancet 2001:357:497-504.

3. Beets Tan RG. MRI in rectal cancer the T stage and circumferential resection margin. Colorectal Dis 2003;5:392-395.

4. Improved survival with preoperative radiotherapy in resectable rectal cancer. Swedish Rectal Cancer Trial. N Engl J Med 1997;336:980-987.

5. Kapiteijn E, Marijnen CA, Nagtegaal ID, Putter H, Steup WH, Wiggers T, Rutten HJ, Pahlman L, G.limelius $\mathrm{B}$, van Krieken JH, Leer JW, Van D, V. Preoperative radiotherapy combined with total mesorectal excision for resectable rectal cancer. N Engl J Med 2001,345:638-646.

6. Marijnen CA, Nagtegaal ID, Kapiteijn E, Kranenbarg EK, Noordijk EM, van Krieken JH, Van D, V, Leer JW. Radiotherapy does nof compensate for positive resection margins in rectal cancer patients: report of a multicenter randomized trial. Int $J$ Radiat Oncol Biol Phys $2003 ; 55: 1311-1320$.

7. Nagtegaal ID, Marijnen CA, Kranenbarg EK, Van D, V, van Krieken JH. Circumferentiall margin involvement is still an important predictor of local recurrence in rectal carcinoma: not one millimeter but two millimeters is the limit. Am J Surg Pathol 2002;26:350-357.

8. Dunst $\mathrm{J}$, Reese T, Sutter T, Zuhlke H, Hinke A, Kolling-Schlebusch K, Frings S. Phase I trial evaluating the concurrent combination of radiotherapy and capecitabine in rectal cancer. J Clin Oncol 2002;20:3983-3991.

9. Cassidy J, Twelves C, Van CE, Hoff P, Bajetta E, Boyer M, Bugat R, Burger U, Garin A, Graeven U, McKendric J, Maroun J, Marshall J, Osterwalder B, Perez-Manga $G_{9}$ Rosso R, Rougier $P$, Schilsky RL. First-line oral capecitabine therapy in metastatic colorectal cancer: a favorable safety profile compared with intravenous 5-fluorouracil/leucovorin. Ann Oncol 2002;13:566-575.

10. Marijnen CA, Nagtegaal ID, Mulder-Stapel AA, Schrier PI, Van D, V, van Krieken JH, Peltenburg LT. High intrinsic apoptosis, but not radiation-induced apoptosis, predicts better survival in rectal carcinoma patients. Int J Radiat Oncol Biol Phys 2003;57:434-443.

11. Ikeda Y, Ito M, Matsuu M, Shichijo K, Fukuda $\mathbb{E}$, Nakayama T, Nakashima M, Naito S, Sekine I. Expression of ICAM-1 and acute inflammatory cell infiltration in the early phase of radiation colitis in rats. I Radiat Res (Tokyo) 2000;41:279-291.

12. Chiba T, Ohtani H, Mizoi T, Naito Y, Sato E, Nagura H, Ohuchi A, Ohuchi K, Shiiba K, Kurokawa Y, Satoni S. Intraepithelial CD8+ T-cell-count becomes a prognostic tactor after a longer follow-up period in human colorectal carcinoma: possibje association with suppression of micrometastasis. Br J Cancer 2004;9 $₫: 1711-1717$.

13. Abdalla SA, Behzad F, Bsharm $\mathrm{S}$, Kumar $\mathrm{S}$, Amini SK, O'Dwyer $S T$, Haboubi NY. Prognostic relevance of microvessel density in colorectal tumours. Oncol Rep 1999;6:839-842.

14. Bouma-ter Steege JC, Baeten Cl, Thijssen VI, Satijn SA, Verhoeven IC, Hillen HF, Wagstaff J, Griffioen AW. Angiogenic profile of breast carcinoma determines leukocyte infiltration. Clin Cancer Res 2004;10:7171-7178.

15. Dirkx AE, Oude Egbrink MG, Kuijpers MJ, wan der Niet ST, Heijnen VV, Bouma-ter Steege JC, Wagstaff I, Griffioen AW. Tumor angiogenesis modulates leukocyte-vessel wall interactions in vivo by reducing endothelial adhesion molecule expression. Cancer Res 2003;63:2322-2329.

16. Hatlahm D, Kuchibhotla $\mathbb{J}$, Wyole $\mathrm{C}$. Cell adhesion molecules mediate radiation-induced leukocyte adhesion to the wascular endothelium. Cancer Res 1996;56:5150-5155.

17. Wang JM, Kumar S, van AA, Kumat P, Pye D. Hunter RD. Irradiation induces up-regulation of $\mathbb{E} 9$ protein (CD105) in human vascular endothelial cells. Int J Cancer 1995;62:791-796.

18. Walther M, Kaffenberger W, Van BD. Influence of clinically used antioxidants on radiation-induced 
expression of intereellular cell adhesion molecule-1 on HUVEC Int Radiat Biol 1999,75:1317-325.

19. Quamby S, Kumar P, Wang J, Macro JA, Hutchinson J, Hunter RD, Kumar S. Irradiation induees upregulation of CD31 in human endothelial cells. Arterioscler Thromb Vase Biol 1999:19:588-597.

20. Molla M, Panes J, Casadevall M, Salas A, Conil C, Biete A, Anderson DC, Granger DN, Piqum IM: Influence of dose-rate on inflammatory damage and adhesion molecule expression after abdoninal radiation in the rat. Int I Radiat Oncoll Biol Phys 1999;45:1011-1018.

21. Molla M, Gironella M, Miquel R, Tovar V, Engel P, Biete A, Pique JM, Panes $I$. Relative roles of ICAM-1 and VCAM-1 in the pathogenesis of experimental radiation-induced mestinal inflanmation. Int J Radiat Oncol Biol Phys 2003;57:264-273.

22. Kruse JJ, te Poele JA, Russell NS, Boersma LJ; Stewart FA. Microarray analysis to identify molecular mechanisms of radiation-induced microvascular damage in nornal tissues.

Int J Radiat Oncol Biol Phys 2004;58:420-426.

23. Ala A, Dhillon A.P, Hodgson HJ. Role of cell adhesion molecules in leukocyte recruitment in the liver and gut. Int I Exp Pathol 2003;84:1-16.

24. Hallahan DE, Virudachalam $\mathrm{S}$. Intercellular adhesion molecule 1 knockout abrogates radiation indiced pulmonary inflammation. Proc Natl Acad Sci U S A 1997;94:6432-6437.

25. Martinez L, 1. [Proctitis due to irradiation.]. Rev Med Chil 1952;80:429-430.

26. Buell MG, Harding RK. Proinflammatory effects of local abdominal irradiation on rat gastrointestinal tract. Dig Dis Sci 1989;34:390-399.

27. Sedgwick DM, Ferguson A. Dose-response studies of depletion and repopulation of rat intestinal mucosal mast cells after irradiation. Int J Radiat Biol 1994;65:483-495.

28. De VA, Holzberger $P$, Kunc $M$, Hengster P. Influence of irradiation on neutrophilitic granulocyte function. Cancer 2001;92:2444-2450.

29. Baeten Cl, Wagstaff $J$, Verhoeven $I^{C}$, Hillen HF, Griffioen AW. Flow cytometric quantilication of tumour endothelial cells; an objective alternative for microvessel density assessment.

Br J Cancer 2002;87:344-347.

30. Reis Neto JA, Quilici FA, Cordeiro F, Ciquini S, Reis JA, Jr. Pre-operative radiotherapy in rectal cancer: evaluation of irradiation effects on cellular undifferentiation and its infuence on prognosis. Hepatogastroenterology 1999;46:2825-2830.

31. Withers $H R$, Haustermans $\mathrm{K}$. Where next with preoperative radiation therapy for rectal cancer? Int J Radiat Oncol Biol Phys 2004;58:597-602.

32. Johansson $M$, Bergenheim AT, Widmark A, Henriksson R. Effects of radiotherapy and estramustine

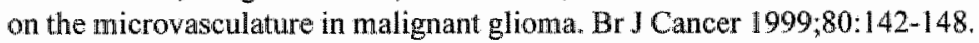

33. Korff T, Kimmina S, Martiny-Baron G, Augustin HG. Blood vessel maturation in a 3-dimensional spheroidal coculture model: direct contact with smooth muscle cells regulates endothelial cell quiescence and abrogates VEGF responsiveness. FASEB $\| 2001 ; 15: 447-457$.

34. Hurwitz $H$, Fehrenbacher $\mathrm{L}$, Nowotny $\mathrm{W}$, Cartwright T, Hainsworth $\mathrm{J}$, Heim W, Berlin $I$, Baron $A$, Griffing S, Holmgren E, Ferrara N, Fyfe $G$, Rogers $B$, Ross $R$, Kabbinavar $F$. Bevacizumab plus irinotecan, fluorouracil and leucovorin for metastatic colorectal sancer.

N Engl J Med 2004;350:2335-2342.

35. Kabbinavar FF, Hambleton J, Mass RD, Hurwitz HI, Bergslland E, Sarkar S. Combind Analysis of Efficacy: The Addition of Bewacizumab to Fhorouracil/Leucovorin Improves Survival for Patients With Metastatic Colorectal Cancer. J Clin Oncol 2005.

36. Haraldsen $G$, Kvale D, Lien B, Farstad $N$, Brandtzaeg P. Cytokine-regulated expression of $\mathrm{E}-$ selectin, intercellular adhesion molecule-1 (ICAM-1), and vascular cell adhesion molecule-1 (VCAM-1) in human microvascular endothelial cells. J Immunol 1996;156:2558-2565.

37. Gaugler $M H$, Squiban $C$, van der MA, Bertho JM, Vandamme M, Mouthon MA Late and persistent up-regulation of intercellular adhesion moleculte-1 (ICAM-1) expression by ionizing radiation in human endothelial cells in witro. Int J Radiat Biol 1997;72:201-209.

38. ten KM, Hofland LJ, van Grevenstein WM, wan Koetsweld PV, Jeekel J, wan Eijck CH. Influence of proinflammatory cytokines on the adhesion of thuman colon carcinoma cells to lung microvasculan" endothelium. Int J Cancer 2004;112:943-950. 
39. Kiani MF, Yuan 1 , Chen $X$, Smith $L_{\text {; }}$ Gaber MW, Goetz DJ. Targeting microparticles to select tissue via radiation-induced upregulation of endothelial cell adhesion molecules. Pharm Res 2002;19:13171322 .

40. Prabhakarpandian $\mathrm{B}_{\mathrm{s}}$ Goetz DJ, Swerlick RA, Chen X, Kiani MF. Expression and functional significance of adhesion molecules on cultured endothelial cells in response to ionizing radiation. Microcirculation $2001 ; 8: 355-364$.

41. Panes I. Anderson DC, Myasaka M, Granger DN, Role of leukocyte-endothelial cell adhesion in radiation-induced microvascular dysfunction in rats Gastroenterology 1995;108:1761-1769.

42. Clark WM, Lauten ID, Lessov N, Woodward W, Coull BM. Time course of ICAM-I expression and leukocyte subset infiltration in rat forebrain ischemia. Mol Chem Neuropathol 1995;26:213-230.

43. Nakano O, Sato M, Naito Y, Suzuki K, Orikasa S, Aizawa M, Suzuki Y, Shintaku I, Nagura H, Ohtan H. Prollferative activity of intratumoral CD $8(+)$ T-lymphocytes as a prognositic factor in human renal cell carcinoma: clinicopathologic demonstration of antitumor immunity. Cancer Res $2001 ; 61: 5132-5136$.

44. Funada $Y$, Noguchi T, Kikuchi R, Takeno S, Uchida Y, Gabbert HE. Prognostic significance of CD8t T cell and macrophage peritumoral infiltration in colorectal cancer. Oncol Rep 2003;10:309-313.

45. Golby $\mathrm{SJ}_{\text {; }}$ Chinyama $\mathrm{C}$, Spencer J. Proliferation of T-cell subsets that contact tumour cells in colorectal cancer. Clin Exp Immunol 2002;127:85-91. 
Influences of radiotherapy in colorectal cancer

87 


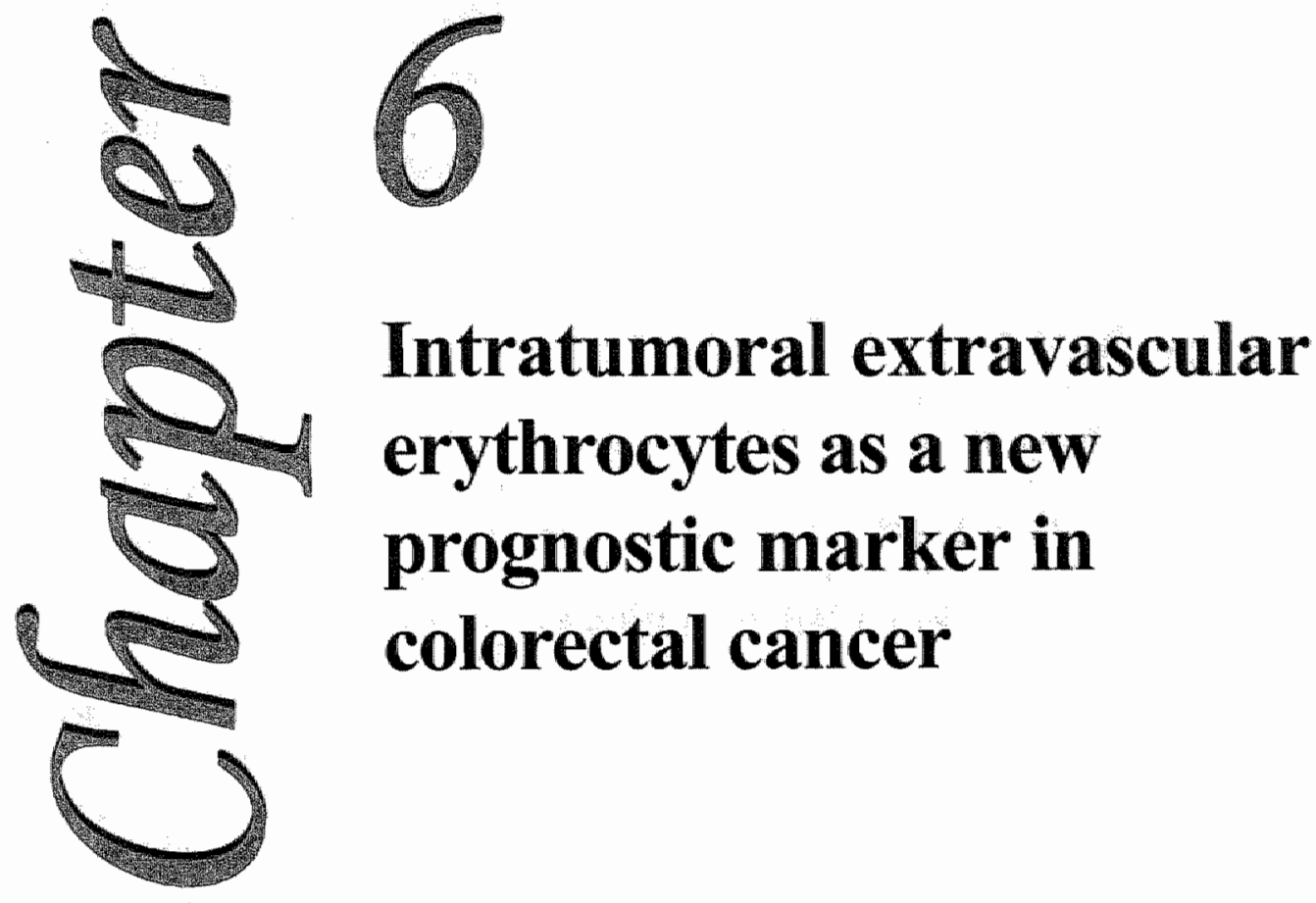

C.I.M. Baeten, D.W.J vd Schaft, F. Hillen, P. Pauwels, A.P. de Bruine, C.G.M.I. Baeten, H.F.P. Hillen, A.W. Griffioen

Submitted for publication

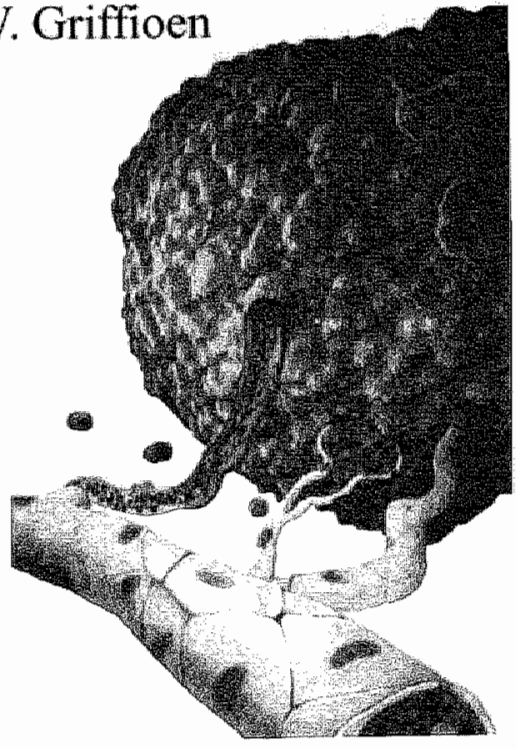




\section{Abstract}

\section{Background}

Angiogenesis has been associated with tumor progression in many tumor types. In many cases microvessel density is not correlated to clinical outcome. We investigated the presence of intratumoral extravasated erythrocytes and their relationship to tumor vasculature in colorectal cancer.

\section{Methods}

The study included 117 colorectal carcinoma (CRC) patients, with a 12 year follow up. Paraffin embedded tissues were used for detection of intratumoral extravasated erythrocytes and immuno-histochemical analysis of microvessel density and proliferating endothelial cells. Cell cultures with 7 colon cell lines, qRT-PCR on cell lines, frozen tissue material and fresh colorectal cancer tissue were used to investigate the relationship between intratumoral extravascular erythrocytes (IEE) and tumor cell plasticity in colorectal carcinomas.

\section{Results}

Micro vessel density (MVD) was not a prognostic marker in the colorectal cancer patients examined. In some $(\%)$ of the tissues we found intratumoral extravascular erythrocytes. The presence of these erythrocytes did predict patient outcome in the total patient group and within the Dukes B and C patients. Cell culture experiments and RT-PCR show tumor cells plasticity of the colon tumor samples that have intratumoral extravascular erythrocytes.

\section{Conclusions}

In this paper we describe the presence of intratumoral extravascular erythrocytes in colorectal cancer. Patients with a Dukes B and C stage of CRC disease can be divided into a group with either good or poor prognosis, depending on the presence of these intratumoral extravasular erythrocytes. 


\section{Introduction}

Due to the localization and the late occurrence of symptoms, colorectal carcinomas (CRC) are often diagnosed in a more advanced clinical stage. The main predictor to outcome is the stage of disease using the Dukes' Classification at time of diagnosis. The clinical outcome of early and advanced stages of $C R C$, respectively Dukes $A$ and $D$, can be predicted reliably. However, there is a large variety of clinical outcome of Dukes B and $\mathrm{C}$ stages of CRC. After potentially curative surgical excision, respectively $60-85 \%$ and $25-65 \%$ of patients have a 5 year survival in Dukes B and in Dukes $C(1 ; 2)$. Alternatives to improve prognostics in colorectal cancer such as molecular predictors $(3 ; 4)$ are still not conclusive to determine between aggressive and non-aggressive Dukes $\mathrm{B}$ and $\mathrm{C}$ stage CRC. Therefore there is a need for more specific and more sensitive prognostic markers.

Angiogenesis, the formation of new blood vessels via sprouting of existing capillaries, is a process of major importance in tumor progression. Because of a diffusion limit, a tumor cannot grow larger than approximately $2 \mathrm{~mm}$ in diameter without new blood vessel formation (5). Until recently, microvessel density (MVD) has been the golden standard for angiogenesis measurement in tumor tissues. In numerous studies a high MVD has been shown to relate to a shorter survival $(6 ; 7)$. However there are also reports showing no correlation or even an opposite correlation between MVD in the tumor and patient survival $(8 ; 9)$.

In addition to the use of regular blood vessels for circulation it has been suggested that tumors can also form a circulation independent of angiogenesis. This is termed vasculogenic mimicry (VM). VM was initially described in melanomas (10) and is caused by tumor cell plasticity and restricted to aggressive and highly metastatic tumors (11). In the current study we observed that in CRC tissues areas occur with blood lakes or pools of extravasated erythrocytes. We demonstrate that these areas strongly predict clinical outcome. In addition we suggest that mechanisms of tumor cell plasticity and dedifferentiation are causally related to the observed phenomenon. 


\section{Materials and Methods}

\section{Patients}

All samples used for these studies concern archival material from the Dept. of Pathology of the University Hospital Maastricht and were made available following the guidelines for additional usage of encoded remnant patient material, as is formulated in the Code of the Dutch Federation of Medical Scientific Societies and with permission of the Medical Ethical Committee of the University Hospital/University Maastricht. Colorectal adenocarcinomas from 117 patients were used in this study. This representative group of patients had been part of two multicentre prospective clinical trials to study "no touch" surgical removal ( 96 patients) and preoperative radiotherapy (21 patients, 10 of whom received preoperative radiotherapy) between 1979 and 1981 (12;13). In these trials no postoperative adjuvant treatment was applied. Cross-sections through the centre of the tumor were sampled and clinical data were collected during a 12 years follow up. None of the patients received post-operative treatment. In our study 59 men and 58 women were included, the median age at time of diagnose was 70 years (Range, 29 to 87), the median survival was 4.5 years (range 0.1 to 12.00 ). Two patients presented with Dukes A, 72 patients with Dukes B, 32 patients with Dukes $C$ and 11 patients with Dukes D stage. The average tumor size was $46.44 \mathrm{~mm}$ ( $\mathrm{SD} \pm 22.27$ ). The primary $\mathrm{CRC}$ location of 113 tumors was known; 18 tumors were located in the ascending colon, 16 in the colon transversum, 32 in the descending colon, 47 in the rectosigmoid. 79 patients had died during the 12 years of follow-up of whom 49 patients due to metastasis (mean survival 2.69 years). For RNA isolation we selected frozen material from 8 additional CRC tissues (on base of no pre-treatment) between 2002 and 2004. Beside tumor tissue we also collected normal mucosa of these CRC patients. For the specific isolation of either tumor cells or endothelial cells, to compare gene expression patterns, we used fresh tissue material of two patients.

\section{Immunohistochemistry}

Serial sections, $4 \mu \mathrm{m}$, were made from the selected paraffin embedded colon bank. The sections were double stained for the endothelial markers CD31 and CD34 and Ki-67 as a proliferation marker. In short, the sections were deparafinized, rehydrated and blocked in $0,3 \% \mathrm{H} 2 \mathrm{O} 2$ in methanol. Subsequently sections were cooked for 10 minutes in citrate buffer ( $\mathrm{pH} 6.0$ ) and blocked with 5\% BSA in PBS. The sections were then incubated for 1 hour at RT with an antibody for human Ki67 (1:200 dilution, NeoMakers, Freemont, CA.), which was followed by a biotin labelled Swine anti-Rabbit IgG (DAKO, Glostrup, Denmark), followed by HRP labelled avidine-biotin complex (DAKO). Subsequently tissues were incubated with diaminobenzidine (Sigma, Zwijndrecht, the Netherlands). After this first staining a cocktail of second primary antibodies against endothelial cells (anti-CD31 1:100, DAKO and anti-CD34 1:50, Monosan, Uden, The Netherlands) was applied to the sections. These primary antibodies were followed by a secondary step with biotin labelled Goat anti-Mouse IgG (DAKO, Glostrup, Denmark) and avidine-biotin 
complex AP (DAKO). The bound antibody was visualized by blue alkalic phosphatase substrate KIT III (Vector Laboraties inc., Burlingame, CA). After covering the slides with imsol mount (Klinipath, Duiven, Netherlands) the slides were mounted in entellan (Merck, Darmstadt, Germany).

The number of vessels was measured at $200 \mathrm{x}$ magnification in 3 random areas of 0.22 $\mathrm{mm}^{2}$ (Zeiss, Germany). In a small number of cases we observed pools of erythrocytes in tumor tissue without an endothelial lining and without any form of glandular formation by the tumor cells. This phenomenon was, to our opinion, best described as intratumoral extravascular erythrocytes (IEE). The criteria were defined by a pathologist (PP). The H\&E stained sections and the adjacent sections stained for endothelial cells were scored for IEE by 3 independent observers (a pathologist (AdB), the principle investigator (CB) and a molecular biologists (DvdS), blinded for clinical data and other results).

\section{Frozen and fresh CRC tissue preparation}

To detect differences in gene expression between CRC showing IEE and CRC without IEE, we selected 30 patients of whom frozen material was available. Four of these additional patients presented IEE, which were used as the IEE+- patients and we randomly selected 4 IEE- patients. The gene expression of the normal mucosa as well as the tumor tissue of these patients was analysed.

For the analysis of gene expression in cell populations two fresh IEE $+\mathrm{CRC}$ tissues were used. Single cell suspensions were generated by incubation with collagenase/dispase $5 \%$ in PBS at $37^{\circ} \mathrm{C}$ for 30 minutes in the presence of DNase $(1 \mathrm{mg} / \mathrm{ml})$. The cell suspension was subsequently filtered through a nylon filter, resuspended and put on a ficoll plaque (Amersham Biosciences $\mathrm{AB}$, Sweden), followed by cenrigugation at $400 \times \mathrm{g}$. The single cell suspension was subsequently incubated with CD31 and CD34 antibody dilutions for 1 hour, followed by incubation with anti-Mouse labelled dynabeads (Dynal biotech, Oslo, Norway). After shifting the endothelial cells from the tumor suspension with a magnet, both suspensions were (after immunohistochemical control, using a cytospin and DAB staining) used for RNA isolation.

\section{Cell cultures and $3 D$ culture}

We used 7 colon carcinoma cell lines: HT29, CaCo2, SW480, SW742, HCT116, RKO, HCA-7 and four mellanoma cells lines C8161, C81-61, MUM2-B and MUM2-C. Of each cell line $3 \times 10^{4}$ cells were seeded on a rat tail collagen coated 96-well plate, each day medium (DMEM/RPMI- 1640 with $10 \% \mathrm{FSC}$ and $1 \%$ Glutamine) was replaced and after 8 days photographs were taken.

\section{RNA isolation and CDNA synthesis}

Total RNA from cell lines, tissues or cell suspensions was isolated using the RNeasy RNA isolation kit (Qiagen, Venlo, The Netherlands) according to the supplier's protocol. Possible genomic DNA contaminations were removed by DNase treatment with the RNase-free DNase set (Qiagen). The purity and integrity of the RNA was checked on Nanodrop and by gel electrophoresis according to standard procedures. RNA was reverse 
transcribed with M-MLV reverse transcriptase (Promega, Leiden, The Netherlands) according to standard procedures: Following inactivation of the reverse transcriptase activity cDNA was stored at $-20^{\circ} \mathrm{C}$.

$P C R$ and $q R T-P C R$

Semi-quantitative PCR was perfomed for the genes b-actin, the tyrosine kinase Tie-1, Tissue factor pathway inhibitor (TFPI)-1 and -2, EphA2 and laminin 5 gamma2 (LAMC2) (13). The genes were amplicied 30 cycles. The PCR products were analysed by electrophoresis on a $1.5 \%$ agarose gel.

Quantitative real-time PCR ( $q R T$-PCR) was performed on an ABI PRISM 7700 Sequence Detection System apparatus (Applied Biosystems). SYBR Green master mix (Applied Biosystems) was used in admission of $40 \mathrm{ng} \mathrm{cDNA}$ and $800 \mathrm{nM}$ of forward and reverse primer sets. The expression of each target gene was normalized to the housekeeping gene b-actin.

\section{Statistical analysis}

We used the student T-test to determine differences between MVD, angiogenesis compared with Dukes stage and differentiation stage and differences between IEE+ CRC and IEE- CRC. Kaplan-Meier survival curves and Log Rank tests were used for survival analyses. The qRT-PCR data were analysed using the Mann-Whitney test.

All calculations were performed using SPSS (version 11) and all P-values $<0.05$ were considered statistically significant. 

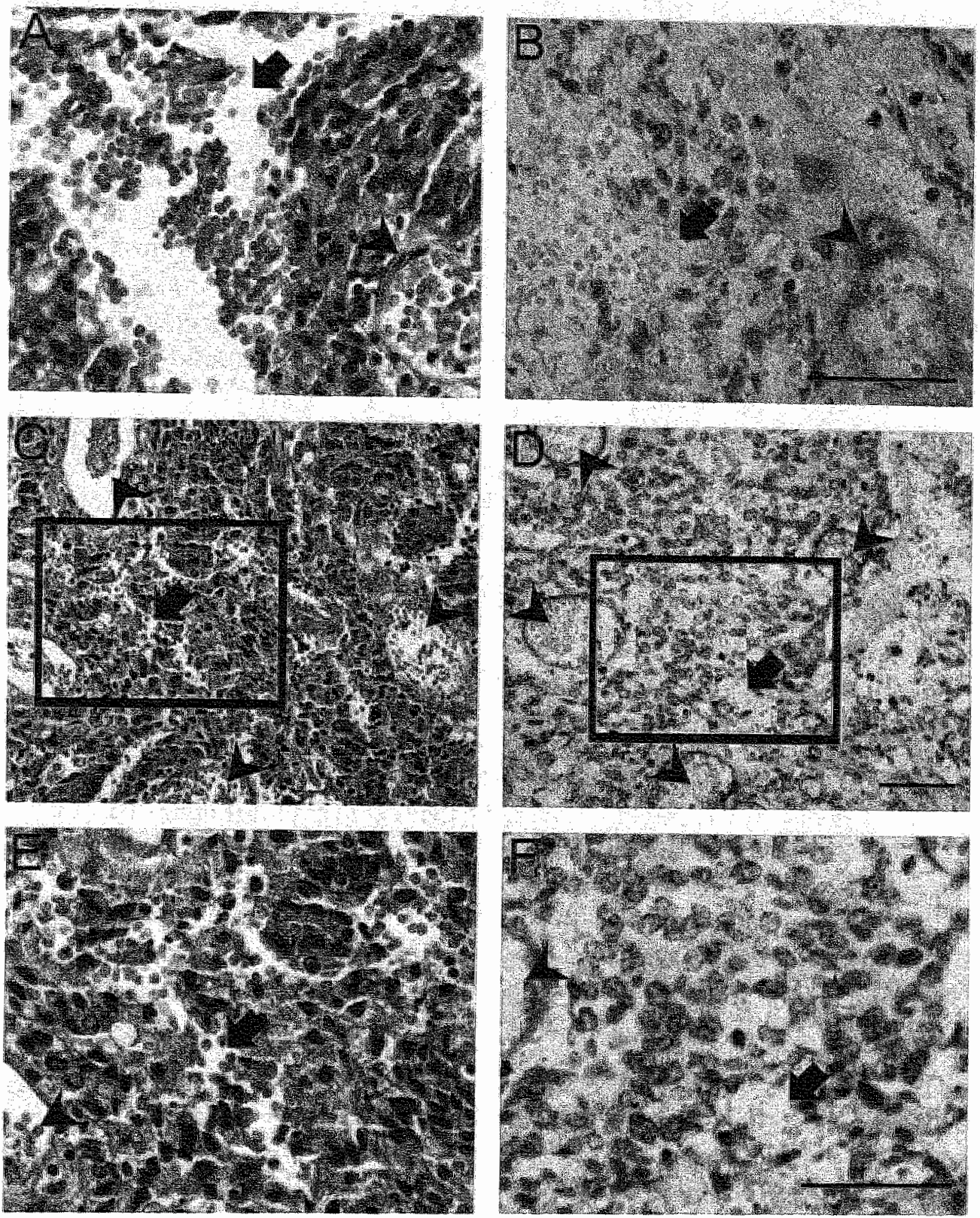

Figure 1.

Next to regular endothelial cell lined blood vessels intratumoral extravascular erythrocyes (IEE) are observed in $C R C$.

H\&E stained colon tumor sections with IEE (A, C and E and) and the Ki-67 (DAB) double stained with CD31/CD34 alkaline phosphatase blue adjacent tissue sections (B, D and F). Magnification of 200x and panels $400 \times$ (bar represents $100 \mathrm{im}$ ). Regular bload vessels are marked by arrowheads and IEE are identified by arrows. 


\section{Results}

Colorectal carcinomas contain areas of intratumoral extravascular erythrocytes. In 23 out of 117 tumor tissues of patients with colorectal carcinoma (CRC) areas were observed with extravascular erythrocytes in between or in direct contact with tumor cells, not lined by endothelial cells and without any signs of coagulation ( 3 independent observers, Kappa $0.884, p<0.001$, Figure 1). This phenomenon occurred mostly in central parts of the tumor. It was excluded that the presence of intratumoral extravascular erythrocytes (IEE) was due to bleeding caused by the surgical procedure, because 96 tissues were from patients that were entered in a clinical trial to study the beneficial effect of no-touch surgery (12), and 21 tissues were from patients that were entered in a preoperative radiotherapy trial (13). Since a minor subgroup of the patients (10 patients) received preoperative radiotherapy, we analyzed whether the results of this subgroup biased the overall data. We were able to exclude a bias of the data (not shown). The absence of coagulation also indicated that the extravasation was not caused by trauma or surgery.

Interestingly, the presence of IEE was strongly correlated to Dukes stage. While in the Dukes A patient group this phenomenon was absent, in the Dukes B staged patients 5 out of $72(6.8 \%)$, in the Dukes C staged patients 9 out of $32(28.1 \%)$ and in the Dukes D staged patients 9 out of $11(81.8 \%)$ showed erythrocyte extravasation. When investigating the relationship of this phenomenon with survival we observed that, in the complete group of $117 \mathrm{CRC}$ patients, the 5 -year survival was $40 \%$ in patients without extravasation compared to $0 \%$ survival in patients with erythrocyte extravasation (Figure 2B). Moreover, even within the groups of Dukes $\mathrm{B}$ and $\mathrm{C}$ staged tumors, the presence of extravasated erythrocytes strongly predicted an unfavourable prognosis (Figure $2 \mathrm{C}$ and $2 \mathrm{D}$ ). No significant correlations were found with age, tumor location, tumor size and sex. Furthermore, in this patient group of 117 patients we did not find a significant correlation between MVD and survival (Figure 2A). When investigating the relationship between IEE and MVD we did not find a higher overall MVD in the IEE + CRC as compared with IEE- CRC. Though within the IEE+ areas of the IEE+ tumor significantly lower MVD (bloodvessels $/ \mathrm{mm}^{2} 41.24$ (SDEV 14.65)) were found $(\mathrm{p}<0.05)$ than in the IEE- areas of these IEE+ tumors (bloodvessels $/ \mathrm{mm}^{2} 60.93$ (SDEV 17.37)).

Evidence for tumor cell plasticity in colorectal cancer; explanation for the presence of IEE

In melanoma it has been demonstrated that tumor cells can dedifferentiate to highly aggressive cells that can express markers usually expressed by other cell types, e.g. endothelial markers such as Tie-1, EphA2, LamC2 and anti-coagulant molecules, such as tissue factor pathway inhibitors (TFPIs) $(10 ; 14)$. This tumor cell plasticity in melanoma was demonstrated to result in vascular-like structures, also referred to as vasculogenic 

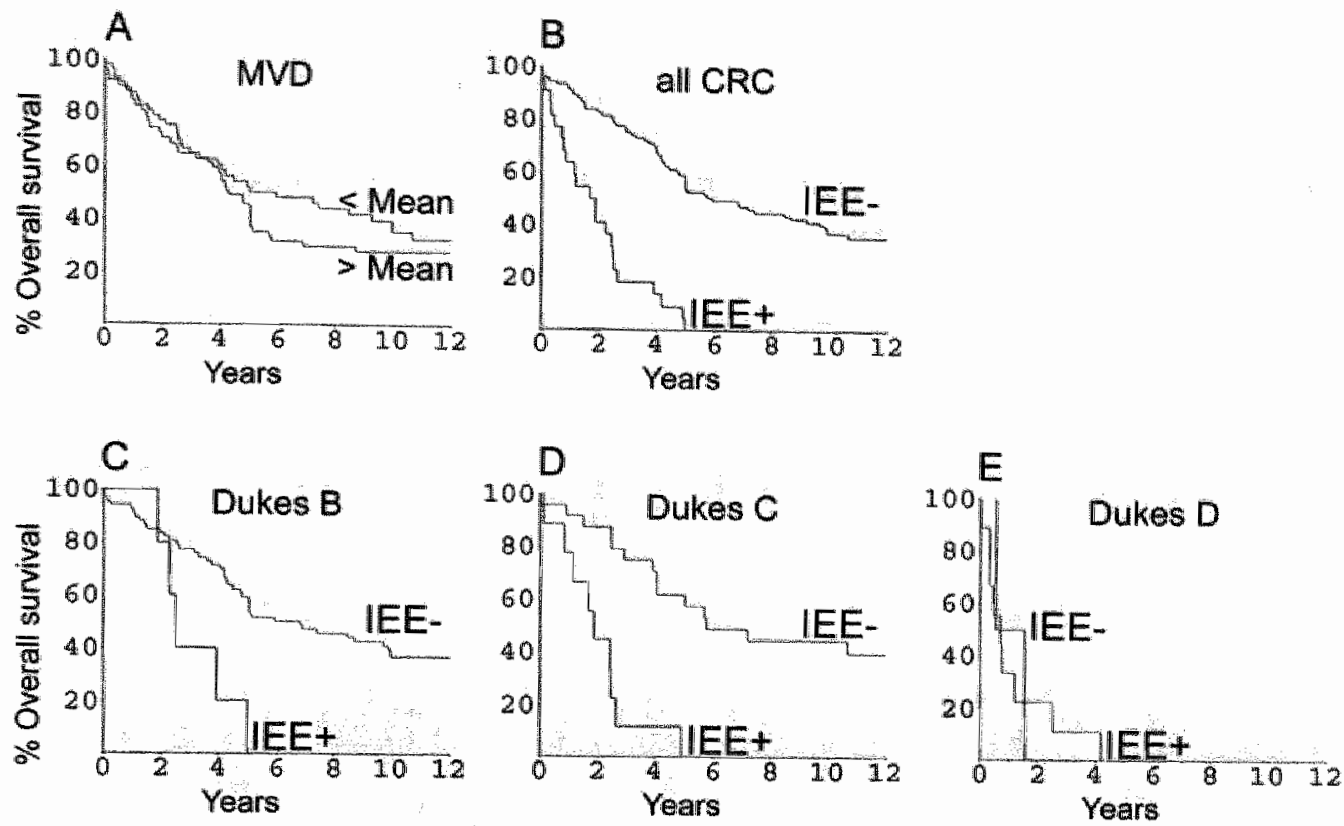

$\mathrm{F}$

\begin{tabular}{|c|c|c|c|c|c|c|c|c|}
\hline Dukes & \multicolumn{2}{|c|}{ A } & \multicolumn{2}{|c|}{ B } & \multicolumn{2}{|c|}{$\mathrm{C}$} & \multicolumn{2}{|c|}{ D } \\
\hline & $\begin{array}{l}\text { \# } \\
\text { Patients }\end{array}$ & $\begin{array}{l}\text { Mean } \\
\text { Sunvival }\end{array}$ & $\begin{array}{l}* \\
\text { Patients }\end{array}$ & $\begin{array}{l}\text { Mean } \\
\text { Survival }\end{array}$ & Patients & $\begin{array}{l}\text { Mean } \\
\text { Survival }\end{array}$ & Patients & $\begin{array}{l}\text { Mean } \\
\text { Survival }\end{array}$ \\
\hline IEE+ & 0 & N.A. & 5 & 2,35 & 0 & 1.96 & 9 & 1,04 \\
\hline IEE. & 2 & $9.14^{5}$ & 68 & 6.72 & 23 & 6,45 & 2 & 1,16 \\
\hline
\end{tabular}

N.A. Not applicable

Mothen overall survival in years

\section{Figure 2.}

Relationship between MVD or IEE and patient survival in CRC.

The survival curves for the total group of patients divided by higher than mean MVD or lower than mean MVD are shown in A (Log Rank; $p=0,5156$ ). B represents the survival for all CRC patients with or without IEE (Log Rank $p<0,0001$ ). The Kaplan Meier survival curves of Dukes B, C and D patients for IEE+ or IEE- patients are presented in Figure C, D and E. (Log Rank tests respectively: Dukes B; $p=0,0277$, Dukes $C ; p<0,0001$ and Dukes $D_{;} p=0,9431$ ). Figure $F$ shows a table with comparison for the Dukes stages, concerning the number of patients and mean overall survival in years for $\mathrm{CE} \mathrm{E}+$ and IEE- tumors. 
mimicry. Such vascular structures are not lined by endothelial cells, but are lined by tumor cells or an extracellular matrix derived from these tumor cells.

To investigate whether the aggressive behaviour of the small subgroup of $\mathrm{CRC}$ could be attributed to tumor cell plasticity as was observed in melanoma, 4 frozen tumor tissue samples with and 4 without IEE and their normal mucosa were selected to analyse above mentioned genes (Figure 3A). Ephrin A2 (EphA2) and laminin C2 (LAMC2) wrere also significantly overexpressed in IEE+ colon cancer tissues as compared to IEE- tumors and normal mucosa's $(p<0.014)$. In order to investigate whether the measured gene expression was not due to expression levels in the endothelial cells, tumor cells and endothelial cells were separated by magnetic sorting and the expression levels of the genes in the subpopullations were compared. The tumor cells as well as the endothelial
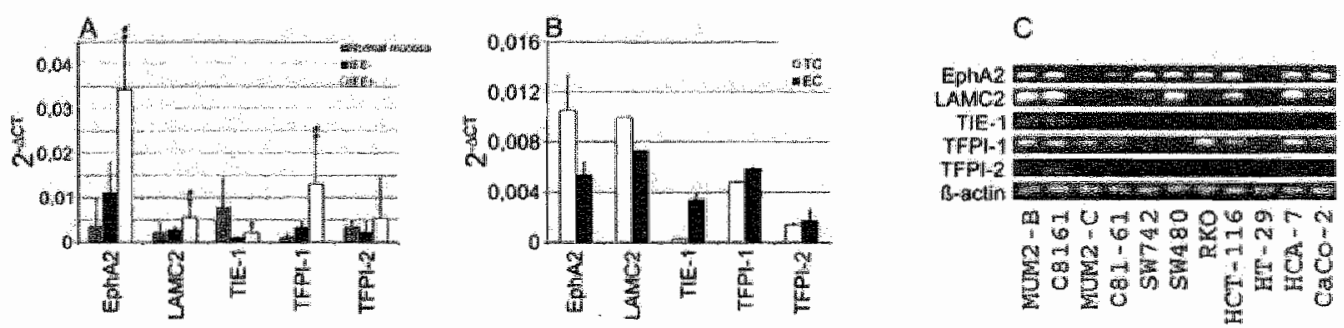

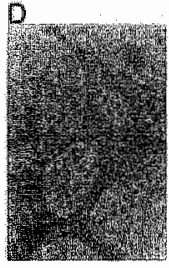

$\mathrm{CaCo}-2$

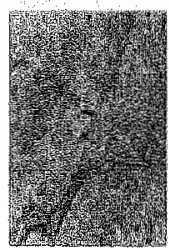

HCA-7

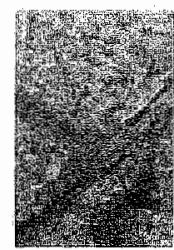

SW-742

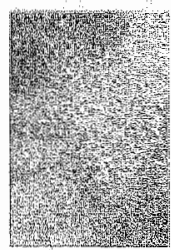

HT-29

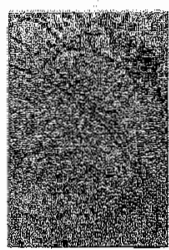

Mum 2B

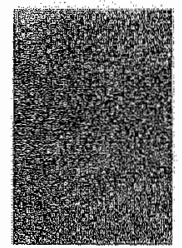

Mum 2C

\section{Figure 3.}

Tumor cell plasticty in $C R C$; explanation for $I E E$.

Figure A shows the relative gene expression of EPHA2, LAM2C Tie-1, TFPI -1 and TFPI-2 corrigated for betamactin expression in normal mucosa $(\mathrm{N}=8), \mathrm{VEE}-\mathrm{CRC}(\mathrm{N}=4)$ and IEE+ CRC $(\mathrm{N}=4)$. 样 indicates a significant difference between IEE $+\mathrm{CRC}$ and normal mucosa $(\mathrm{p}<0.05 \%$.

- indicates a significant difference between IEE + and IEE- CRC $(\mathrm{p}<0.05)$. The gene expression of these genes was also examined using qRT-PCR in isolations of tumor cells (TC) and endothelial cells (EC) from 2 fresh IEE+ colon tissues (B). The expression of these same genes was also examined using semi-quantitative PCR in 7 colon cell lines (SW-742, SW-480, CaCo-2, HCA-7, RKO, HT-29 and HCT-116) and 4 Melanoma cell lines (MUM2-B, MUM2-C, $\mathrm{C} 8161$ and $\mathrm{C} 81-61$ ). The MUM2-B and $\mathrm{C} 8161$ represent positive control cell lines and MUM2-C and C8 $1-61$ represent negative control cell lines. Tube formation by colon cancer cell lines was examined on 3D cultures (Figure D). 
cells expressed the genes of interest (Figure 3B), with higher expression levels of EphA2 and LAMC2 in the tumor cells.

Since we found overexpression of EphA2 and LAMC2, both molecules known to be of major importance for the tube formatting capacity of the melanoma tumor cells (10), we studied the expression of these molecules in the colon cancer cell lines RKO, SW742, SW480, CaCo-2, HCA-7, HT-29 and HCT116. EphA2, and LAMC2 were found to be expressed in SW742, SW480, HCT-116, HCA-7, RKO and CaCo-2, but not in HT29. Interestingly this correlated with tube forming capacity on $3 \mathrm{D}$ collagen matrix in vitro, confirmed by melanoma cell lines (Figure 3D-1). One celline, RKO, expressed low levels of LAMC2 and was found to have an intermediate activity at the level of tube formation. Similar to what was described in melanoma, we also observed the overexpression of tissue factor pathway inhibitors (TFPI) -1 and -2 in both IEE+ tumor tissues and in tube forming tumor cell lines, explaining the lack of coagulation activity. 


\section{Discussion}

The most reliable prognostic factor to date in CRC is the staging of the disease according to Dukes classification at the time of diagnosils. Dukes' stages include stage A through $\mathrm{D}$. The clinical course and the survival of Dukes stages B and C, however, may vary considerably. Currently, the large patient group with Dukes B staged tumors, does not receive additional treatment, although a recurrence rate of $20 \%$ exists. For this reason there is a great need for further discrimination of aggressive tumors within Dukes B tumors. Immunohistochemical approaches and gene profiling of colon carcinomas, so far, have not identified appropriate additional prognostic markers. In the current study, also microvessel density, a parameter that presumably reflects angiogenic potential, was not found to be correlated to cancer progression or patient survival in these colorectal cancer patients. We have observed areas of intratumoral extravasated erythrocytes (IEE). Intriguingly, we did find the presence of IEE to correlate significantly to patient survival in CRC. It might be argued that the presence of IEE in these sections is a result of mechanical damage. However, the patient material was obtained from "no touch" surgically removed tumors (12). Furthermore, if the extravascular blood is the result of vascular damage, signs of coagulation would have been expected. We did not observe any coagulation or thrombus formation in the areas of IEE. Moreover, even within the group of Dukes B staged tumors, a marked difference in survival was observed between IEE+ and IEE- tumors.

While discussing on the underlying mechanism behind the presence of IEE in tumors, it was realized that Maniotis et al. presented data on the occurrence of what they termed vasculogenic mimicry in melanomas (10). A similar process was also described in carcinomas such as breast- and ovarian carcinoma $(16 ; 17)$. These studies described that due to plasticity and dedifferentiation of tumor cells, characteristics and a genetic profile of endothelial cells can be obtained, resulting in the formation of vascular-like tubes. In support of these results, we have recently published that the blood lakes, characteristic of Ewing sarcoma, are an exacerbation of this phenomenon (14). The areas of IEE in CRC do not resemble the vascular-like tube formation as observed in melanoma or breast cancer. They do not show periodic acid Schiff's reagent (PAS) positive patterns as observed in melanoma (10) and do not show the regular shape of the blood lakes as observed in breast cancer and Ewing sarcoma. However, the overlapping gene profiles between the CRC and melanoma/Ewing sarcoma cells (i.e. LAMC2, EphA2 and TFPIs) show great similarity. We therefore favor the view that the IEE as observed in CRC is induced by a similar phenomenon as in melanoma/Ewing sarcoma, based on plasticity of tumor cells and dedifferentiation to a more aggressive phenotype.

In conclusion, the presence of IEE in $\mathrm{CRC}$ is demonstrated to be a strong prognostic factor, also for patients with Dukes B and C staged tumors.

\section{Acknowledgements:}

Prof. Dr. T. Wiggers (founder of CRC bank) 


\section{References}

1. Greene F, Page D, Fleming I et al. AJCC Cancer Staging Manual. 6th ed. ed. 2002.

2. Hermanek P. pTNM and residual tumor classifications: problens of assessment and prognostic significance. World J Surg 1995; 19(2): 184-190.

3. McLeod HL, Murray GI. Tumour markers of prognosis in colorectal cancer. Br J Cancer. 1999; $79(2): 191-203$.

4. Graziano F, Cascinu S. Prognostio molecular markers for planning adjuvant chemotherapy trials in Dukes' B colorectal cancer patients: how much evidence is enough?

Ann Oncol 2003; 14(7):1026-1038.

5. Folkman I. What is the evidence that tumors are angiogenesis dependent?

INatl Cancer Inst 1990; 82(1):4-6.

6. Weidner $N$, Folkman J. Tumoral vascularity as a prognostic factor in cancer. Important Adv Oncol 1996;167-190.

7. Choi HJ, Hyun MS, Jung GJ, Kim SS, Hong SH. Tumor angiogenesis as a prognostic predictor in colorectal carcinoma with special reference to mode of metastasis and recurrence. Oncology $1998 ; 55(6): 575-581$.

8. Hillen HF, Hak LE, Joosten-Achjanie SR, Arends. JW. Microvessel density in unktown primary tumors. Int J Cancer 1997; 74(1):81-85.

9. Bossi P, Viale G, Lee AK, Alfano R, Coggi G, Bosari S. Angiogenesis in colorectal tumors: microvessel quantitation in adenomas and carcinomas with clinicopathological correlations. Cancer Res 1995; 55(21):5049-5053.

10. Maniotis AJ, Folberg $R$, Hess $A$ et al. Vascular channel formation by human melanoma cells in vivo and in vitro: vasculogenic mimicry. Am J Pathol 1999; 155(3):739-752.

11. Folberg R, Hendrix MJ, Maniotis AJ. Vasculogenic mimicry and tumor angiogenesis. Am J Pathol 2000; 156(2):361-381.

12. Wiggers $\mathrm{T}$, Jeekel $\mathrm{J}$, Arends JW et al. No-touch isolation technique in colon cancer: a controlled

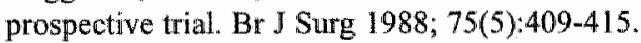

13. de Bruine AP, Wiggers T, Beek $C$ et al. Endocrine cells in colorectal adenocarcinomas: incidence, hormone profile and prognostic relevance. Int J Cancer 1993; 54(5):765-771.

14. Van der Schaft DWJ, Hillen. F, Pawwels $P$ et al. Tumor cell plasticity in Ewing sarcoma; an alternative circulatory system stimulated by hypoxia. Cancer Res. In press.

15. Sharma N, Seftor RE, Seftor EA et al. Prostatic tumor cell plasticity involves cooperative interactions of distinct phenotypic subpopulations: role in vasculogenic mimiery. Prostate 2002; 50(3):189-201.

16. Shirakawa $\mathrm{K}$, Wakasugi $\mathrm{H}_{3}$ Heike $\mathrm{Y}$ et al . Vasculogenic mimicry and pseudo-comedo formation in breast cancer. Int J Cancer 2002; 99(6):821-828.

17. Sood AK, Sefior EA, Fletcher MS et ad. Molecular determinants of ovarian cancer plasticity. Am J Pathol 2001; 158(4):1279-1288. 


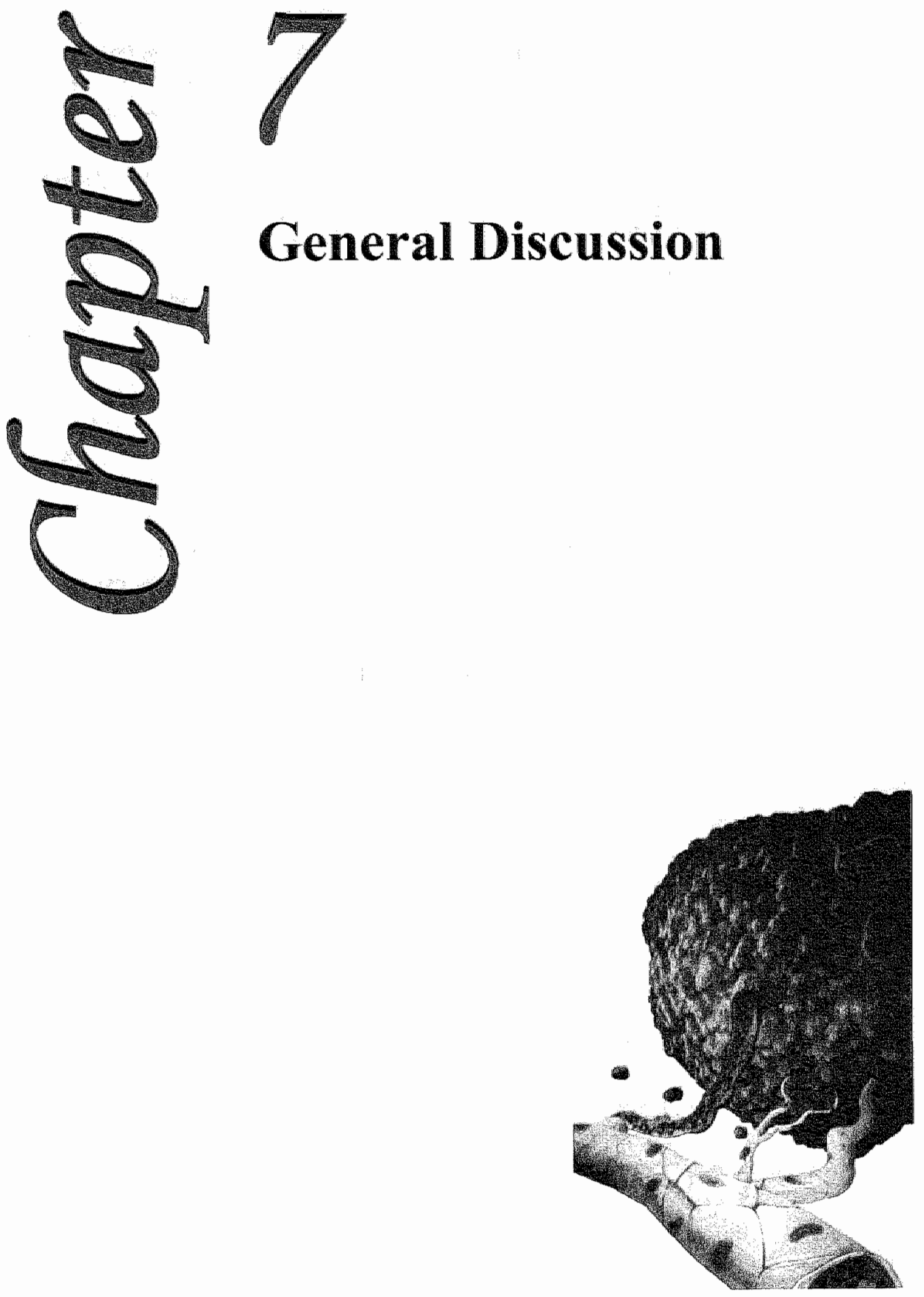




\section{General discussion}

Since 1966 it is known that angiogenesis is crucial for tumor growth and development ${ }^{1}$ and that angiogenesis leads to a significant decrease in survival ${ }^{2}$. We are interested in the pathofysiological and chemical relevance of angiogenesis. Infiltration of leukocytes in the tumor is also known to have a better prognostic outcome ${ }^{3}$. From literature we know there is a strong relationship between angiogenesis and leukocyte infiltration "; therefore we studied several aspects of angiogenesis and angiogenesis related leukocyte infiltration in cancer tissues.

The definition of angiogenesis "development of blood vessels from already existing bloodvessels" is clear. However, measurement of these newly formed vessels has been shown to be difficult in practice. This might explain why several studies reported a correlation between angiogenesis and prognosis in tumors ${ }^{2,5}$, where others could not confirm this ${ }^{{ }^{*}}$. This discrepency might be explained by the heterogeneity of a tumor. For instance, the local hypoxic areas ${ }^{8}$ in a tumor stimulate the surrounding bloodvessels to proliferate ${ }^{9}$. Therefore measurement of a single area, as used in hotspot counting, might not always reflect a total tissue, but only a local process. Angiogenesis measurement should therefore be done by overall counting of bloodvessels (micro vessel density (MVD)) in a tumor, although this overall MVD is of limited significance because the measurement only shows the total number of bloodvessels, independent on vessel diameter, in a tumor and is a static end result of bloodvessel growth in time. To better determine ongoing angiogenesis, a physiological element should be introduced in angiogenesis measurement. Therefore we used two new methods to improve detection of ongoing angiogenesis, (i) detection of percentages of endothelial cells in a tissue by flowcytometry (Chapter 2, 3 and 5) and (ii) detection of numbers of proliferating endothelial cells by immunohistochemistry ${ }^{10}$ (Chapter 4,5 and 6), and compared these with MVD measurements and several other parameters. The flowcytometric method is fast, accurate and objective. Moreover the physiological behavior of endothelial cells can also be shown. A disadvantage of this method is that the composition, for example large or small vessels, and localization of the tissue can not be studied with this method and that paraffin embedded tissue can not be used. The measurement of ongoing angiogenesis is of interest in view of actual vessel growth as a prognostic and as a predictive marker. We found proliferating $\mathrm{EC}$ in colorectal carcinoma tissue to be significantly correlated to survival, in contrast to overall MVD measurement. We therefore favor ongoing angiogenesis as a better prognostic marker for survival than MVD.

In rapidly growing tumors the nutrient need is probably too high for angiogenesis to keep up. Leaky and irregular bloodvessels are a result of high angiogenic factor release in tumors ${ }^{11,12}$. This leakiness allows bloodcells to easily migrate into extra-vascular space and form collections in surrounding tumor tissue as a compensation for angiogenesis. Moreover tumor cells can also use this leakiness to enter the circulation and form metastasis. This phenomenon has been described as vasculogenic mimicry in aggressive melanoma and other carcinoma tissues ${ }^{13.14}$. In chapter 6 we describe these extravascular 
collections of erythrocytes surrounded by tumor cells in colorectal carcinomas. In order to retrain nutrients, tumor cells undergo differentiation to EC like cells. In colorectal carcinomas we found a similar gene expression pattern as described in vasculogenic mimicry melanomas. In vitro studies of several colorectal carcinona cell lines showed vessel structures similar to vasculogenic mimicry positive melanoma cell lines.

Most interesting is the significant decrease in survival when extravascular collections of erythrocytes were found in a tissue. Controversies in MVD determination in colorectal carcinomas might be explained by this phenomenon. We found local parts with extravasations of erythrocytes that showed a low MVD compared to the whole tumor tissue, probably because an alternative circullation had been formed. This finding might explain why some studies showed no or even an inverse correlation between high MVD and survival in colorectal carcinomas. Nevertheless an optimal determination for angiogenesis or blood vessel enlargement has not been found so far and probably for future studies a combination of proliferating $\mathrm{EC}$ and determination of extravasated collections of erythrocytes might dissolve this problem.

Not only angiogenesis, also leukocyte infiltration is correlated with survival ${ }^{3}$. In colorectal cancer (CRC) studies showed significant correlations between survival and numbers of infiltrated leukocytes ${ }^{15-16}$. However, some studies show no correlation or even an inverse correlation ${ }^{17}$. The leukocyte subset determination and localization differs in several studies. Intratumoral leukocytes have been shown to have anti-tumor effects and are therefore important for tumor survival ${ }^{3,15}$. Next to the determination, some leukocyte subsets are more important than others. For instance, T-cells have been shown to become active when these are in direct contact with tumor cells ${ }^{15,16,18}$. In chapter 4 we point out this discrepancy in findings between studies. Where other studies mainly focus on one leukocyte subset, we performed research on a number of different leukocyte subsets. We found that several different leukocyte subsets, infiltrated within the tumor (stromal or intratumoral), are significant prognostic factors for survival. Therefore in our vision the positive correlation between survival and leukocytes is not dependent to one single parameter.

In chapter 4 we also found that both angiogenesis and infiltrated leukocytes are independent prognostic factors in colorectal carcinomas. From studies it is known that in order to proliferate, endothelial cells undergo a number of physiological changes. One of these physiological changes is the downregulation of adhesion molecule expression on membranes of proliferating endothelial cells and that this downregulation of adhesion molecules is important for leukocyte adhesion ${ }^{19,20}$. Leukocytes need several adhesion molecules on endothelial cells to adhere to the endothelial cell layer and migrate into the surrounding tissue ${ }^{4}$. Therefore downregulation of adhesion molecules would lead to less infiltration of leukocytes. Indeed we found high levels of angiogenesis correlating with lower adhesion molecules and lower leukocyte infiltrations. We also found a direct correlation between angiogenesis and leukocyte infiltration in breast (chapter 3 ) and colorectal (chapter 4 and 5) carcinomas. Moreover, a combination of angiogenesis and leukocyte infiltration is a more accurate prognostic factor. As we are convinced that the physiological processes have such a delicate balance, interference in these processes can be compensated or 
even overcompensated by other factors, not necessarily resulting in a change. We conclude from our results that combinations of parameters are a better prognosticator for patient survival. As a conclusion to these findings, a cancer not only stimulates angiogenesis to grow, it also inhibits a normal immune response against itself. If angiogenesis is inhibited, this phenomenon will be inversed (inhibition of angiogenesis leads to upregulation of immune response) and is therefore a good target for cancer treatment. In cancer treatment local effective treatment is still the mainstay of cancer treatment. Systemic treatment has been introduced concomitantly, because it has been shown to further improve local control of radiotherapy. Not much is known about the local physiological effects on angiogenesis of local radiotherapy in vivo. Most studies on radiotherapy focus mainly on tumor regression and survival, whereas several in vitro studies mainly show results of one physiological parameter ${ }^{21-23}$. In rectal carcinomas, local radiotherapy is normally given. We believe that next to inhibition of proliferating tumor cells, also inhibition of proliferating $\mathrm{EC}$ is induced by radiotherapy. In order to find out what the local physiological influence of therapy is, we collected tissues from a patient before and after therapy. This way we were able to measure the effects of therapy for each individual. We found an (1) inhibition of proliferating tumor cells, (2) inhibition of MVD, (3) inhibition of proliferating endothelial cells (4) an upregulation of adhesion molecules and (5) increased amounts of infiltrated leukocytes after radiotherapy. The inhibition of proliferating endothelial cells can be a direct inhibitory effect of radiotherapy to proliferation or an indirect effect of enhanced levels of inflammatory cytokines released by surrounding tissue. We found an increase in angiogenic factors, while no proliferating EC were found, suggesting a direct inthibitory effect of radiotherapy. The increase in adhesion molecule expression results in enhanced leukocyte infiltration which in our vision is of importance to the clinical outcome. Although several adhesion molecules have been shown to be of major importance for leukocyte infiltration, it is still not known which adhesion molecules are fully responsible. This suggests there are several different pathways to organize leukocyte infiltration. Indeed, full inhibition of leukocyte infiltration in ICAM-1 knock-outs has not been accomplished and therefore more study should be performed to better understand the interactions between adhesion molecules and leukocytes ${ }^{24,25}$. Because infiltrated leukocytes are known to have an anti-tumor response, tumor rests or local metastasis might be attacked by this radiotherapy induced infiltrate. Nevertheless, future studies to unravel all physiological effects of radiotherapy on angiogenesis inhibition, adhesion molecule expression and leukocyte infiltration need to be performed.

The combination of radiotherapy with chemotherapeutics has extended survival in rectal cancer patients ${ }^{26-28}$. An apparent paradox is the inhibition of circulating leukocytes by chemotherapeutics, which would lead to potentially lower amounts of infiltrating leukocytes. Interestingly, we found an increased amount of granulocytes and macrophages in the rectal cancer tissue after radio-chemotherapy treatment. Both subsets are more residential cells and might not be sensitive to chemotherapy. Moreover, cytostatic drugs probably insufficiently penetrate within the tumor tissue, as we found a decreased MVD after radio-chemotherapy. We therefore presume that additional chemotherapy in rectal cancers has a limited local effect, but given clinical results it has effect on metastasis. Chemotherapy 
and radiotherapy have an effect on all cells, whereas anti-angiogenesis onlly effects endothelial cells. Anti-angiogenesis therapy is therefore considered as a means to control only tumor growth and development ${ }^{29}$. Very promising animal results, in vitro as well as in vivo, to endogenous angiogenic compounds (endostatin, angiostatin) were not always effective in human conditions ${ }^{30.31}$. It is not known if these compounds really infiltrate into the tumor vasculature and if so, in what concentrations. Some compounds, which are used in combination with other therapeutics in clinical trials (like bevacizumab), have shown correlation with an evidently better clinical outcome ${ }^{32.34}$. A disadvantage of antiangiogenesis is that vasculogenic mimicry is not sensitive to this therapy. Therefore not all cancers might fully respond to anti-angiogenic therapeutics ${ }^{14}$. Moreover antiangiogenesis therapy might bring cancer to vasculogenic mimicry because of nutrient deficiency. New therapeutics need to be designed and for the time being the most efficient treatment of rectal carcinoma is surgery. 


\section{References}

1. Folkman $\pi$, Cole $\mathbb{P}_{3}$ Zimmerman $\mathrm{S}$. Tumor behavior in isolated perfused organs: in vitro growth and metastases of biopsy material in rabbit thyroid and canine intestinal segment.

Ann Surg 1966; 164:491-502.

2. Weidner N, Folkman J, Pozza F, Bevilacqua P, Allred EN, Moore DH, Meli S, Gasparini G Tumor angiogenesis: a new significant and independent prognostic indicator in early-stage breast carcinoma. J Natl Cancer Ingt 1992;84:1875-1887.

3. Zhang L, Conejo-Garcia JR, Katsaros D, Gimoty PA, Massobrio M, Regnani G, Makrigiannakis A, Gray $\mathrm{H}$, Schlienger $\mathrm{K}$, Liebman $\mathrm{MN}$, Rubin $\mathrm{SC}_{\mathrm{y}}$ Coukos $\mathrm{G}$. Intratumoral $\mathrm{T}$ cells, recurrence, and survival in epithelial owarian cancer. N Engl J Med 2003:203-213.

4. Melder RJ, Koenig GC, Witwer BP, Safabakhsh N, Murn LL, Jain RK. During angiogenesis, vascular endothelial growth factor and basic fibroblast growth factor regulate natural killer cell adhesion to tumor endothelium. Nat Med 1996;2:992-997.

5. Weidner $\mathrm{N}$, Folkman J. Tumoral vascularity as a prognostic factor in cancer. Important Adv Oncol 1996;167-190.

6. Chandrachud LM, Pendleton N, Chisholm DM, Horan MA, Schor AM. Relationship between wascularity, age and survival in non-small-cell lung cancer. Br J Cancer $1.997 ; 76: 1367-1375$.

7. Hillen HF, Hak LE, Joosten-Achjanie SR, Arends JW. Microvessel density in unkmown primary tumors. Int J Cancer 1997;74:81-85.

8. Yu JL, Rak JW, Carmeliet P, Nagy A, Kerbel RS, Coomber BL. Heterogeneous vascular dependence of tumor cell populations. Am J Pathol 2001;158:1325-1334.

9. Rossler J, Breit S, Havers W, Schweigerer L. Vascular endothelial growth factor expression in human neuroblastoma: up-regulation by hypoxia. Int J Cancer 1999;81:113-117.

10. Vermeullen PB, Gasparini $G$, Fox SB, Colpaert C, Marson LP, Gion M, Belien JA, de Waal RM, Van ME, Magnani E, Weidner N, Harris AL, Dirix LY. Second international consensus on the methodology and criteria of evaluation of angiogenesis quantification in solid human tumours.

Eur J Cancer 2002;38:1564-1579.

11. Yancopoulos GD, Davis S, Gale NW, Rudge JS, Wiegand SJ, Holash J. Vascular-specific growth factors and bllood vessel formation. Nature 2000;407:242-248.

12. Carmeliet P, Jain RK. Angiogenesis in cancer and other diseases Nature 2000;407:249-257

13. Maniotis AJ, Folberg R, Hess A, Seftor EA, Gardner LM, Pe'er J, Trent JM, Meltzer PS, Hendrix MJ. Vascular channel formation by human melanoma cells in vivo and in vitro: vasculogenic minicry. Am J Pathol 1999;155:739-752.

14. wan der Schaft DW, Seftor RE, Seftor EA, Hess AR, Gruman LM, Kirschmann DA, Yokoyama Y, Griffioen AW, Hendrix MJ. Effects of angiogenesis inhibitors on vascular network formation by human endothelial and melanoma cells. J Natl Cancer Inst 2004;96:1473-1477.

15. Naito $Y$, Saito K, Shiba K, Ohuchi A, Saigenji K, Nagura H, Ohtani H. CD8+ T cells infiltrated within cancer cell nests as a prognostic factor in human colorectal cancer. Cancer Res 1998;58:349I-3494.

16. Golby SJ, Chinyama $\mathrm{C}$, Spencer J. Proliferation of T-cell subsets that contact tumour cells in colorectal cancer. Clin Exp Immunol 2002; 127:85-911.

17. Bodey B, Bodey B, Jr., Siegel SE, Kaiser HE. Controversies on the prognostic significance of tumor infiltrating leukocytes in solid human tumors. Anticancer Res 2000;1759-1768.

18. Funada $Y$, Noguchi T, Kikuchi R, Takeno $S$, Uchida Y, Gabbert HE. Prognostic significance of CD8+ $T$ cell and macrophage peritumoral infiltration in colorectal cancer. Oncol Rep 2003;10:309-313.

19. Chen Q, Wang WC Evans SS. Tumor microvasculature as a barrier to antitumor immunity. Cancer Immunol Immunother 2003;52:670-679.

20. Griffioen $A W_{\text {, Damen }} \mathrm{CA}$, Martinotti S, Blijham GH, Groenewegen $\mathrm{G}$. Endothelial intercellular adhesion molecule- 1 expression is suppressed in human malignancies: the role of angiogenic factors. Cancer Res 1996;56:1111-1117. 
21. Improved survival with preoperative radiotherapy in resectable rectal cancer. Swedish Rectal Cancer Trial. N Engl J Med 1997;336:980-987.

22. Quarmby $\mathrm{S}$, Kumar $\mathrm{P}$, Wang $\mathrm{J}$, Macro JA, Hutchinson JJ, Hunter RD, Kumar $\mathrm{S}$. Irradiation induces upregulation of CD31 in human endothelial cells. Arterioscler Thromb Vase Biol 1999:19:588-597.

23. Hallahan D, Kuchibhotla $J_{\text {, }}$ Wyble $C$. Cell adhesion molecules mediate radiation-induced leukocyte adhesion to the vascular endothelium. Cancer Res 1996;56:5150-5155.

24. Blank $\mathrm{C}$, Brown I, Kacha AK, Markjewicz MA, Gajewski TF. ICAM-I contributes to but is not essential for tumor antigen cross-priming and CD8+ $\mathrm{T}$ cell-mediated tumor rejection in vivo. J Immunol 2005; 174:3416-3420.

25. Yanaba K, Kaburagi Y, Takehara K, Steeber DA. Tedder TF, Sato S. Relative contributions of selectins and intercellular adhesion molecule-1 to tissue injury induced by immune complex deposition. Am J Pathol 2003; 162:1463-1473.

26. Watanabe M, Nishida O, Kunii Y, Kodaira S, Takahashi T, Tominaga T, Hojyo K, Kato T, Nuimoto M, Kunitomo K, Isomoto H, Ohashi Y, Yasutomi M. Randomized controlled trial of the efficacy of adjuvant immunochemotherapy and adjuvant chemotherapy for colorectal cancer, using different combinations of the intracutaneous streptococcal preparation OK-432 and the oral pyrimidines 1 . hexylcarbamoyl-5-fluorouracil and uracil/tegafur. Int J Clin Oncol 2004;9:98-106.

27. Sauer R. Adjuvant and neoadjuvant radiotherapy and concurrent radiochenotherapy for rectal cancer. Pathol Oncol Res 2002;8:7-17.

28. Wachsberger $P, B u r d$, , Dicker AP. Tumor response to ionizing radiation combined with antiangiogenes is or vascular targeting agents: exploring mechanisms of interaction. Clin Cancer Res 2003;9:1957-1971.

29. Folkman J. Anti-angiogenesis: new concept for therapy of solid tumors. Ann Surg 1972;175:409-416.

30. O'Reilly MS, Boehm T, Shing Y, Fukai N, Vasios G, Lane WS, Flynn E, Birkhead IR, Olsen BR, Folkman J. Endostatin: an endogenous inhibitor of angiogenesis and tumor growth. Cell 1997;88:277-285.

31. Radema SA, Witteveen $\mathrm{PO}$, Gebbink MB, Voest EE. [The clinical perspective of angiogenesis inhibitors]. Ned Tijdschr Geneeskd 2003;147:1675-1680.

32. Kabbinavar F, Hurwitz HI, Fehrenbacher L, Meropol NJ, Novotny WF, Lieberman G, Grifing S, Bergsland E. Phase $\mathbb{I}_{,}$randomized trial comparing bevacizumab plus fluorouracil (FU)/leucovorin (LV) with FU/LV alone in patients with metastatic colorectal cancer. J Clin Oncol 2003;21:60-65.

33. Kabbinavar FF, Hambleton J, Mass RD, Hurwite HL, Bergsland E, Sarkar S. Combined analysis of efficacy: the addition of bevacizumab to fuorouracil/leucovorin improves survival for patients with metastatic colorectal cancer. J Clin Oncol 2005;23:3706-3712.

34. McCarthy M. Antiangiogenesis drug promising for metastatic colorectal cancer. Lancet 2003;361:1959. 


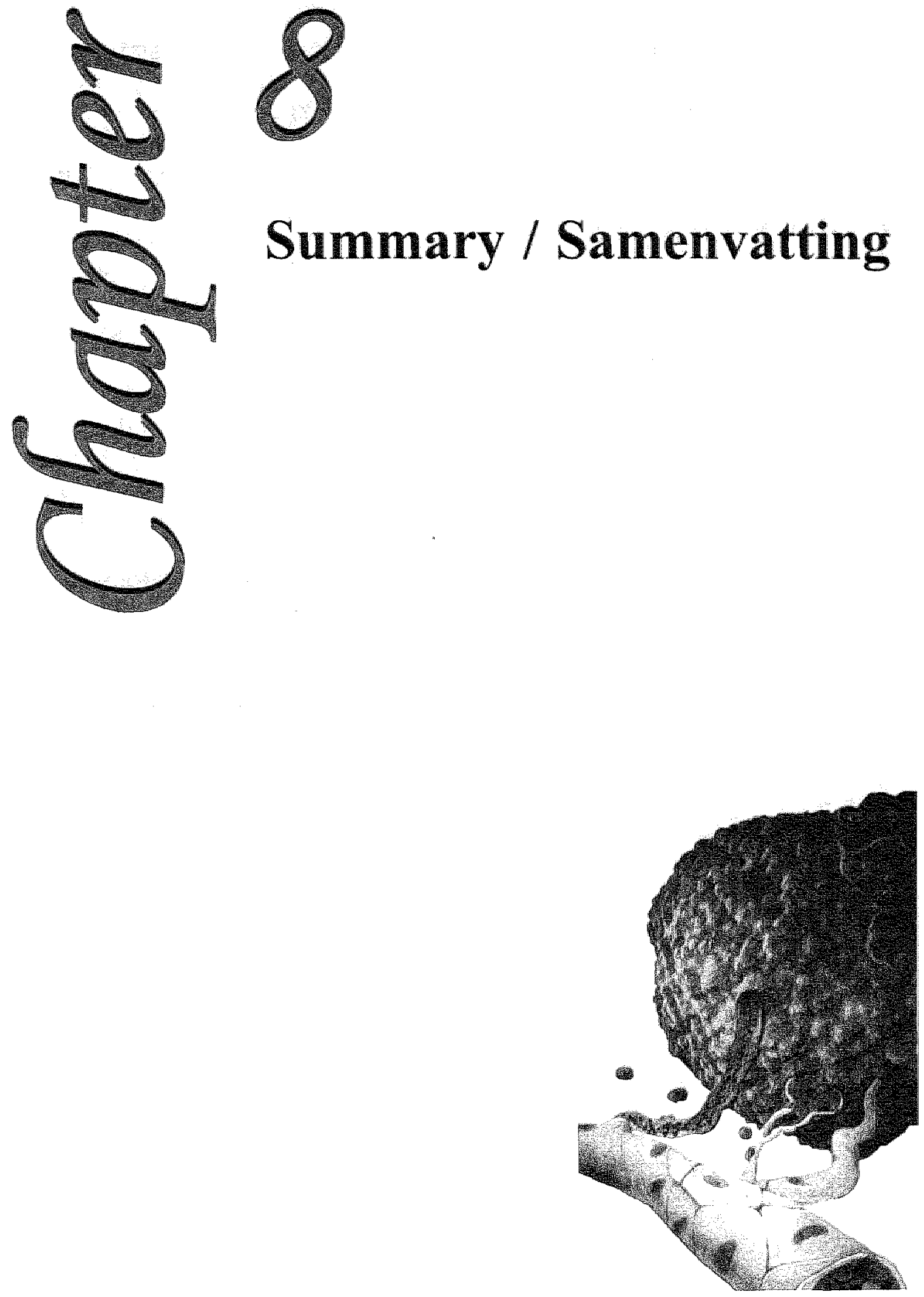




\section{Summary}

Cancer is one of the leading causes of mortality in western countries. A cancer can not grow larger than $2 \mathrm{~mm}^{2}$, if no new blood vessels can be attracted. Angiogenesis, growth or sprouting of blood vessels from already existing blood vessels, is therefore of major importance in cancer growth. Endothelial cells form the inner layer of blood vessels and these endothelial cells need to proliferate to extend the vascular network. Proliferating endothelial cells have been shown to decrease their adhesion molecule expression on the cell membrane. Adhesion molecules are necessary for leukocytes to migrate extravascularly to the infected area. As a result a cancer not only stimulates endothelial cell proliferation but also inhibits leukocytes to infiltrate.

Detection of angiogenesis is normally performed by micro vessel density assessment. This method, based on determination of the number of blood vessels in an area, in several studies showed a positive correlation with survival. However, a number of studies did not find a relation and negative correlations were shown by others. Therefore we developed a new method based on flow-cytometry to better determine angiogenesis by measuring the percentage of endothelial cells in a frozen tissue (Chapter 2). The level of adhesion molecule expression on endothelial cells in a tissue can be measured simultaneously with this new method. Moreover we were also able to show the relation between angiogenesis and adhesion molecule expression and as a result the high correlation between angiogenesis and leukocyte infiltration in breast carcinoma (Chapter 3).

In colorectal cancer many studies on angiogenesis and infiltration of different leukocyte subsets showed contradicting results in relation to clinical outcome, probably as a result of the used detection methods. In chapter 4 we show that in in paraffin embedded tissues angiogenesis, measured by proliferating $\mathrm{EC}$, is a better predictor than micro-vessel density determination for survival. Leukocytes infiltration measured by stromal and intratumoral leukocytes, showed a correlation with survival for several subsets. In contrast, peritumoral leukocyte measurement did not show a significant correlation. Furthermore in chapter 4 we show the relation of leukocyte subsets and angiogenesis to survival in colorectal carcinomas. 
In the Netherlands rectal cancers are usually pre-surgically treated with radiotherapy or radiotherapy in combination with chemotherapy. One of the complications of irradiation therapy is the chance of inflammation of normal tissue. We think a combination of physiological changes is responsible for this inflammation. Endothelial cell proliferation is inhibited by radiotherapy, leading to adhesion molecule upregulation and, as a result, to leukocyte infiltration. We also think that this mechanism of inhibiting endothelial cell proliferation is important in rectal carcinoma tissue. In chapter 5 we evaluated this mechanism for both normal rectal mucosa and rectal carcinoma and found that radiotherapy directly inhibits endothelial cell proliferation. As a result, leukocytes infiltrate and this causes an inflammatory reaction in normal reetum mucosa. On the other hand this infiltration suggestively reduces local metastasis and recurrence in rectal carcinomas.

Since MVD determination in tumors shows large variations within a tumor section and does not always correlate with its behavior, other pathways in the supply of nutrients have been proposed. In 1999 an alternative tumor lined vasculature next to endothelial lined vasculature was shown in melanoma. Several studies have shown similar vasculature in other cancers. In chapter 6 we show evidence for such an alternative blood flow in colorectal cancers and prove that this phenomenon has a major impact on patient survival: 


\section{Samenvatting}

Kanker is een van de meest voorkomende doodsoorzaken in de westerse wereld. Een kankergezwel kan normaal gesproken niet groter worden dan $2 \mathrm{~mm}^{2}$, als er geen nieuwe bloedvaten naar het gezwel toe groeien. Angiogenese, gedefinieerd als groei of spruiten van bloedvaten uit bestaande bloedvaten, is daarom een belangrijke voorwaarde voor kankergroei. Endotheelcellen vormen de binnenste laag van een bloedvat en deze moeten prolifereren om het netwerk van bloedvaten uit te breiden. Het is bekend dat prolifererende endotheelcellen een verlaagde expressie van adhesiemoleculen op hun celmembraan vertonen. Verscheidene van deze adhesiemoleculen zijn belangrijk om leukocyten door de bloedvatwand naar geïnfecteerde gebieden te laten infiltreren. Een kanker stimuleert dus niet alleen endotheelcel proliferatie, maar voorkomt ook een afweerreactie van het immuninsysteem.

Voor meting van angiogenese wordt meestal gebruik gemaakt van micro-vaat-dichtheid (MVD). Deze meetmethode, gebaseerd op het aantal bloedvaten in een gebied, heeft in meerdere studies een goede correlatie met overleving getoond. Toch is er ook een aantal studies in welke deze relatie niet gevonden is of zelfs een negatieve correlatie. Daarom hebben we een nieuwe methode ontworpen, gebaseerd op flow-cytometry, waarmee we angiogenese bepalen door het percentage endotheelcellen in een vriesweefsel te meten (Hoofdstuk 2). De mate van adhesiemolecuul expressie kan gelijktijdig worden bepaald met deze nieuwe methode. Hierdoor zijn we in staat de hoge correlatie tussen angiogenese en adhesiemolecuul expressie aan te tonen, en als gevolg hiervan ook de goede correlatie tussen angiogenese en leukocyten infiltratie (Hoofdstuk 3).

In studies naar colorectale tumoren zijn er meerdere tegenstrijdige uitkomsten beschreven, waarschijnlijk als gevolg van de gebruikte meet methode, tussen angiogenese, leukocyten infiltratie en overleving. In hoofdstuk 4 laten we zien dat angiogenese bepaling in in

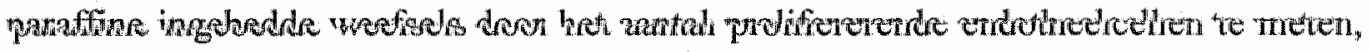
een betere prognostische waarde heeft dan de micro-vaat-dichtheid bepaling. In tegenstelling tot peritumorale leukocyten geven stromaal en intratumoraal gemeten aantallen leukocyten beide een goede indicatie voor overleving in colorectale tumoren. Bovendien laten we in hoofdstuk 4 zien dat de combinatie van deze gerelateerde metingen een betere marker is voor overleving. 
In Nederland worden rectale tumoren, vóor chirurgische resectie, behandeld met radiotherapie alleen of in combinatie met chemotherapie. Een van de complicaties als gevolg van radiotherapie is een ontsteking van normale weefsels.

Wij denken dat er een combinatie van fysiologische veranderingen optreedt waardoor een ontsteking kan ontstaan. Endotheelcel proliferatie wordt geremd door radiotherapie. Dit leidt tot verhoogde expressie van adhesiemoleculen en dit heeft als resultaat dat er een verhoogde leukocyteninfiltratie plaatsvindt: Wij vonden dat ook in rectale tumoren dit mechanisme van inhibitie van prolifererende endotheelcellen plaatsvindt.

In hoofdstuk 5 hebben we dit mechanisme bestudeerd in zowel normaal rectum weefsel als in tumor weefsel bij patiënten met rectum carcinomen. Wij vonden dat radiotherapie direct de endotheelcelproliferatie remt. Hierdoor zien we een ontstekingsreactie als gevolg van een toename van leukocyten in normaal weefsel. We argumenteren dat deze infiltratie de reden kan zijn waarom bestraling een vermindering geeft van lokale tumor metastasen. Omdat micro-vaat-dichtheid in tumoren een grote heterogeniteit vertoont en niet altijd een correlatie met overleving laat zien, zijn er enkele mechanismen beschreven waardoor tumoren toch aan hun voedingsstoffen kunnen komen. In 1999 is in melanoom een alternatieve tumor begrensde vaatstructuur beschreven naast de al bekende endotheel begrensde vasculatuur. Enkele andere studies hebben deze vasculatuur ook in andere weefsels gevonden. In hoofdstuk 6 laten we zien dat er ook in colorectale tumoren een alternatieve vasculatuur bestaat en dat dit fenomeen een grote invloed heeft op de overleving. 

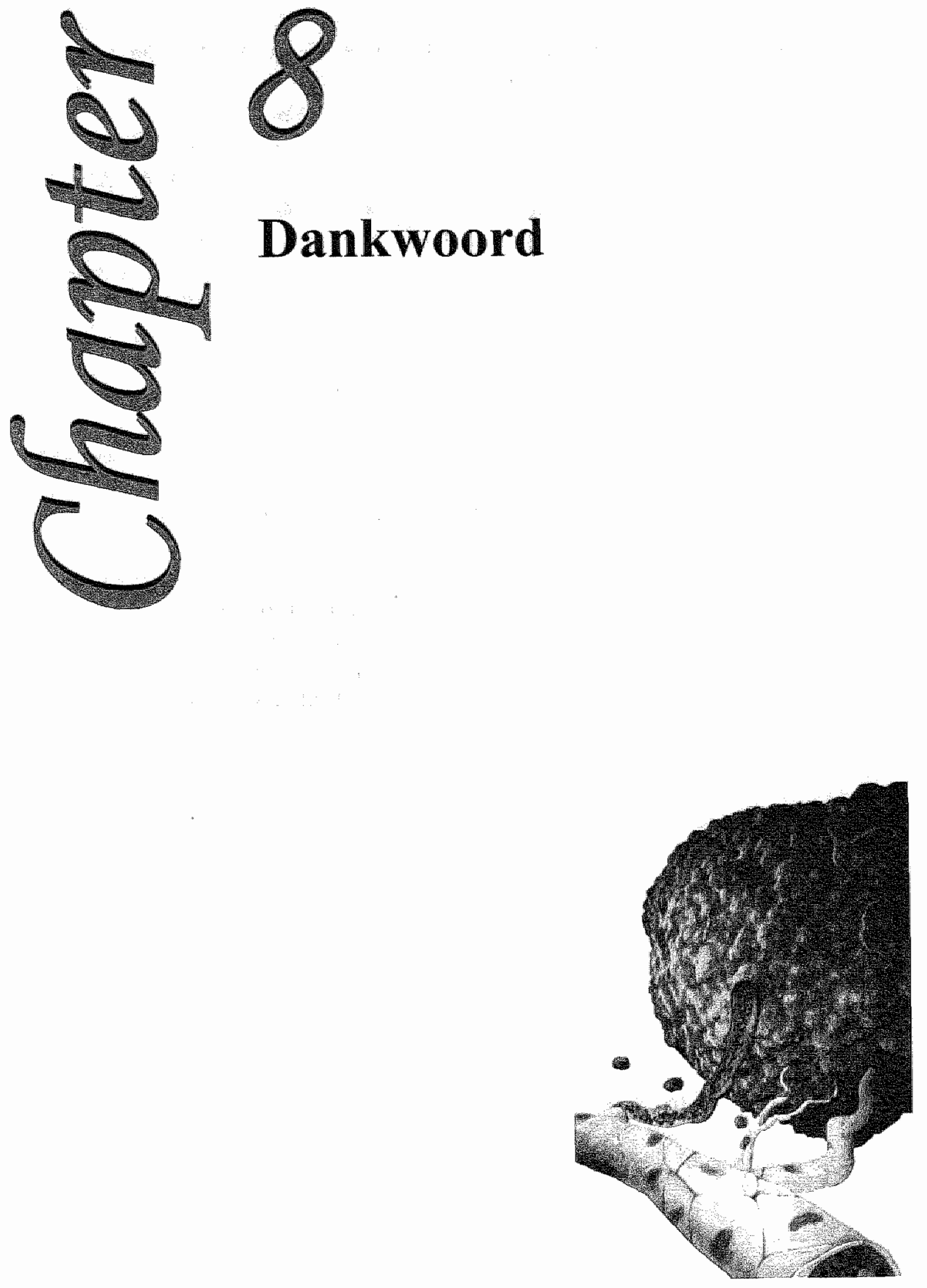


\section{Dankwoord}

Dit onderzoek, in volle kracht vooruit, was op zulk een korte termijn niet realiseerbaar geweest zonder hulp en steun van velen.

Mijn dank gaat allereerst uit naar u, prof. dr. Hillen; al in mijn tweede studiejaar geneeskunde heb ik onder uw enthousiaste leiding tijdens het OTG traject mijn eerste voetstapjes in het onderzoek gezet. De uren die ik naast mijn studie heb doorgebracht met onderzoek, ook als student-assistent, hebben ertoe geleid dat $\mathrm{ik}$, na mijn studie, mijn promotieonderzoek met uw volledige steun in 2 jaar kon afronden. $\mathrm{lk}$ ben heel erg dankbaar dat $\mathrm{u}$ mij deze mogelijkheden heeft geboden. Ook dank aan Arjan Griffioen. Prof dr. Wagstaff, $u$ hebt me als oncoloog wegwijs gemaakt in het gedrag van tumoren en veel ideeën naar voren gebracht. Toen ik begon als AlO, was u net uit Maastricht vertrokken en is het contact helaas verwaterd. Ik heb veel van u geleerd. Heel veel dank hiervoor.

Graag wil ik de beoordelingscommissie bedanken: prof. von Meyenfeldt, prof. Cohen Tervaert, prof. Lambin en prof. Ramaekers.

Prof. L. Påhlman, thank you for your willingness to read my thesis. I'm very happy and honoured with your presence in Maastricht on December 22.

Daisy, al sinds het begin van mijn lab-ervaringen ben jij erbij geweest. Jij als AIO met veel meer ervaring, ik als broekie nog erg onhandig met labwerkzaamheden; pipetteren

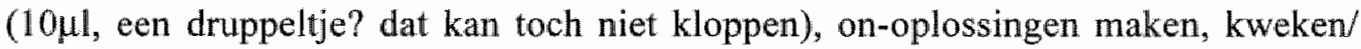
kwekken etc... terugkijkend: een film een Oscar waard. Met je onderzoek naar VM heb je mijn interesse op dat gebied gewekt; dank hiervoor.

Femke en Karolien, ongeveer tegelijk met mij begonnen als AIO, jullie hebben me met een heleboel moleculaire experimenten, kweken en als duplo, triplo scorers geholpen. We hebben veel steun aan elkaar gehad, ook als de experimenten weer eens iets minder vlot verliepen. Heel veel dank en veel succes met het afronden van jullie eigen promotieonderzoek! Veel dank ook aan mijn beide kamergenoten; een groter contrast is er niet! Debby (chaooootisch) en Victor de rust zelve. Debby, met veel plezier kijk ik terug op onze gesprekken de afgellopen 2 jaar; die ga ik zeker missen. Ik reken erop dat je binnenkort met stip de PUBMED lijst binnenkomt en wens je nog veel succes met je onderzoek. Victor, dank voor alle hulp bij het oplossen van diverse problemen met o.a. qRT-PCR, SPSS, EXCEL, PHOTOSHOP 5 (wanneer wordt het nou versie 7 ?). Veerle, Judy en Ricardo bedankt voor de gezellige tijden op het lab. Ook jullie boekjes hoop ik snel te zien! En naturrlijk dank aan alle andere labmedewerkers - Edith, Loes, Sietske, Nicole en studenten - voor al jullie hulp, vlaaien, appeltaartwedstrijden en gezellige praatjes. 
Alle medewerkers van de afdeling pathologie wil ik bedanken voor de hulp, steun en goede werksfeer tijdens mijn onderzoek. Marcella Baldewijns, prof dr. Patrick Pauwels en prof. dr. Adriaan de Bruine wil ik in het bijzonder noemen en bedanken. Jullie hebben mij enorm gesteund en veel geleerd over het vak pathologie. Mijn keuze om chirurg te worden is hierdoor niet veranderd, maar jullie geven me veel nuttige bagage mee!

Verder wil ik de afdelingen chirurgie, radiotherapie en gastro-enterologie bedanken voor de steun bij mijn onderzoek. De mensen uit Weert waarmee ik heb samengewerkt, $\mathrm{dr}$. $\mathrm{K}$ wee en in het bijzonder $\mathrm{dr}$. Verkooijen, heel erg dank voor jullie hulp bij het verzamelen van mijn studiemateriaal!

Mijn studiegenoten en andere AIO's: Xavier, Robert N, Niels, Max, dr. Quido, Roeland, Robert M, Martine en alle anderen. Veel succes met jullie onderzoeken en ik ben ervan overtuigd dat onze wegen elkaar nog zullen kruisen.

Ontspanning is ook nodig in een promotie traject. Justin, Frans en Guido: de goede maandagavond-diners en discussies zijn helaas voorbij nu we over Nederland verspreid wonen. Maar we zullen de draad, misschien in een iets minder frequente vorm, weer gaan oppakken. Toussin en Toine bedankt voor al jullie hulp en steun; de Maastrichtse horeca zal ons gaan missen nu we allemaal uit Maastricht zijn/gaan vertrekken. Ook dank aan de mensen van de hockeyclub (alle commissies, de LG-ers en natuurlijk Heren 6) waar ik veel ontspanning en plezier heb gevonden. Jammer dat het nu voorbij is, maar ik beloof nog vaak langs te komen om een pilsje te drinken.

Kortom, er gaat niets boven goede vrienden!

Mijn thuishaven, mijn vader en moeder, mijn broer en zusje, jullie hebben de basis gelegd voor mijn ontwikkeling en uiteindelijk dit boekje! $\mathrm{Pa}$, ik wil je enorm bedanken voor je steun en goede adviezen! Onze brainstorm sessies op de bank over onderzoek en de vele revisies van artikelen door jou hebben een grote bijdrage geleverd aan de totstandkoming van dit proefscrift!

Allerliefste Laurence, jij bent mijn steun en toeverlaat. Jij ving me op als het moeilijk was en zette me weer met beide benen op de grond. De tijden van promotie-onderzoek zijn voorbij maar.....ik reken op je steun in de toekomst, zoals jij op de mijne kunt rekenen! Hééééél erg bedankt, lief!

Martijn en Justin, ik ben blij en trots dat jullie beiden als paranimf niet alleen in figururlijke, maar vandaag ook in letterlijke zin achter mij staan! Dank voor jullie inzet om deze dag onvergetelijk te maken. 

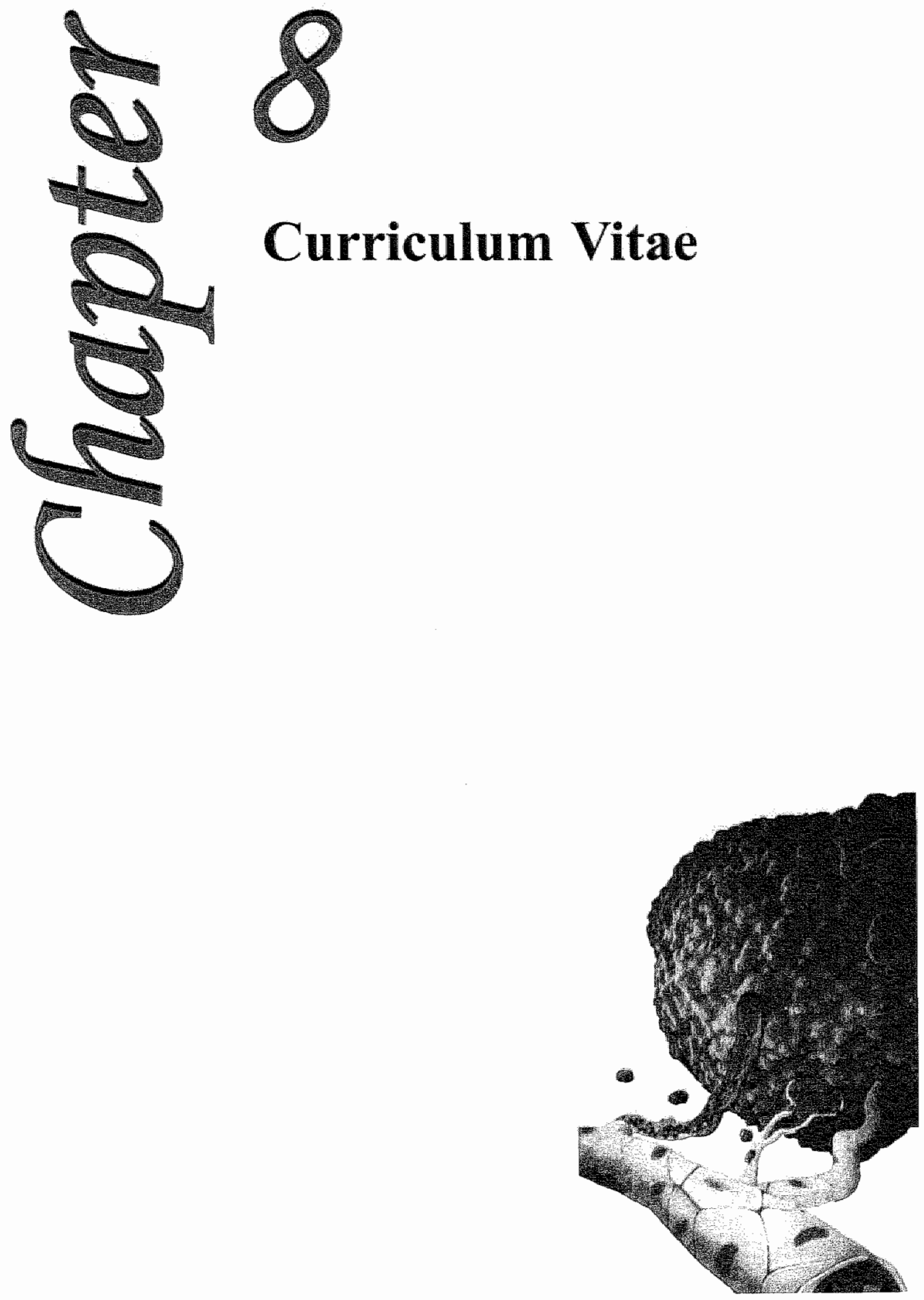


\section{Curriculum Vitae}

Name: $\quad$ Coen I.M. Baeten

Date of birth: $\quad$ February 19, 1977

Place of birth: Maastricht, The Netherlands

Education: $\quad$ 1989-1995 Secondary (High) School (HAVO)

Jeanne d'Arc College, Maastricht (The Netherlands)

1995-1996 Secondary (High) School (VWO)

ROV, Sittard (The Netherlands)

1996-1997 Medical study

LUC University Diepenbeek ( Belgium)

1997-2003 Medical study

University Maastricht (The Netherlands)

1998 Propaedeutic degree Medicine

2001 Msc degree Medicine

2003 M.D. degree

Research: $\quad$ 1998-2003 Research assistent "Angiogenesis Laboratory"

Dep. of Internal Medicine, Academic Hospital Maastricht

2003-2005 PhD-study "Angiogenesis Laboratory"

Dep. of Pathology and Internal Medicine,

Academic Hospital Maastricht

Clinical practice: 2006- Surgical resident at the Department of General Surgery,

Groene Hart Hospital, Gouda, The Netherlands and

Leiden University Medical Centre, The Netherlands 


\section{List of publications}

Baeten CIM, Wagstaff J, Verhoeven ICL, Hillen HFP, Griffioen AW. Flow cytometric quantification of tumour endothelial cells an objective alternative for microvessel density assessment. The British Journal of Cancer 2002 Jul 29;87(3):344-7.

Bouma-ter Steege JCA, Baeten CIM, Verhoeven ICL, Thijssen VLJ, Satijn SS, Hillen HFP, Wagstaff J, Griffioen AW. Leukocyte infiltrate in breast cancinoma correlates positively with endothelial ICAM-1 expression and negatively with angiogenic profile. Clinical Cancer Research 2004 Nov 1;10(21):7171-8.

de Lussanet QG, Backes WH, Griffioen AW, Padhani A, Baeten CI,van Baardwijk A, Lambin P, BeetsS GL, van Engelshoven. JMA, Beets-Tan RGH. Dynamic contrastenhanced magnetic resonance imaging of radiation therapy induced microcircullation changes in rectal cancer. Int. J. Radiation Oncology Biol. Phys. 2005 (in press)

Baeten CIM, Castermans K, Hillen HFP, Griffioen AW. Proliferating endothelial cells and leukocyte infiltration as interdependent prognostic markers in colorectal cancer. (submitted)

Baeten CIM, vd Schaft DW, Hillen F, Pauwels P, de Bruine AP, Baeten CGMI, Hillen HFP, Griffioen AW. Intratumoral extravascular erythrocytes as a new prognostic marker in colorectal cancer. (submitted)

Baeten CIM, Castermans K, Hillen F, Lammering G, de Bruine AP, Hillen HFP, Griffioen AW, Baeten CGMI. Radiotherapy influence angiogenesis and leukocyte infiltration in rectal cancer (submitted)

van der Hagen SJ, van Gemert WG, Baeten CIM, Baeten CGMI. The use of PTQ-implants to bulk anal scar tissue (Key-hole defects) and faecal stickiness measurement in patients with anal soiling not associated with internal anal sphincter dysfunction. (submitted)

Baldewijns M, Baeten CIM, Dings RPM, Verstraelen E, Roskams T, Nieman F, v Poppel $\mathrm{H}$, Griffioen AW. New insights on angiogenesis parameters in renal cell cancers. (in preparation) 